\title{
Homogeneous and Heterogeneous Reaction and Transformation of Hg and Trace Metals in Combustion Systems
}

\author{
Final Technical Report \\ Reporting Period: September 1, 2004 - August 31, 2009 \\ J. Helble (subcontract PI), Dartmouth College \\ Clara A. Smith, Graduate Student, Dartmouth College \\ David Miller (PI), U. Connecticut
}

Date of Report: December 2009 (format revised March 2010)

DOE Award Number: DE-FG26-04NT42174

\author{
Submitting Organization: \\ University of Connecticut \\ Office for Sponsored Programs \\ Whetten Graduate Center \\ 438 Whitney Road Extension, Unit 1133 \\ Storrs, CT 06269-1133 \\ Principal Subcontractor: \\ Dartmouth College \\ Office of Sponsored Projects \\ 11 Rope Ferry Road \#6210 \\ Hanover, NH 03755-1404
}




\section{DISCLAIMER}

This report was prepared as an account of work sponsored by an agency of the United Sates Government. Neither the United States Government nor any agency therefore, nor any of their employees, makes any warranty, express or implied, or assumes any legal liability or responsibility for the accuracy, completeness, or usefulness of any information, apparatus, product, or process disclosed, or represents that its use would not infringe privately owned rights. Reference herein to any specific commercial products, process, or service by trade name, trademark, manufacturer, or otherwise does not necessarily constitute or imply its endorsement, recommendation, or favoring by the United States Government or any agency thereof. The views and opinions of authors expressed herein do not necessarily state or reflect those of the United States Government or any agency thereof. 


\begin{abstract}
The overall goal of this project was to produce a working dynamic model to predict the transformation and partitioning of trace metals resulting from combustion of a broad range of fuels. The information provided from this model will be instrumental in efforts to identify fuels and conditions that can be varied to reduce metal emissions. Through the course of this project, it was determined that mercury $(\mathrm{Hg})$ and arsenic (As) would be the focus of the experimental investigation. Experiments were therefore conducted to examine homogeneous and heterogeneous mercury oxidation pathways, and to assess potential interactions between arsenic and calcium. As described in this report, results indicated that the role of $\mathrm{SO}_{2}$ on $\mathrm{Hg}$ oxidation was complex and depended upon overall gas phase chemistry, that iron oxide (hematite) particles contributed directly to heterogeneous $\mathrm{Hg}$ oxidation, and that As-Ca interactions occurred through both gas-solid and within-char reaction pathways. Modeling based on this study indicated that, depending upon coal type and fly ash particle size, vaporization-condensation, vaporization-surface reaction, and $\mathrm{As}-\mathrm{CaO}$ in-char reaction all play a role in arsenic transformations under combustion conditions.
\end{abstract}




\section{TABLE OF CONTENTS}

Disclaimer $\quad$ ii

$\begin{array}{ll}\text { Abstract } & \text { iii }\end{array}$

Executive Summary 1

Project Objectives 3

Approach, Results, and Discussion $\quad 4$

Section 1: Heterogeneous and Homogeneous Mercury Oxidation 4

Section 2: Arsenic Transformations $\quad 21$

Section 3: Arsenic Partitioning Model 53

References

$\begin{array}{ll}\text { List of Acronyms and Abbreviations } & 68\end{array}$ 


\section{EXECUTIVE SUMMARY}

The overall goal of this project was to produce a working dynamic model to predict the transformation and partitioning of trace metals resulting from combustion of a broad range of fuels. The information provided from this model will be instrumental in efforts to identify fuels and conditions that can be varied to reduce metal emissions. Through the course of this project, it was determined that mercury $(\mathrm{Hg})$ and arsenic (As) would be the focus of the experimental investigation because of their high volatility relative to other potentially hazardous trace elements present in coal, and because of their being the focus of either current or potential regulation. Mercury was particularly relevant, given the 2005 announcement of the Clean Air Mercury Rule by the United States Environmental Protection Agency (EPA), which occurred at the beginning of this project. Although the Clean Air Mercury Rule was vacated by the District of Columbia Circuit in February 2008 for removing power plants from the list of sources of hazardous pollutants, emissions restrictions exist in several states, and EPA is acting upon the 2008 court decision by developing federal standards under the provisions of Section 112 of the Clear Air Act.

In the experimental portion of this project, homogeneous and heterogeneous mercury oxidation pathways were both examined in an entrained flow flame-based bench scale reactor. The effects of $\mathrm{HCl}$ and $\mathrm{SO}_{2}$ concentrations and particle type were considered separately and collectively in these studies. Mercury oxidation was found to increase with the addition of hydrochloric acid $(\mathrm{HCl})$, as expected. The addition of $\mathrm{SO}_{2}$ to the flame based system increased mercury oxidation, with no significant dependence on $\mathrm{SO}_{2}$ concentration. With the addition of $\mathrm{HCl}$ and $\mathrm{SO}_{2}$, mercury oxidation increased from the addition of $\mathrm{HCl}$ alone when the $\mathrm{SO}_{2}: \mathrm{Cl}$ ratio was more than 1 . To test heterogeneous effects, iron oxide $\left(\mathrm{Fe}_{2} \mathrm{O}_{3}\right)$ and montmorillonite particles were injected into the system. It was found that at low particle loadings, there was little effect on mercury oxidation. At higher particle loadings, the presence of hematite led to heterogeneous oxidation whereas montmorillonite did not.

Separate experiments were conducted to elucidate arsenic transformations, focusing on interactions between arsenic and calcium. To assess these interactions, three types of polymerderived synthetic chars were developed: one containing calcium oxide inclusions, one containing dispersed arsenic (cacodylic acid), and one containing both $\mathrm{CaO}$ and As. Through collaboration with colleagues at the University of Utah, synthetic char combustion experiments were conducted in a drop tube furnace at oxygen partial pressures of 0.2 and $0.4 \mathrm{~atm}$. In one set of experiments, the pulverized chars containing either $\mathrm{CaO}$ or As were mixed and burned together; in the other, chars containing both $\mathrm{CaO}$ and $\mathrm{As}$ in individual char particles were combusted. Size-segregated ash particles were then conducted and examined for the presence of As and $\mathrm{Ca}$ concentration, and spectroscopically through the use of XAFS via a subcontract to the University of Kentucky, for the form of occurrence of the arsenic. $\mathrm{As}_{4} \mathrm{O}_{6}(\mathrm{~g})-\mathrm{CaO}(\mathrm{s})$ reaction rates reported in the literature appeared to be too slow to account for the calcium arsenate routinely observed in laboratory and pilot scale coal combustion studies; these experiments were devised to determine whether such reactions were feasible (and reported reaction rates therefore too slow), or whether such reaction As-Ca reactions only occurred within individual char 
particles. Results clearly indicated the feasibility of both pathways, suggesting that reported gassolid reaction rates were indeed too slow to account for the observed interactions.

These arsenic experimental results were incorporated into a general dynamic model to describe the transformation and partitioning of trace metals under post-flame conditions. Adjusting the $\mathrm{As}_{4} \mathrm{O}_{6}(\mathrm{~g})-\mathrm{CaO}(\mathrm{s})$ reaction rate to be consistent with literature reports of single particle reaction rates for another reaction provided results that qualitatively agreed with laboratory experimental data for arsenic partitioning. Results indicated that, depending upon coal type and fly ash particle size, vaporization-condensation, vaporization-surface reaction, and $\mathrm{As}-\mathrm{CaO}$ in-char reaction all play a role in arsenic transformations under combustion conditions. 


\section{Project Objectives}

The general goals established at the outset of this project, focused on improving understanding of the transformations of trace metals during coal combustion, were:

- measurement of heterogeneous mercury oxidation reactions on solid surfaces including fly ash and synthetic fly ash surfaces to determine the effect of individual constituents in the ash, in a flame-based flow reactor in the presence of important post-flame radical species;

- determination of gas-solid reaction rates between coal-based trace elements such as As, $\mathrm{Cd}, \mathrm{Sb}$, and $\mathrm{Se}$, and fly ash constituents to obtain parameters needed for modeling metal partitioning;

- measurement of selected trace metal reactions in a flow reactor in the presence of contaminants such as NOx and SOx to determine the effects of these constituents on reaction chemistry;

- further development and expansion of a dynamic model to predict partitioning by calculating competing rates of condensation and surface reaction for each metal.

Through the course of this project, these goals were refined towards the following areas of focus:

- examination of mercury oxidation under both homogeneous and heterogeneous conditions in a bench-scale flame reactor under controlled conditions, with an emphasis on determining the effects of $\mathrm{HCl}, \mathrm{SO}_{2}$, and particle concentrations, and particle composition, on the extent of mercury oxidation;

- a detailed examination of the factors affecting arsenic transformations under conditions relevant to coal combustion, with arsenic, due to its relatively high volatility and presence in a variety of forms-of-occurrence in coal, serving as a surrogate for the broader class of hazardous trace elements identified above;

- further development and expansion of a dynamic model to predict partitioning by calculating competing rates of condensation and surface reaction, as originally intended and indicated above.

The overall results of this study are summarized in this report. 


\section{Approach, Results, and Discussion}

\section{Section 1: Homogeneous and Heterogeneous Mercury Oxidation}

Literature studies have consistently shown that $\mathrm{HgCl}_{2}$ is the gas phase mercury species expected under equilibrium conditions. Laboratory and field studies under relevant conditions have consistently found elemental mercury present in high concentrations, however, indicating that mercury oxidation is not governed by equilibrium thermodynamics $[1,2]$. This difference is attributed to kinetic limitations in the oxidation sequence. This portion of the study therefore focused on improving our understanding of the conditions favoring mercury oxidation, with consideration given to both homogeneous and heterogeneous oxidation pathways.

Previous studies of homogeneous mercury oxidation have shown that molecular chlorine $\left(\mathrm{Cl}_{2}\right)$ strongly oxidizes elemental mercury, hydrochloric acid $(\mathrm{HCl})$ oxidizes mercury, and depending upon the study and conditions, sulfur dioxide $\left(\mathrm{SO}_{2}\right)$ either slightly oxidizes mercury [3] or has no effect on mercury oxidation [4]. When these gases are added in combination, $\mathrm{SO}_{2}$ strongly inhibits mercury oxidation by $\mathrm{Cl}_{2}$, weakly inhibits oxidation by $\mathrm{HCl}$, and with the addition of $\mathrm{H}_{2} \mathrm{O}$ further inhibits mercury oxidation by chlorine species. While homogeneous oxidation of mercury in coal combustion flue gas is therefore possible, the results from controlled homogeneous studies have yet to explain the extent of mercury oxidation observed in operating coal combustion systems.

Limited heterogeneous oxidation studies have shown that some solids including copper chloride $(\mathrm{CuCl})$ and fly ash oxidize mercury without the addition of $\mathrm{HCl}$ or $\mathrm{SO}_{2}$. In the presence of iron oxide or copper oxide, the presence of $\mathrm{HCl}$ is needed for mercury oxidation to occur, and calcium oxide inhibits mercury oxidation by $\mathrm{HCl}$. The presence of $\mathrm{SO}_{2}$ in flue gas is found to have both enhancing and inhibiting effects.

A methane flame-based experimental system described in detail in earlier progress reports and depicted in Figure 1 was therefore used to conduct homogeneous and heterogeneous mercury oxidation experiments. The importance of constituents including $\mathrm{HCl}$ and $\mathrm{SO}_{2}$ concentrations, hematite $\left(\alpha-\mathrm{Fe}_{2} \mathrm{O}_{3}\right)$ particle concentrations, and montmorillonite particle concentrations was examined under entrained flow conditions.

In these experiments, commercial grade methane was burned with oxygen in the presence of nitrogen at an equivalence ratio of 0.9 in a multi-element micro-diffusion flat-flame burner. Peak flame temperature was measured at $1290 \mathrm{~K}$. Particles, $\mathrm{HCl}$, and $\mathrm{SO}_{2}$ were added by injection into a stainless steel mixing chamber $16 \mathrm{~cm}$ in length, $17 \mathrm{~cm}$ in width, and $21 \mathrm{~cm}$ in height located directly above the flat-flame burner. Elemental mercury, $\mathrm{HCl}, \mathrm{SO}_{2}$, and particles were injected using four separate ports on the mixing chamber to investigate mercury oxidation under well-controlled conditions. Mercury, provided by flowing $0.75 \mathrm{slpm}$ of nitrogen past a mercury permeation tube, was injected directly into the burner as shown in the figure. A quartz reactor inserted into a $13 \mathrm{~cm}$ orifice in a vertical wall of the mixing chamber provided the necessary temperature zone for examining mercury oxidation. The junction between the reactor and the mixing chamber was sealed with furnace cement prior to the start of experiments each day. 


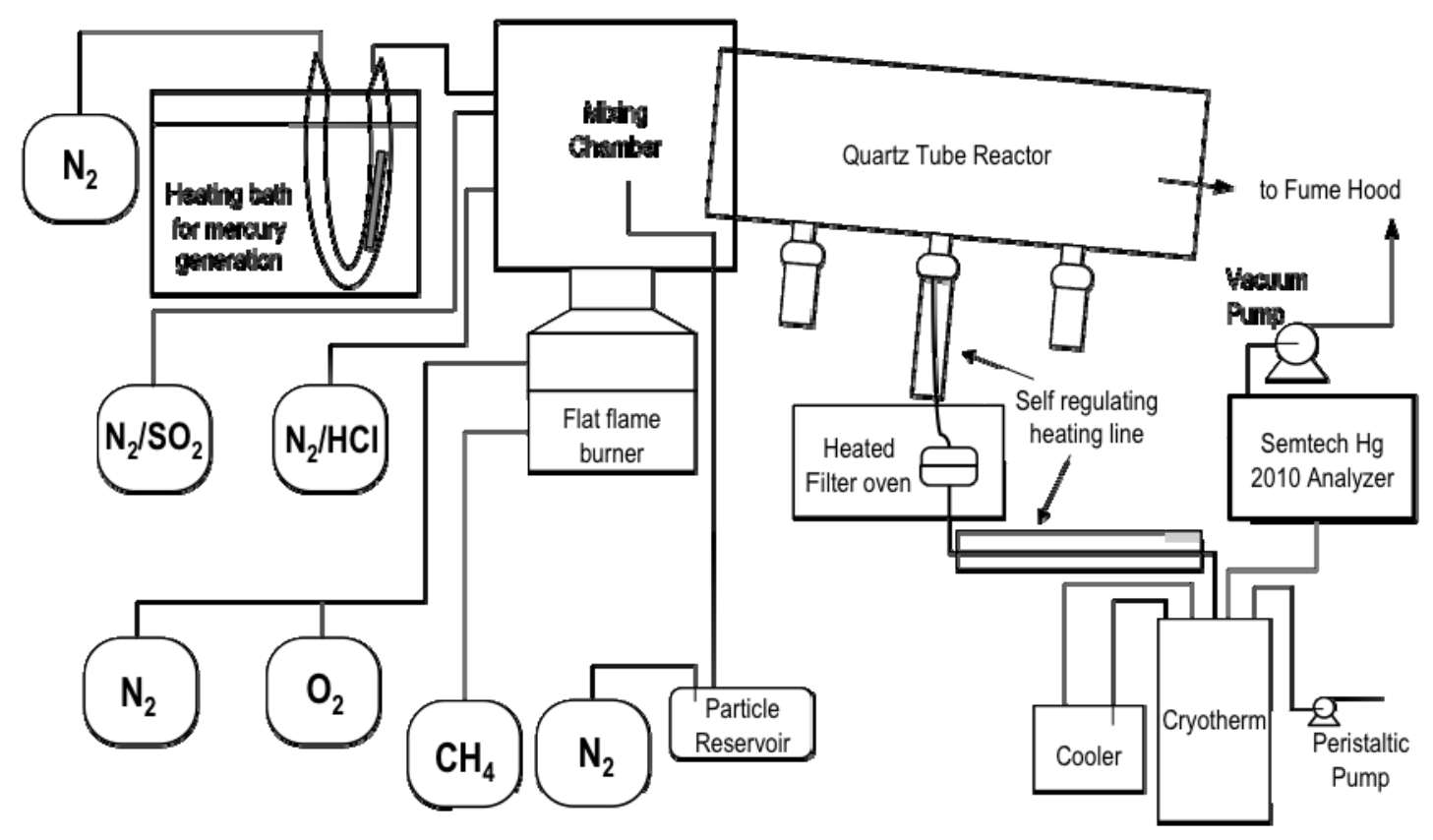

Figure 1: Homogeneous and heterogeneous mercury oxidation experimental system. Figure modified from Sterling [43, 44]

Five centimeters of length of the cylindrical quartz reactor were inserted into the mixing chamber and arranged with the outlet $3.5 \mathrm{~cm}$ lower than the inlet to prevent accumulation of condensation at the outlet. The first $20 \mathrm{~cm}$ of the quartz reactor length were covered with heating tape and insulation to reduce heat loss and produce the desired temperature profile.

Three sampling ports were located at distances of $6.5 \mathrm{~cm}, 25 \mathrm{~cm}$, and $45 \mathrm{~cm}$ from the mixing chamber. Throughout this work, mercury measurements were conducted by extracting flue gas from sample port 2 because the temperature profile of this configuration was similar to the thermal history of the economizer zone of coal-fired power plants where mercury oxidation is believed to occur.

The injection of high concentrations of $\mathrm{SO}_{2}, \mathrm{HCl}$, and/or high particle loadings resulted in interactions with or deposits on the reactor walls such that the system mercury concentration did not return to baseline levels when injection was terminated. This resulted in an unusually low extent of oxidation by $\mathrm{HCl}$ prior to the quartz reactor repairs [6]. During the repair process, the quartz reactor was washed with a hydrofluoric acid solution. Experiments conducted after the hydrofluoric acid wash produced results similar to those observed in the literature [5]. Subsequent to this repair process, whenever unusually low mercury oxidation was observed during experiments, the experiments were stopped and the reactor cleaned with $30 \%$ nitric acid to remove any accumulated deposits prior to continuation of the measurements. Mercury 
oxidation results described herein were collected post-acid wash.

In experiments designed to study heterogeneous mercury oxidation chemistry, the entrainment of the particle stream required injection of an additional $5 \mathrm{slpm} \mathrm{N}_{2}$. This altered the temperatures within the system. The additional $\mathrm{N}_{2}$ gas stream was therefore included for the entire duration of heterogeneous experiments because any temperature change was likely to affect the observed extent of mercury oxidation.

Hematite $\left(\alpha-\mathrm{Fe}_{2} \mathrm{O}_{3}\right)$ and montmorillonite were both used in the examination of heterogeneous mercury oxidation chemistry. Hematite powder (AlfaAesar) had a manufacturer specified particle size range of 20-50 nanometers (nm) and surface area of 30-60 square meters per gram $\left(\mathrm{m}^{2} / \mathrm{g}\right)$. The surface area of the iron oxide powder was measured using $\mathrm{N}_{2}$-adsorption BET analysis and found to be $29.9 \mathrm{~m}^{2} / \mathrm{g}$. Montmorillonite (WARD'S Natural Science) was size segregated with a cyclone to remove larger particles, producing a size cut of $0.6-2.7 \mu \mathrm{m}$ that was subsequently used in experiments. The $\mathrm{N}_{2}$-adsorption BET measured surface area of the montmorillonite sample was $28.9 \mathrm{~m}^{2} / \mathrm{g}$. Although the montmorillonite particles were much larger in diameter than the hematite particles, the measured surface area was similar because nitrogen molecules partially penetrate the silicate layers during $\mathrm{N}_{2}$-adsorption BET analysis [7]. To calculate the average particle feed rate during an experiment, the weight loss of the vessel was divided by time elapsed during particle injection.

Samples were extracted from the system by withdrawing 4 slpm of flue gas from the quartz reactor via sample port 2 . The gas traveled through a heated teflon line to a heated quartz filter, with the filter maintained at a temperature of $323 \mathrm{~K}$ to remove particulate from the sampled stream. Downstream of the filter, the gas stream passed through a second heated line transferring the gas to a circulating cold water $(<278 \mathrm{~K})$ impinger to remove water present in the flue gas. The flue gas was then analyzed for elemental mercury concentration using a Semtech 2010 Zeeman modulated atomic absorption spectrometer.

Gas concentrations used in these experiments are provided in Table I. Additional detail on the system and its operation are presented in the Ph.D. thesis by Smith [8].

Initial experiments to examine the effect of $\mathrm{HCl}$ concentrations on homogeneous mercury oxidation are shown in Figure 2. Here, more than 15 replicates were randomly completed for each $\mathrm{HCl}$ concentration. The extent of mercury oxidation was seen to increase with increasing $\mathrm{HCl}$ concentration, ranging from $8 \pm 5 \%$ oxidation at $100 \mathrm{ppmv} \mathrm{HCl}$ to $29 \pm 7 \%$ oxidation at 555 ppmv $\mathrm{HCl}$. No oxidation was observed when $\mathrm{HCl}$ was not present.

In examining the effect of $\mathrm{SO}_{2}$ on homogeneous mercury oxidation, eight or more experiments were completed for each $\mathrm{SO}_{2}$ concentration of $500 \mathrm{ppmv}$ and below while three repeat experiments were conducted at an $\mathrm{SO}_{2}$ concentration of $900 \mathrm{ppmv}$. Figure 3 shows that the extent of mercury oxidation remained essentially constant with changing $\mathrm{SO}_{2}$ concentration. $\mathrm{HCl}$ was not present in these experiments. 


\section{Table I}

Concentrations of $\mathrm{HCl}$ and $\mathrm{SO}_{2}$ used in mercury oxidation experiments. $(\mathrm{H}=$ hematite, $\mathrm{M}=$ montmorillonite)

\begin{tabular}{llll} 
Gases & {$[\mathbf{H C l}] \mathbf{( p p m v )}$} & {$\left[\mathbf{S O}_{2}\right]$ (ppmv) } & Particles \\
\hline $\mathrm{HCl}$ & $0,100,200,300,400,555$ & 0 & None \\
$\mathrm{SO}_{2}$ & 0 & $0,100,200,300,400,500,900$ & None \\
$\mathrm{HCl}, \mathrm{SO}_{2}$ & $0,200,400,555$ & $0,100,200,300,400$ & None \\
$\mathrm{HCl}$ & $0,200,300,400,555$ & 0 & $\mathrm{H}$ \\
$\mathrm{HCl}$ & $0,300,555$ & 0 & $\mathrm{M}$ \\
$\mathrm{SO}_{2}$ & 0 & $0,100,200,300,400,500$ & $\mathrm{H}$ \\
$\mathrm{SO}_{2}$ & 0 & $0,300,500$ & $\mathrm{M}$ \\
$\mathrm{HCl}_{2} \mathrm{SO}_{2}$ & $0,200,300,400,555$ & $0,100,200,300,400,500$ & $\mathrm{H}$ \\
\hline
\end{tabular}

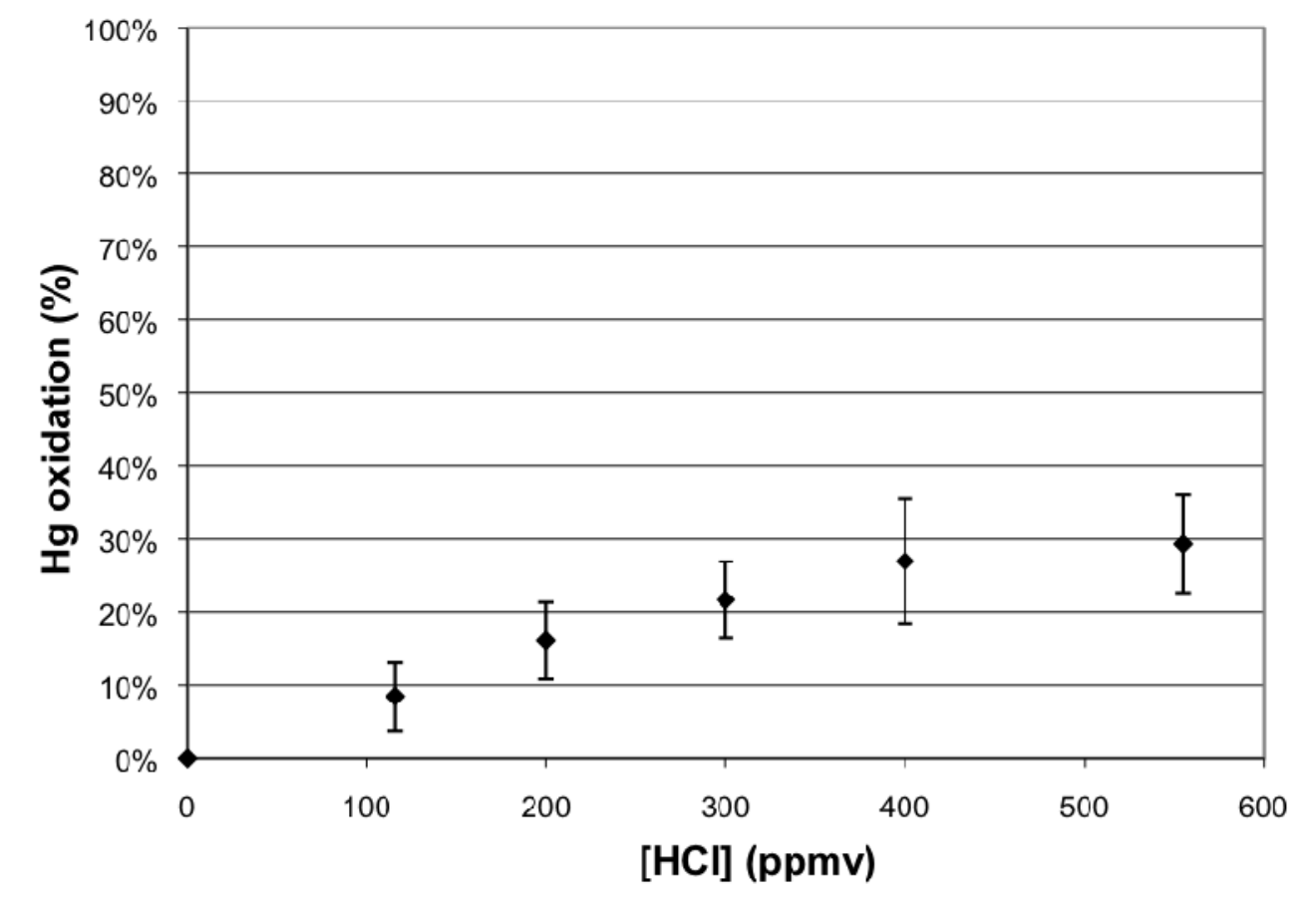

Figure 2: Effect of [HCl] on $\mathrm{Hg}$ oxidation in homogeneous flame based experiments. Error bars represent standard deviation from the mean of the series of experiments at each condition. 
To examine mercury oxidation in the presence of both $\mathrm{HCl}$ and $\mathrm{SO}_{2}$, four concentrations of $\mathrm{HCl}$ and five concentrations of $\mathrm{SO}_{2}$ were considered with three or more replicates for each condition. The results shown in Figure 4 demonstrate the varying effects of $\mathrm{SO}_{2}$ on mercury oxidation by $\mathrm{HCl}$. The data points connected by the broken line depict the results from homogeneous mercury oxidation experiments when the concentration of $\mathrm{SO}_{2}$ in the flue gas was zero.

The addition of $\mathrm{SO}_{2}$ to the flue gas containing $\mathrm{HCl}$ at a concentration of $200 \mathrm{ppmv}$ increased the extent of mercury oxidation relative to that observed with either of these gases alone. With an $\mathrm{HCl}$ flue gas concentration of $200 \mathrm{ppmv}$ and $\mathrm{SO}_{2}$ concentration of $100 \mathrm{ppmv}$, mercury oxidation was observed to be $30 \pm 1 \%$, greater than that observed when the $\mathrm{SO}_{2}$ concentration was 100 ppmv, absent $\mathrm{HCl}(23 \pm 9 \%)$ or when the $\mathrm{HCl}$ concentration was 200 ppmv, absent $\mathrm{SO}_{2}(16 \pm$ $5 \%$ ). When $\mathrm{SO}_{2}$ at a concentration of $400 \mathrm{ppmv}$ was present in flue gas containing $\mathrm{HCl}$ at a concentration of $200 \mathrm{ppmv}$, the extent of mercury oxidation decreased to $20 \pm 1 \%$, approaching the level observed in the presence $200 \mathrm{ppmv} \mathrm{HCl}$ alone at $16 \pm 5 \%$, as mentioned previously.

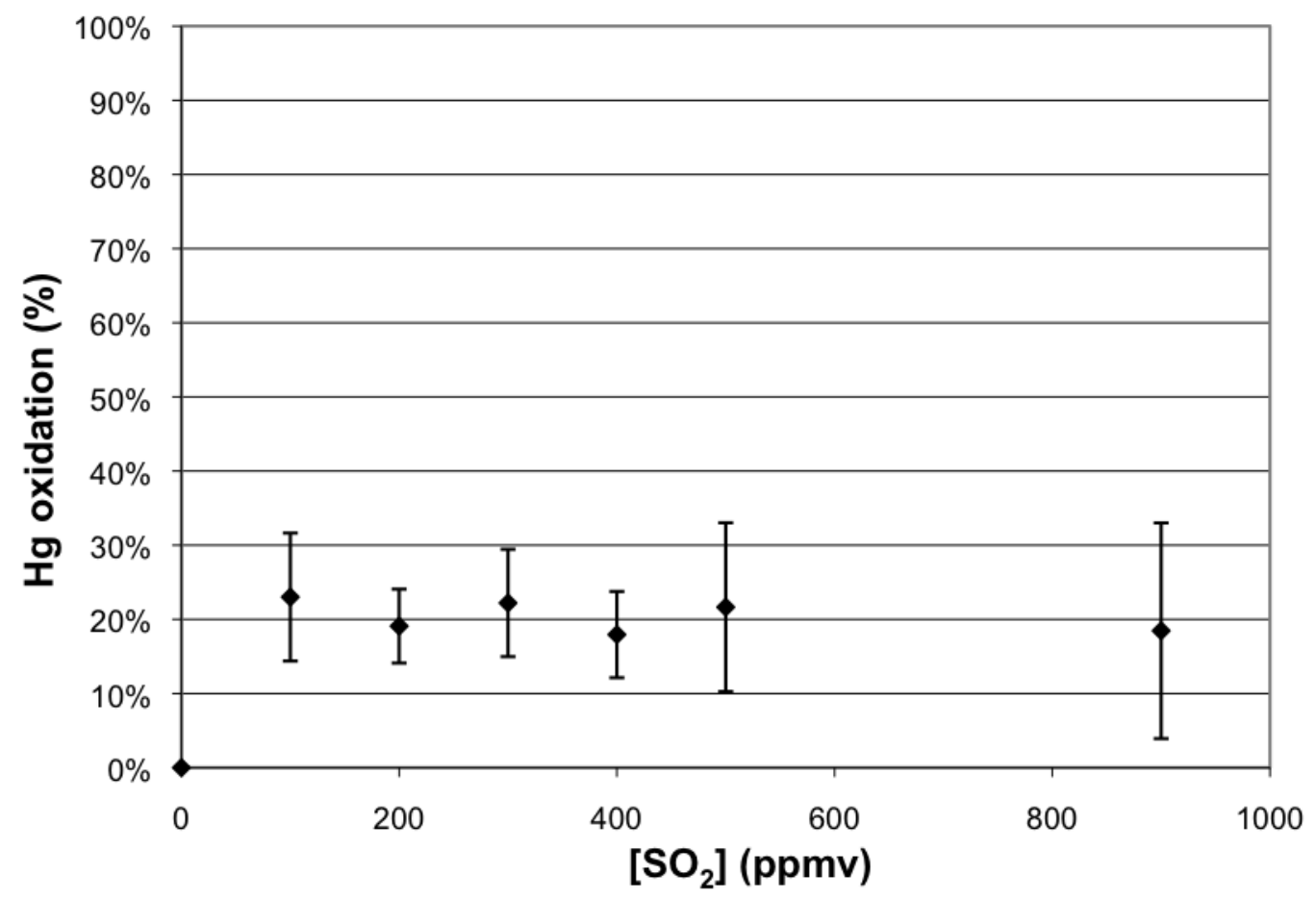

Figure 3: Effect of $\mathrm{SO}_{2}$ concentration on mercury oxidation in homogeneous flame based experiments. Error bars represent one standard deviation from the mean of the series of experiments at each condition. 


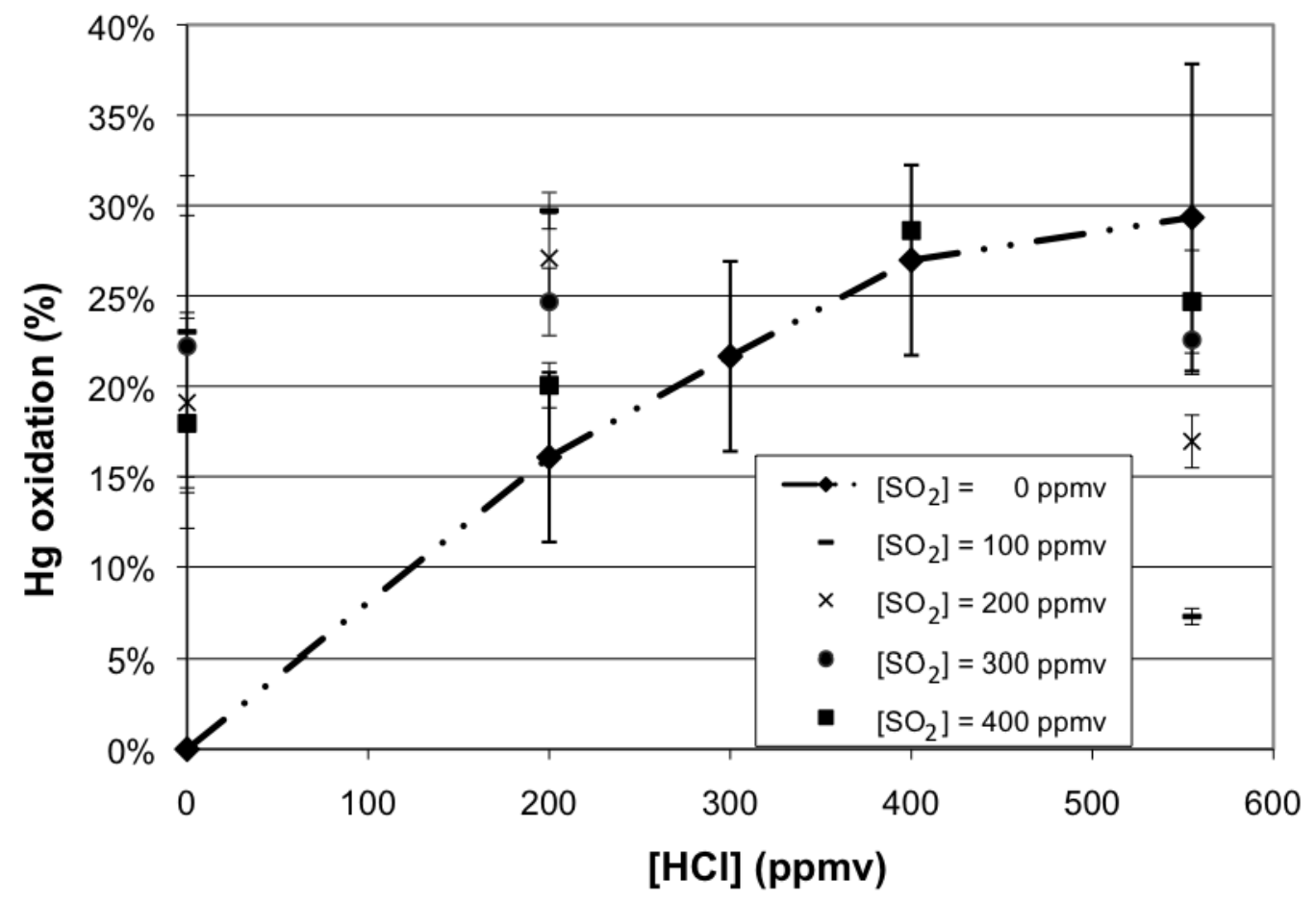

Figure 4: Effect of $\mathrm{HCl}$ and $\mathrm{SO}_{2}$ concentrations on mercury oxidation in homogeneous flame based experiments. Error bars represent the standard deviation from the mean of the series of experiments at each condition.

Mercury oxidation was inhibited by the addition of $\mathrm{SO}_{2}$ at an $\mathrm{HCl}$ concentration of $555 \mathrm{ppmv}$. The experiments conducted at this level of $\mathrm{HCl}$ showed the greatest inhibition in the presence of $\mathrm{SO}_{2}$ at 100 ppmv, with oxidation levels decreasing from $29 \pm 9 \%$ in the absence of $\mathrm{SO}_{2}$ to $7 \pm$ $0.5 \%$ oxidation. When the concentration of $\mathrm{SO}_{2}$ was increased to $400 \mathrm{ppmv}$, the mercury oxidation was measured as $25 \pm 3 \%$, approaching that seen when no $\mathrm{SO}_{2}$ was injected into the system. The trends reported in the literature of inhibited mercury oxidation with the addition of $\mathrm{SO}_{2}$ at concentrations much greater than the $\mathrm{HCl}$ concentration and enhanced oxidation when the concentration of $\mathrm{SO}_{2}$ was equal to or less than the concentration of $\mathrm{HCl}$ [9] were not observed in the present work.

Heterogeneous oxidation experiments were conducted by injecting hematite or montmorillonite in the presence and absence of $\mathrm{HCl}$ and $\mathrm{SO}_{2}$ and the results compared to the levels of oxidation observed in the homogeneous experiments described above. To assess the baseline, experiments were conducted by injecting particles into the flue gas without addition of $\mathrm{HCl}$ or $\mathrm{SO}_{2}$. Under these conditions, negligible mercury oxidation was observed.

The effect of $\alpha-\mathrm{Fe}_{2} \mathrm{O}_{3}$ particles on mercury oxidation by $\mathrm{HCl}$ can be seen in the results shown in Figure 5. At particle loadings near $1 \mathrm{~m}^{2} \alpha-\mathrm{Fe}_{2} \mathrm{O}_{3} / \mathrm{m}^{3}$ flue gas there was no observed enhancement in the level of mercury oxidation compared to the homogeneous case at any $\mathrm{HCl}$ concentration. At all $\mathrm{HCl}$ concentrations, however, mercury oxidation increased with increasing $\alpha-\mathrm{Fe}_{2} \mathrm{O}_{3}$ 
concentration. A comparison of these results with those obtained by injecting montmorillonite, seen in Figure 6, clearly indicates it is the presence of iron oxide particles and not surface area alone that is responsible for the observed increase in the extent of mercury oxidation.
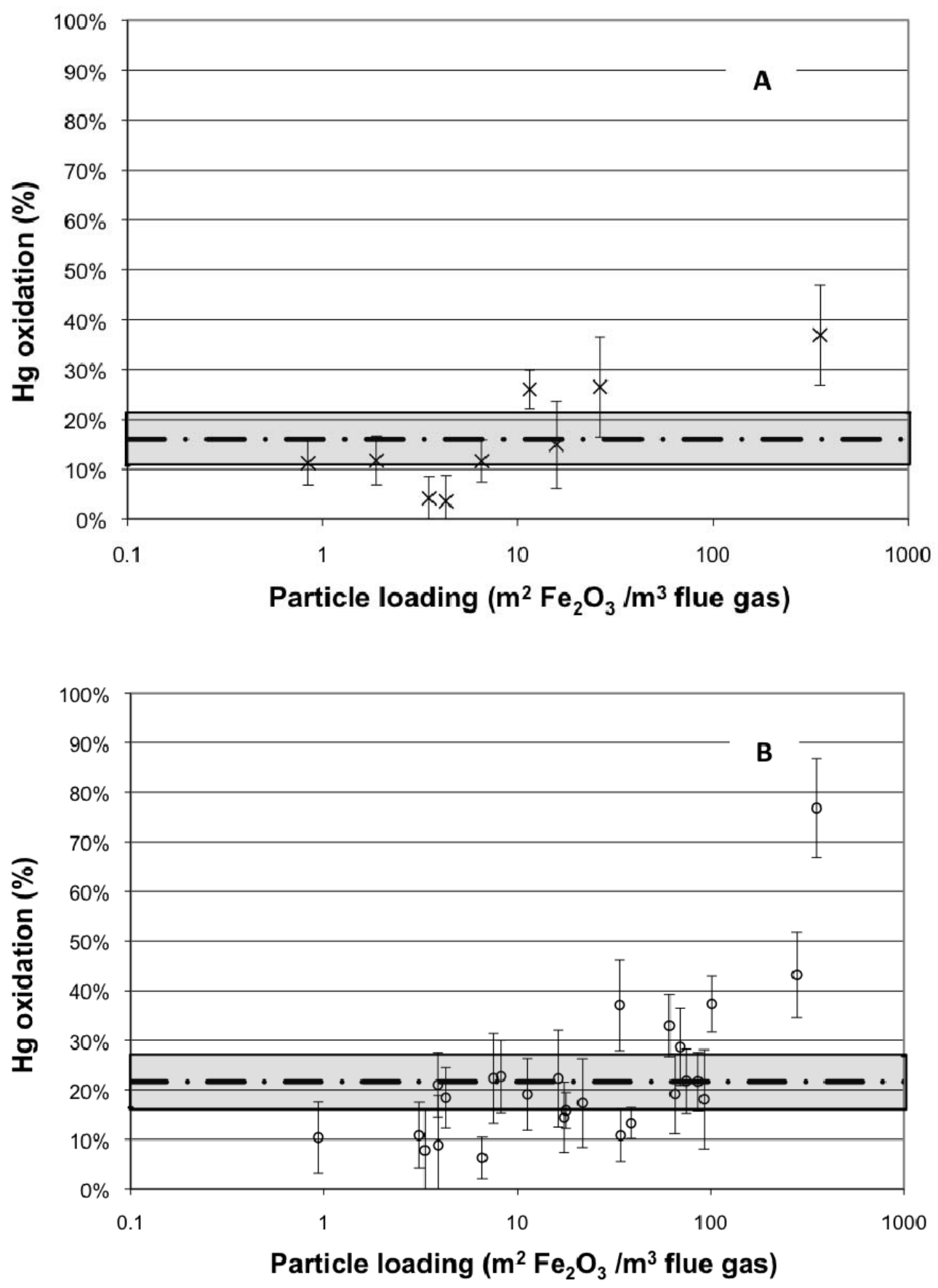

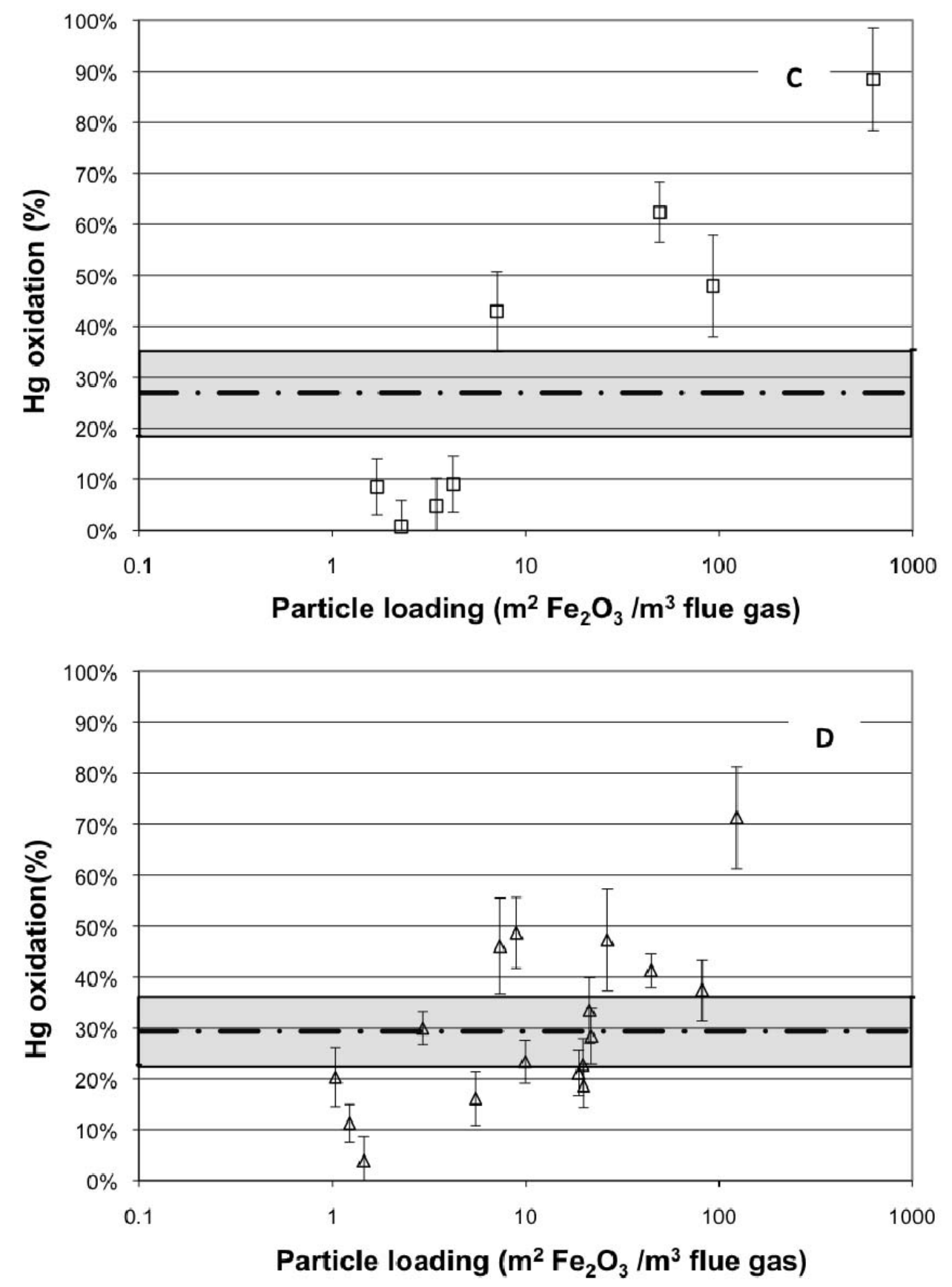

Figure 5: Effect of $\mathrm{HCl}$ and entrained a- $\mathrm{Fe}_{2} \mathrm{O}_{3}$ concentration on mercury oxidation in heterogeneous flame-based experiments. A) $[\mathrm{HCl}]=200 \mathrm{ppmv}, \mathrm{B})[\mathrm{HCl}]=300 \mathrm{ppmv}, \mathrm{C})[\mathrm{HCl}]$ $=400 \mathrm{ppmv}$, and $\mathrm{D})[\mathrm{HCl}]=555 \mathrm{ppmv}$. Error bars represent the measurement error for any given experiment, the dashed line signifies the mean extent of the homogeneous mercury oxidation at the given $\mathrm{HCl}$ concentration, and the shaded area represents one standard deviation about the mean. 

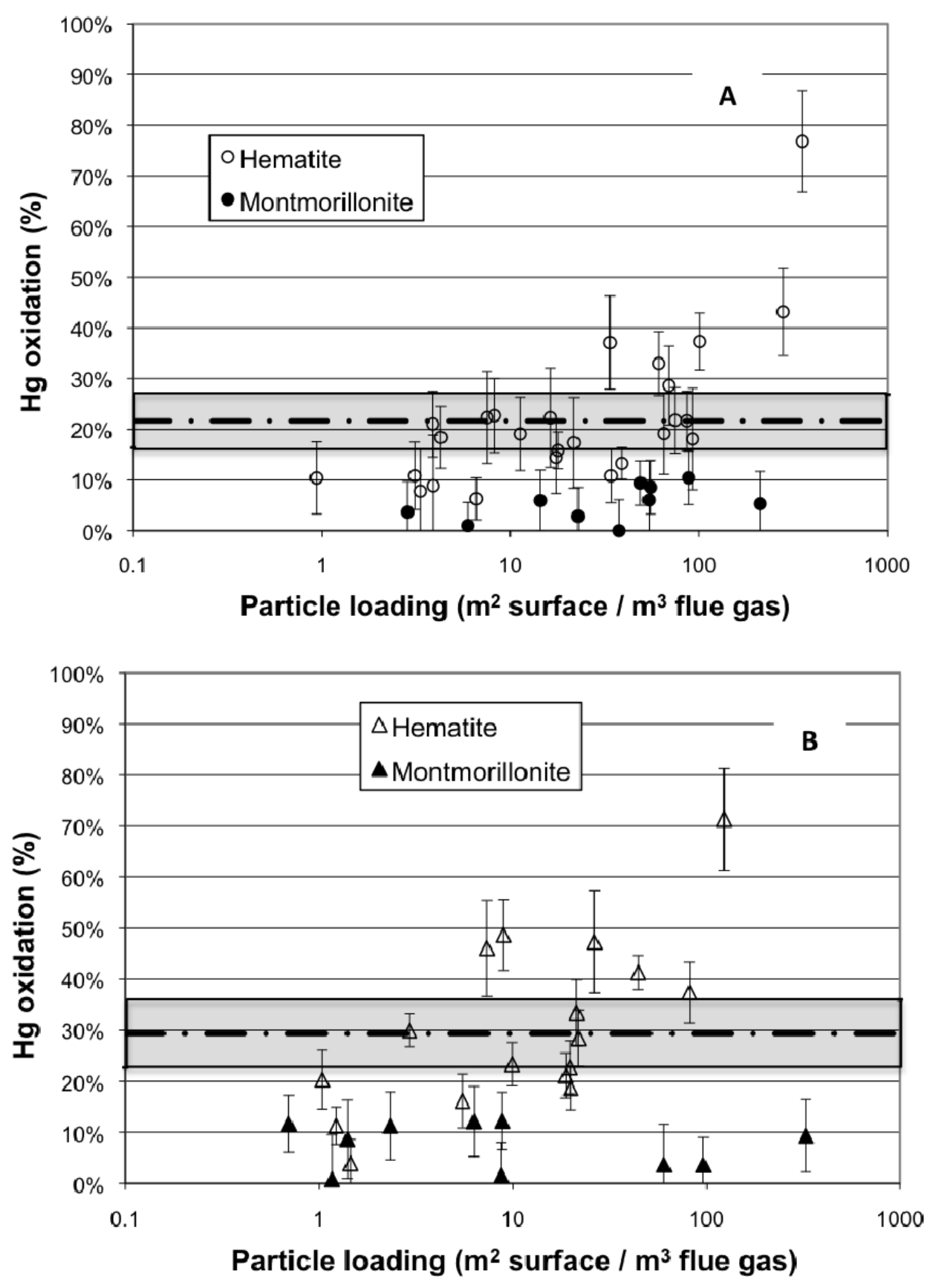

Figure 6: Effect of $\mathrm{HCl}$ concentration and entrained hematite on mercury oxidation compared to montmorillonite in heterogeneous flame-based experiments. A) $[\mathrm{HCl}]=300 \mathrm{ppmv}$ and $\mathrm{B}$ ) $[\mathrm{HCl}]$ $=555 \mathrm{ppmv}$. Error bars represent the measurement error for any given experiment, the dashed line signifies the mean of the homogeneous mercury oxidation at the given $\mathrm{HCl}$ concentration, and the shaded area represents one standard deviation about the mean. 
Sulfur dioxide is known to form sulfuric acid $\left(\mathrm{H}_{2} \mathrm{SO}_{4}\right)$ on the surface of $\alpha-\mathrm{Fe}_{2} \mathrm{O}_{3}$ in the presence of $\mathrm{O}_{2}$, with the fraction of $\mathrm{SO}_{2}$ converted to $\mathrm{H}_{2} \mathrm{SO}_{4}$ increasing with the presence of water vapor [10]. $\mathrm{H}_{2} \mathrm{SO}_{4}$, a strong acid, has the potential to oxidize elemental mercury to mercuric sulfate [11]. Heterogeneous experiments were therefore conducted with entrained hematite and $\mathrm{SO}_{2}$ in the flame-based system.

Figure 7 shows the effect of $\mathrm{SO}_{2}$ on mercury oxidation in the presence of $\alpha-\mathrm{Fe}_{2} \mathrm{O}_{3}$ particles. Different trends are noted for $\mathrm{SO}_{2}$ concentrations of $100 \mathrm{ppmv}$ to $400 \mathrm{ppmv}$ and an $\mathrm{SO}_{2}$ concentration of $500 \mathrm{ppmv}$. When the concentration of $\mathrm{SO}_{2}$ is varied from $100 \mathrm{ppmv}$ to 400 ppmv, the presence of both $\mathrm{SO}_{2}$ and $\alpha-\mathrm{Fe}_{2} \mathrm{O}_{3}$ particles enhance mercury oxidation near $1 \mathrm{~m}^{2} \alpha$ $\mathrm{Fe}_{2} \mathrm{O}_{3} / \mathrm{m}^{3}$ flue gas as compared to the homogeneous case, with the extent of oxidation decreasing as particle loading increases. At particle loadings above $10 \mathrm{~m}^{2} \alpha-\mathrm{Fe}_{2} \mathrm{O}_{3} / \mathrm{m}^{3}$ flue gas, mercury oxidation decreases below that observed in the homogeneous case. As seen in Figure 7, mercury oxidation is observed to increase with increased particle loading when the $\mathrm{SO}_{2}$ concentration is 500 ppmv. At iron oxide concentrations above $100 \mathrm{~m}^{2} \alpha-\mathrm{Fe}_{2} \mathrm{O}_{3} / \mathrm{m}^{3}$ flue gas, there appears to be some enhancement relative to the corresponding homogeneous $\mathrm{SO}_{2}$ mercury oxidation experiments.

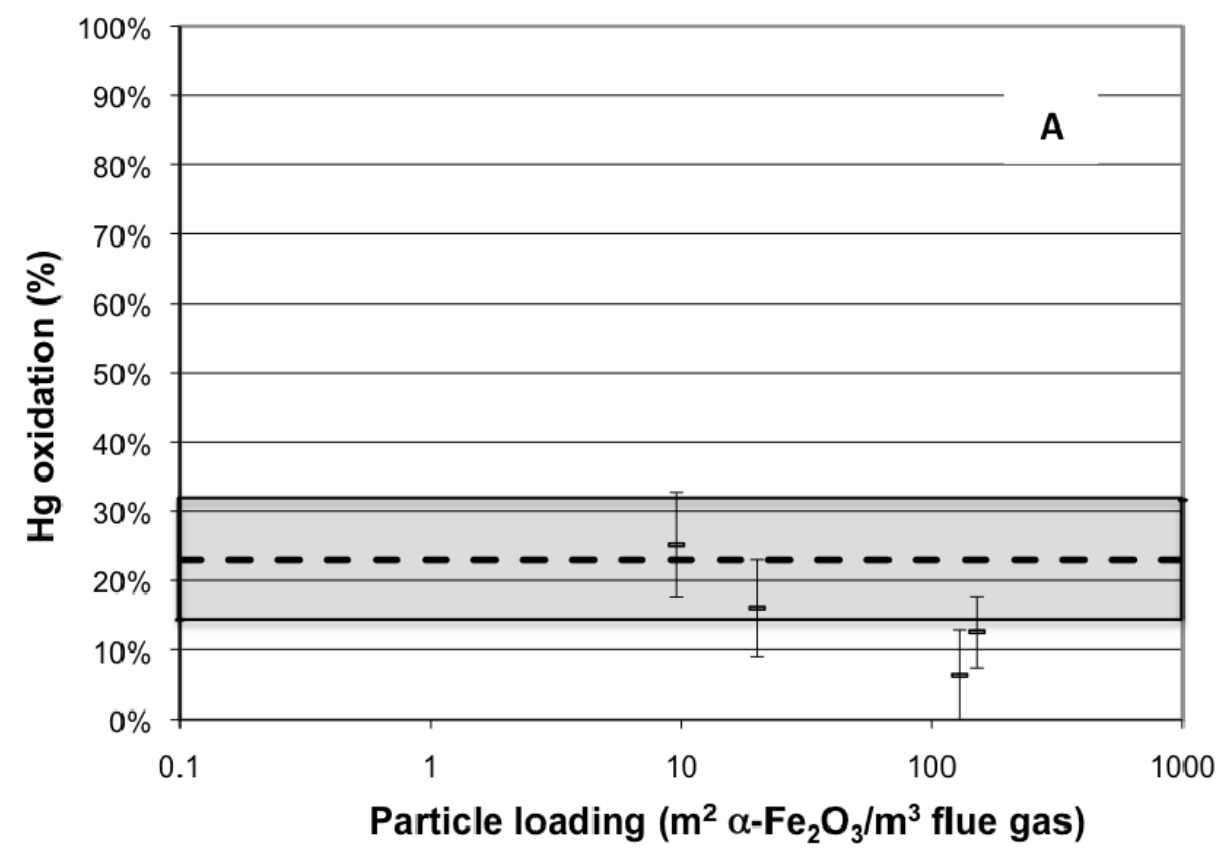



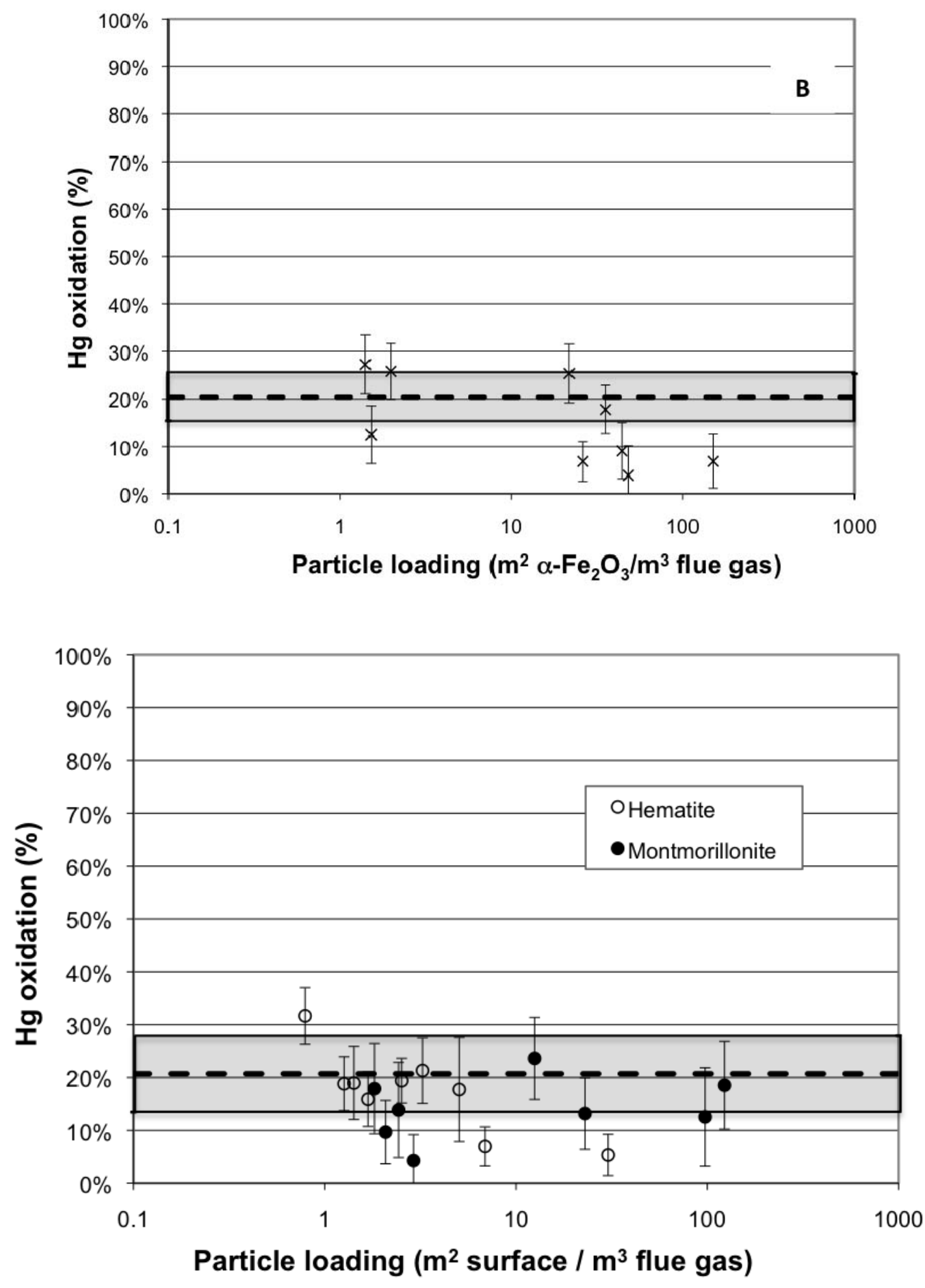

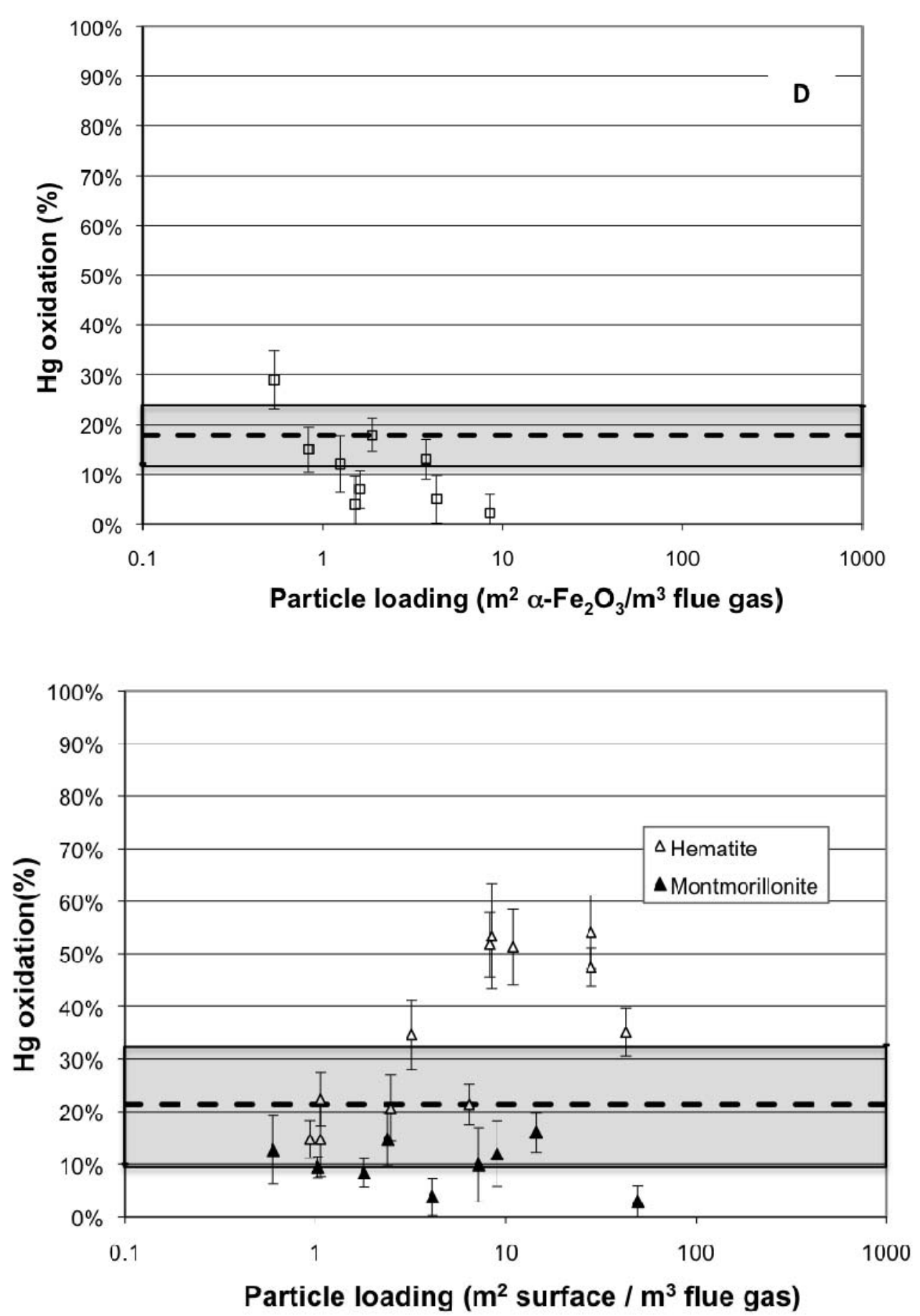

Figure 7: Semi-log plots of the effect of $\mathrm{SO}_{2}$ concentration and entrained $\alpha-\mathrm{Fe}_{2} \mathrm{O}_{3}$ or montmorillonite on mercury oxidation in heterogeneous flame based experiments. A) $\left[\mathrm{SO}_{2}\right]=$ $\left.\left.100 \mathrm{ppmv}, \mathrm{B})\left[\mathrm{SO}_{2}\right]=200 \mathrm{ppmv}, \mathrm{C}\right)\left[\mathrm{SO}_{2}\right]=300 \mathrm{ppmv}, \mathrm{D}\right)\left[\mathrm{SO}_{2}\right]=400 \mathrm{ppmv}$, and E) $\left[\mathrm{SO}_{2}\right]=$ $500 \mathrm{ppmv}$. Error bars signify measurement error for any given experiment, the dashed line signifies the mean of the extent of homogeneous mercury oxidation at the given $\mathrm{SO}_{2}$ concentration while the shaded area is one standard deviation from the mean. 
For comparison purposes, mercury oxidation measured in the presence of hematite or montmorillonite is presented in Figures $7 \mathrm{C}$ and $\mathrm{E}$ for $\mathrm{SO}_{2}$ concentrations of 300 and 500 ppmv, respectively. The results indicate the injection of montmorillonite in the presence of $\mathrm{SO}_{2}$ at either concentration has little effect on mercury oxidation in comparison to the homogeneous case. The mercury oxidation in the presence of hematite suggests a slight inhibition as particle loading increases from $1 \mathrm{~m}^{2} \alpha-\mathrm{Fe}_{2} \mathrm{O}_{3} / \mathrm{m}^{3}$ flue gas at an $\mathrm{SO}_{2}$ concentration of $300 \mathrm{ppmv}$ while increased mercury oxidation is seen with increasing particle loading from $1 \mathrm{~m}^{2} \alpha-\mathrm{Fe}_{2} \mathrm{O}_{3} / \mathrm{m}^{3}$ flue gas at an $\mathrm{SO}_{2}$ concentration of $500 \mathrm{ppmv}$. This demonstrates the catalytic potential of hematite in oxidizing elemental mercury at high hematite particle loadings and $\mathrm{SO}_{2}$ concentrations. The results of lower mercury oxidation than in homogeneous experiments during the montmorillonite injection experiments show the increased oxidation was not due to the increased surface area alone.

With the interactions observed in the homogeneous experiments in the presence of both $\mathrm{HCl}$ and $\mathrm{SO}_{2}$ and the interactions observed in heterogeneous hematite experiments with $\mathrm{HCl}$ or $\mathrm{SO}_{2}$, interactions were expected when mercury oxidation was examined in the presence of $\mathrm{HCl}, \mathrm{SO}_{2}$, and $\alpha-\mathrm{Fe}_{2} \mathrm{O}_{3}$ particles. Figure 8 illustrates the results from these heterogeneous experiments. A maximum of $62 \pm 12 \%$ mercury oxidation was observed at conditions of $300 \mathrm{ppmv} \mathrm{SO}_{2}$ concentration, $200 \mathrm{ppmv} \mathrm{HCl}$ concentration, and $2 \mathrm{~m}^{2} \alpha-\mathrm{Fe}_{2} \mathrm{O}_{3} / \mathrm{m}^{3}$ flue gas corresponding to the figure's independent variable of $400 \mathrm{ppmv} \mathrm{HCl} \cdot \mathrm{m}^{2} \alpha-\mathrm{Fe}_{2} \mathrm{O}_{3} / \mathrm{m}^{3}$ flue gas. This extent of mercury oxidation was much larger than that observed at similar hematite loadings in the presence of $\mathrm{SO}_{2}$ alone (16 $\pm 5 \%$ at $300 \mathrm{ppmv} \mathrm{SO}_{2}$ concentration) or $\mathrm{HCl}$ alone $(12 \pm 5 \%$ at 200 ppmv $\mathrm{HCl}$ concentration). In the comparable homogeneous mercury oxidation experiments with $\mathrm{SO}_{2}$ at a concentration of $300 \mathrm{ppmv}$ and $\mathrm{HCl}$ at a concentration of $200 \mathrm{ppmv}$ presented in Figure 4 , mercury oxidation was $25 \pm 2 \%$, showing the addition of hematite enhanced mercury oxidation. Mercury oxidation decreased from this apex with increasing particulate loading with no significant dependence on the $\mathrm{SO}_{2}$ concentration. The trend of decreasing mercury oxidation with increasing particle loading was similar to that observed for the heterogeneous oxidation experiments containing $\mathrm{SO}_{2}$ alone at concentrations of $100 \mathrm{ppmv}$ to $400 \mathrm{ppmv}$. 


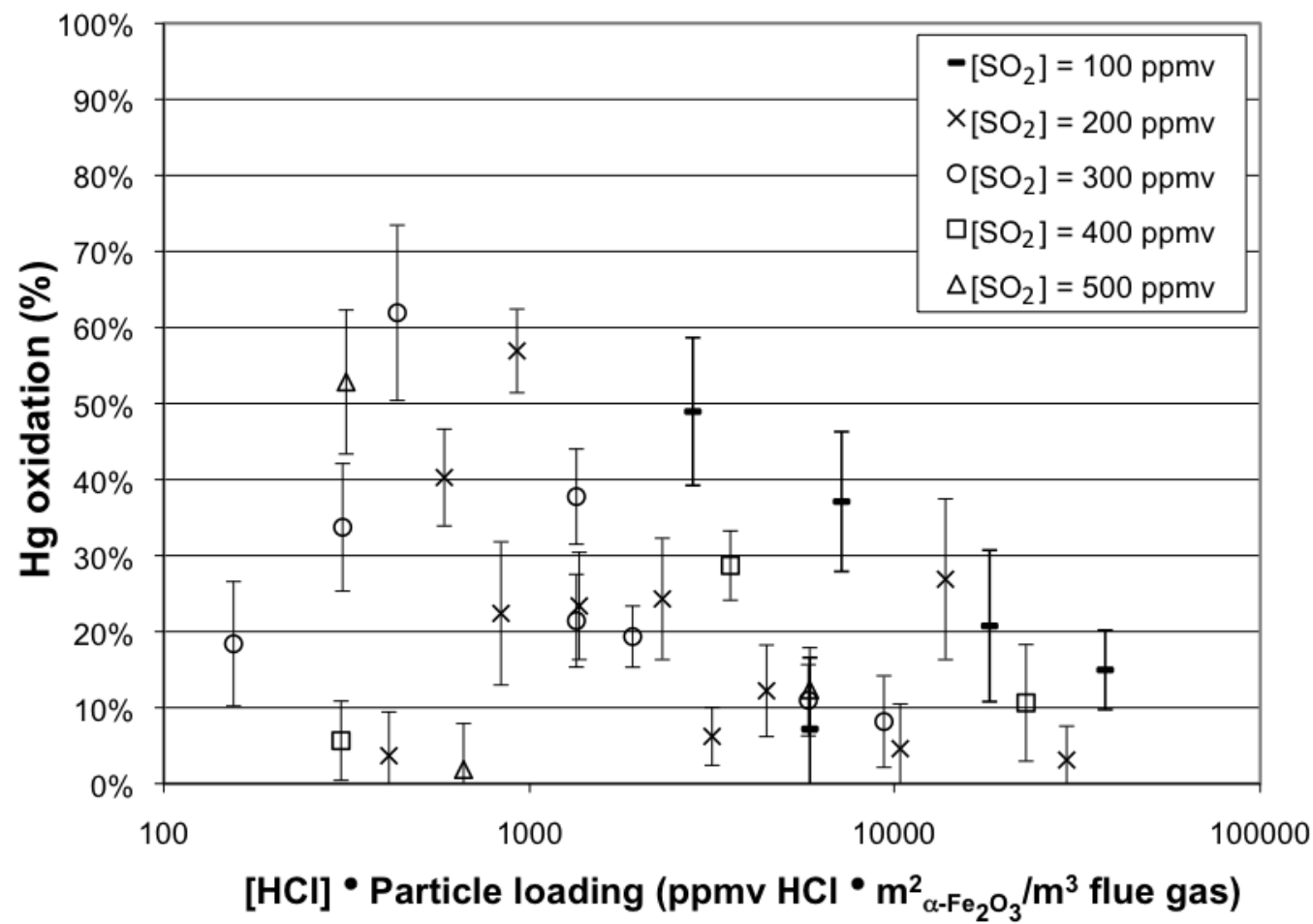

Figure 8: Mercury oxidation in the presence of $\mathrm{HCl}, \mathrm{SO}_{2}$, and entrained hematite in heterogeneous flame based experiments. Error bars signify measurement error for any given experiment.

The presence of hematite is seen to enhance mercury oxidation by $\mathrm{HCl}$ and $\mathrm{SO}_{2}$ under a fairly broad range of conditions. For example, the mercury oxidation observed at a concentration of 200 ppmv $\mathrm{SO}_{2}, 555 \mathrm{ppmv} \mathrm{HCl}$, and $25 \mathrm{~m}^{2} \alpha-\mathrm{Fe}_{2} \mathrm{O}_{3} / \mathrm{m}^{3}$ flue gas corresponding to the figure's independent variable of $13800 \mathrm{ppmv} \mathrm{HCl} \cdot \mathrm{m}^{2} \alpha-\mathrm{Fe}_{2} \mathrm{O}_{3} / \mathrm{m}^{3}$ flue gas is $27 \pm 11 \%$, whereas the extent of mercury oxidation in the corresponding homogeneous case is measured as $17 \pm 1 \%$. When the result from the experiment with $200 \mathrm{ppmv} \mathrm{SO} \mathrm{S}_{2}, 555 \mathrm{ppmv} \mathrm{HCl}$, and $25 \mathrm{~m}^{2} \alpha-\mathrm{Fe}_{2} \mathrm{O}_{3} / \mathrm{m}^{3}$ flue gas experiment is compared to corresponding heterogeneous experiments in the presence of $\mathrm{HCl}$ or $\mathrm{SO}_{2}$ alone, the extent of mercury oxidation is less than that observed at $26 \mathrm{~m}^{2} \alpha-\mathrm{Fe}_{2} \mathrm{O}_{3} / \mathrm{m}^{3}$ flue gas for an $\mathrm{HCl}$ concentration of $555 \mathrm{ppmv}$ alone $(47 \pm 10 \%)$ and more than that observed at the same hematite loading and an $\mathrm{SO}_{2}$ concentration of $200 \mathrm{ppmv}(7 \pm 4 \%)$, suggesting that the inhibition seen in the homogeneous case when $\mathrm{HCl}$ and $\mathrm{SO}_{2}$ are jointly present may also occur in the heterogeneous case.

Using linear least squares regression, the extent of mercury oxidation $(\epsilon)$ from heterogeneous mercury oxidation experiments is fit to the linear model shown below for each $\mathrm{HCl}$ concentration.

$$
\varepsilon=m \cdot \log _{10}(A)+b
$$


where

$$
\begin{aligned}
& \mathrm{m}=\text { slope } \\
& \mathrm{A}=\text { hematite particle loading }\left(\mathrm{m}^{2} \alpha-\mathrm{Fe}_{2} \mathrm{O}_{3} / \mathrm{m}^{3} \text { flue gas }\right), \text { and } \\
& \mathrm{b}=\mathrm{y} \text {-intercept }
\end{aligned}
$$

Figure 9 shows the data collected from heterogeneous mercury oxidation experiments with an $\mathrm{HCl}$ concentration of $555 \mathrm{ppmv}$ and various hematite concentrations and the fitted logarithmic model.

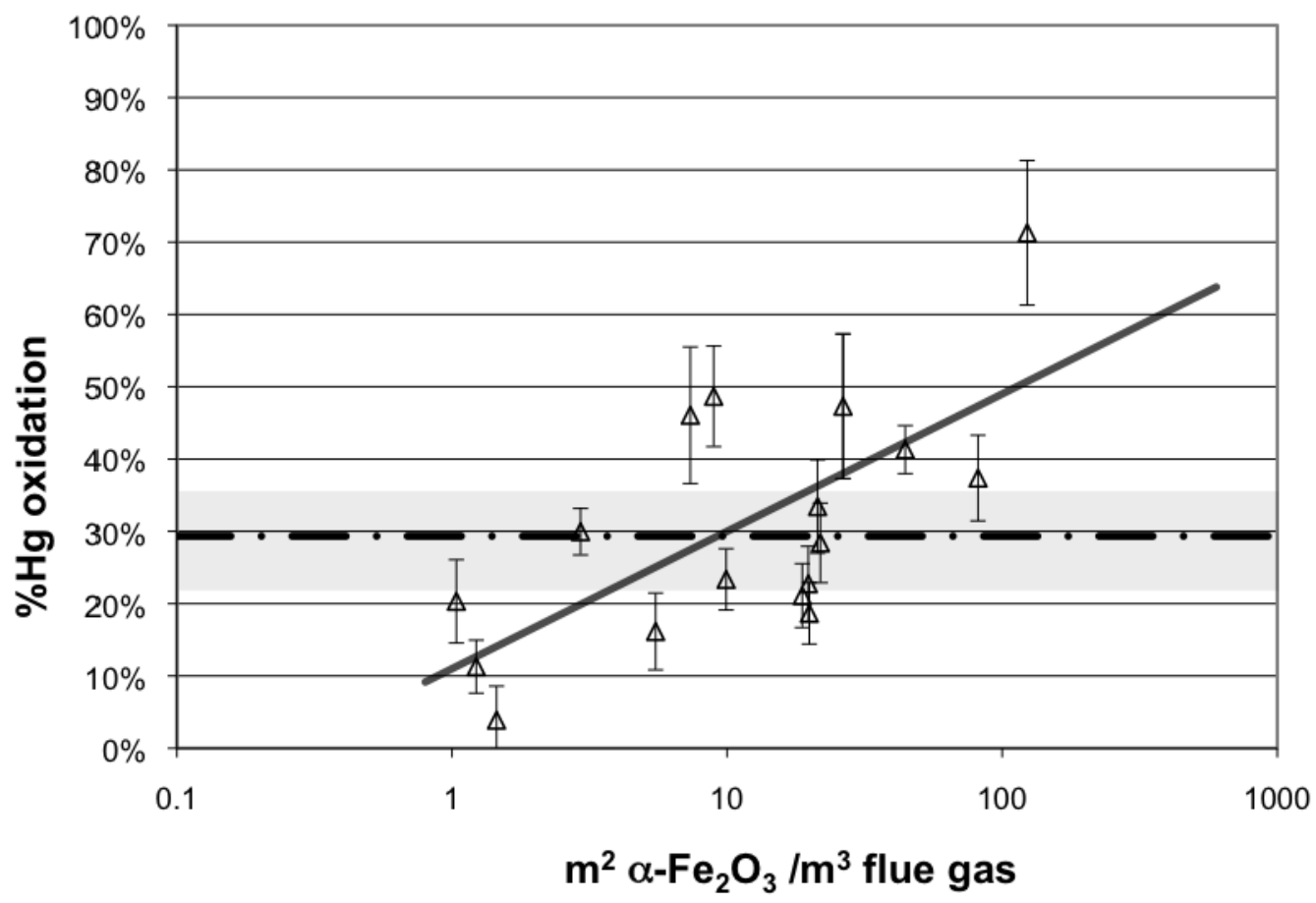

Figure 9: Semi-log plot of mercury oxidation in the presence of $[\mathrm{HCl}]=555 \mathrm{ppmv}$ and entrained hematite in heterogeneous flame-based experiments with linear least squares regression fit. Error bars represent the measurement error for each experiment; the dashed line signifies the mean of the extent of homogeneous mercury oxidation at the given $\mathrm{HCl}$ concentration while the shaded area is one standard deviation from the mean.

Trends of mercury oxidation by $\mathrm{HCl}$ in the presence of hematite are presented in Table II, which show that with the exception of the experiments at an $\mathrm{HCl}$ concentration of $400 \mathrm{ppmv}$, the slope of the logarithmic model fitted to the data increases with increasing $\mathrm{HCl}$ concentration. The 
increased slope for an $\mathrm{HCl}$ concentration of $400 \mathrm{ppmv}$ is attributed to the collection of fewer data points within the range of $10-100 \mathrm{~m}^{2} \alpha-\mathrm{Fe}_{2} \mathrm{O}_{3} / \mathrm{m}^{3}$ flue gas particle loading. This outcome is similar to the homogeneous mercury oxidation case in the presence of different $\mathrm{HCl}$ concentrations. For comparison purposes, the model prediction of heterogeneous mercury oxidation at $100 \mathrm{~m}^{2} \alpha-\mathrm{Fe}_{2} \mathrm{O}_{3} / \mathrm{m}^{3}$ flue gas is $29 \%$ at an $\mathrm{HCl}$ concentration of $200 \mathrm{ppmv}$, increasing with increasing $\mathrm{HCl}$ concentration to $49 \%$ at an $\mathrm{HCl}$ concentration of $555 \mathrm{ppmv}$. The root mean squared error (RMSE) and coefficient of determination $\left(\mathrm{R}^{2}\right)$ are provided as statistics for the fit of the model to the data.

\section{Table II}

Constants for linear models of heterogeneous mercury oxidation with $\mathrm{HCl}$ concentration

\begin{tabular}{lllll} 
[HCl] (ppmv) & $\mathbf{m}$ & $\mathbf{b}$ & $\mathbf{R M S E}$ & $\mathbf{R}^{2}$ \\
200 & 0.12 & 0.05 & 0.06 & 0.68 \\
300 & 0.15 & 0.03 & 0.11 & 0.44 \\
400 & 0.33 & -0.04 & 0.10 & 0.95 \\
555 & 0.19 & 0.11 & 0.12 & 0.45 \\
\hline
\end{tabular}

The same linear model is used to fit the data for $\mathrm{SO}_{2}$ with the results shown in Table III. The trends of mercury oxidation by $\mathrm{SO}_{2}$ in the presence of hematite show that with the exception of the experiments at an $\mathrm{SO}_{2}$ concentration of 500 ppmv, the slope of the logarithmic model is negative. With the trend differing for an $\mathrm{SO}_{2}$ concentration of $500 \mathrm{ppmv}$, it is postulated that the presence of $\mathrm{SO}_{2}$ at high concentrations and the presence of hematite transforms the chemistry in the flue gas to favor mercury oxidation.

\section{Table III}

Constants for linear models of heterogeneous mercury oxidation with $\mathrm{SO}_{2}$ concentration

$\begin{array}{lllll}\text { [SO }_{2} \text { ] (ppmv) } & \mathbf{m} & \mathbf{b} & \mathbf{R M S E} & \mathbf{R}^{2} \\ 100 & -0.12 & 0.34 & 0.03 & 0.79 \\ 200 & -0.08 & 0.24 & 0.07 & 0.41 \\ 300 & -0.13 & 0.24 & 0.04 & 0.92 \\ 400 & -0.16 & 0.16 & 0.06 & 0.50 \\ \underline{500} & 0.21 & 0.19 & 0.10 & 0.24\end{array}$


To determine if adsorbed chlorine or sulfur species on the surface of iron particles produce the catalytic effect on mercury oxidation, particles were collected from the wall of the quartz reactor after experiments conducted with either $\mathrm{HCl}$ or $\mathrm{SO}_{2}$. Ten particles from three types of experiments were examined for elemental composition in a scanning electron microscope using energy-dispersive X-ray (EDX) spectroscopy: $\alpha-\mathrm{Fe}_{2} \mathrm{O}_{3}$ and $555 \mathrm{ppmv} \mathrm{HCl}, \alpha-\mathrm{Fe}_{2} \mathrm{O}_{3}$ and 500 ppmv $\mathrm{SO}_{2}$, and montmorillonite and $500 \mathrm{ppmv} \mathrm{SO}_{2}$. One particle from those examined from the $\alpha-\mathrm{Fe}_{2} \mathrm{O}_{3}$ and $\mathrm{SO}_{2}$ concentration of 500 ppmv experiment contained $2 \%$ by volume sulfur, its peak significantly greater than the background noise. All other particles examined did not produce any peaks for chlorine or sulfur above the background noise.

To compare particle loadings to those found in coal combustion systems, data from coal combustion experiments completed at the University of Arizona were used to calculate particle loadings from the combustion of Illinois \#6 bituminous coal, Elkhorn Kentucky bituminous coal, North Dakota lignite coal, Ohio bituminous coal, Pittsburgh bituminous coal, and Wyodak subbituminous coal. In these calculations, it was assumed that the fly ash particles were spherical in shape, the fly ash density was $2200 \mathrm{~kg} / \mathrm{m}^{3}$, and the fraction of ash as fly ash was 0.75 . Data utilized in these calculations include coal feedrate $(\mathrm{g} / \mathrm{hr})$, flue gas flowrate (slpm), and the size distribution of ash in fly ash [12]. The ash content ( $\mathrm{g}$ ash/g coal) was used from previously reported values $[13,14]$. From these values, the range of particle loading in 43 coal combustion experiments was 2 to $183 \mathrm{~m}^{2}$ particles $/ \mathrm{m}^{3}$ flue gas with a median at $12 \mathrm{~m}^{2}$ particles $/ \mathrm{m}^{3}$ flue gas, within the 0.54 to $620 \mathrm{~m}^{2}$ particles $/ \mathrm{m}^{3}$ flue gas produced in these experiments.

The data from experiments injecting $\mathrm{HCl}, \mathrm{SO}_{2}$, and hematite illustrate the complex interactions between these materials. The general trend of decreased mercury oxidation with increasing particle loading from $2 \mathrm{~m}^{2} \alpha-\mathrm{Fe}_{2} \mathrm{O}_{3} / \mathrm{m}^{3}$ flue gas in the presence of $\mathrm{HCl}, \mathrm{SO}_{2}$, and hematite is similar to that seen for experiments with hematite and at $\mathrm{SO}_{2}$ concentrations of $100-400 \mathrm{ppmv}$. The maximum mercury oxidation of $62 \pm 12 \%$ in the presence of $\mathrm{HCl}, \mathrm{SO}_{2}$, and hematite is larger than that observed in the homogeneous experiments, however, larger mercury oxidation is observed with experiments conducted with hematite at particle loadings above $100 \mathrm{~m}^{2} \alpha$ $\mathrm{Fe}_{2} \mathrm{O}_{3} / \mathrm{m}^{3}$ flue gas and $\mathrm{HCl}$ at concentrations of 300 to $555 \mathrm{ppmv}$ when $\mathrm{SO}_{2}$ is not present. 


\section{Section 2: Arsenic Transformations}

As discussed in several project progress reports, during combustion, arsenic may vaporize and oxidize to form arsenic trioxide $\left(\mathrm{As}_{4} \mathrm{O}_{6}\right)$, vaporize and then react with other components present in fly ash through gas-solid reaction processes, or react with mineral constituents within the burning char particle, without vaporizing, to form arsenates such as calcium arsenate $\left(\mathrm{Ca}_{3}\left(\mathrm{AsO}_{4}\right)_{2}\right)$. This latter process is referred to as the "unvaporized" pathway through the balance of this report as an indication that arsenic reaction and transformation may occur without requiring vaporization.

Because of the relatively low volatility of arsenic, it is generally accepted that arsenic only partially vaporizes at the high temperatures of coal combustion [15]. The majority of the vaporized arsenic is eventually associated with the sub-micron ash particles because of this relatively high surface area. The presence of arsenic in super-micron fly ash particles cannot be explained solely by condensation or gas-solid reaction of the vaporized arsenic, and has largely been attributed to retention in silicate and aluminosilicate-derived fly ash particles or with nonsilicate compounds such as calcium oxide, hematite, magnetite, and alumina [16, 17].

Equilibrium calculations were used as a starting point for the examination of arsenic combustion transformations. As expected, $\mathrm{As}_{4} \mathrm{O}_{6}$ was found to be the dominant arsenic-containing compound when considering the combustion of Ohio bituminous coal at a stoichiometric ratio of 1.2 and at temperatures between $800 \mathrm{~K}$ and $1150 \mathrm{~K}$. When calcium was included in the calculations, calcium arsenate became dominant at temperatures between $1150 \mathrm{~K}$ and $1623 \mathrm{~K}$ as shown in Figure 10.

Combustion experiments using synthetic char and coal were therefore conducted to assess the formation of calcium arsenate and provide a better understand the partitioning of arsenic in fly ash.

Two synthetic char experiments were conducted, one utilizing chars containing calcium and arsenic in the same char particles and the other utilizing chars containing calcium and arsenic in in separate char particles. The literature has suggested that trace metals such as arsenic volatize during coal combustion and then react with solid fly ash constituents (i.e. $\mathrm{CaO}$ ) as shown by Path A in Figure 11, below. If however, the trace metal contacts a reactive fly ash compound as it diffuses through the burning char particle during coal combustion, a reaction within the char might also occur. This pathway is shown as Path B in the figure. 


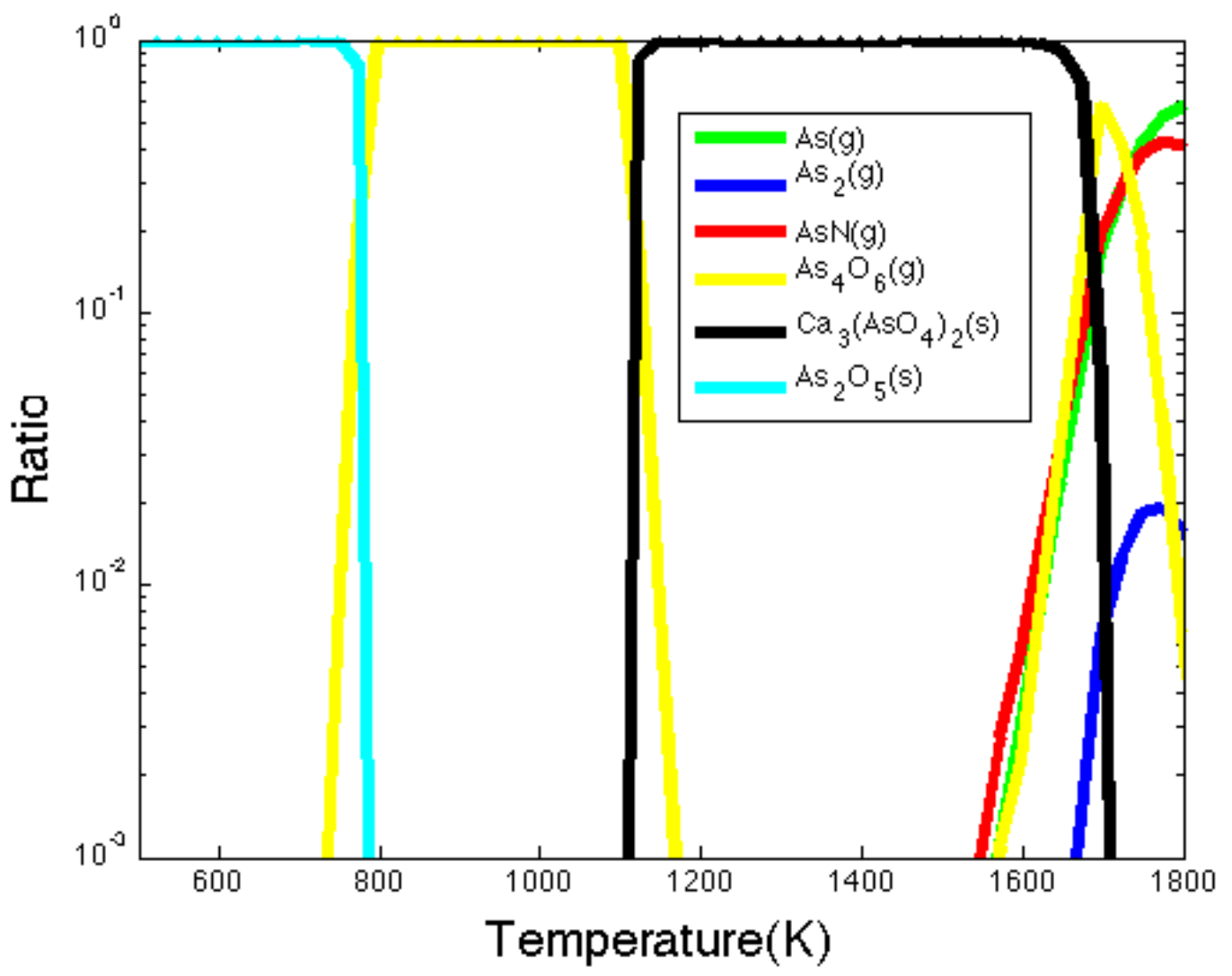

Figure 10: Ratios of arsenic in the arsenic-containing compounds to total arsenic in equilibrium calculations at a stoichiometric ratio of 1.2 .
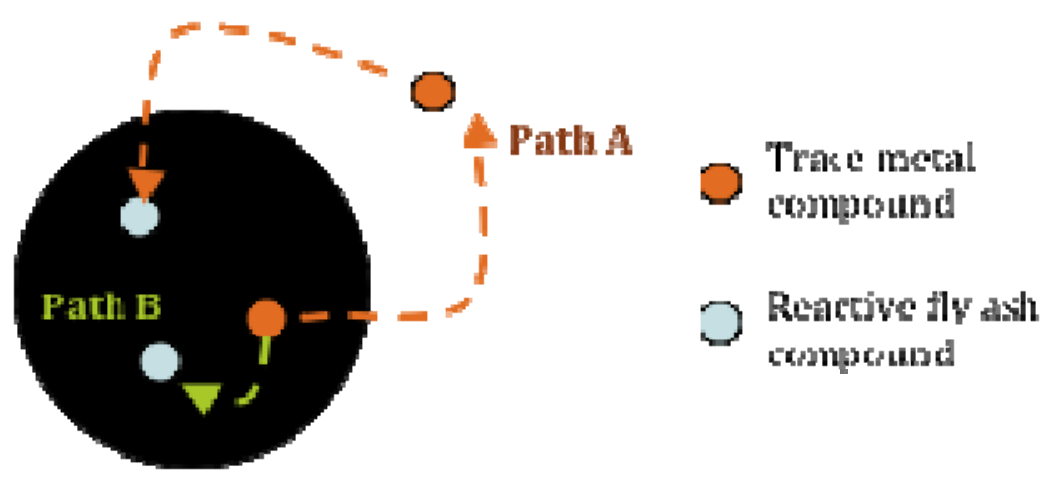

Figure 11: Possible pathways of trace metal interaction with reactive fly ash constituents within a coal particle.

The potential for in-char reaction of trace metal compounds with minerals in fly ash was 
examined by developing three types of synthetic char to probe the in-char verses external-tocalcium reaction pathways depicted above. Synthetic chars containing dispersed trace metal compounds such as cacodylic acid $\left(\left(\mathrm{CH}_{3}\right)_{2} \mathrm{AsO}_{2} \mathrm{H}\right)$ and separate synthetic chars containing inclusions of reactive fly ash materials such as calcium oxide were produced to be combusted together. A third type of synthetic char containing both trace metal compounds and reactive fly ash materials was also developed for combustion. Interactions were then examined when these chars were combusted and the resulting fly ash collected and analyzed

If the products of a reaction such as calcium arsenates are found in fly ash from burning synthetic char A and synthetic char B separately, it is likely that Path A is the dominant pathway. If however, the trace metal in the fly ash from synthetic char Syn-4 (that containing both As and $\mathrm{Ca}$ in individual char particles) is in the form of calcium arsenates while that from synthetic chars Syn-2 and Syn-3 is mainly in an oxidized form (i.e. $\mathrm{As}_{2} \mathrm{O}_{3}$ for arsenic), the likely pathway for the gas-solid reaction would be Path B.

To examine potential arsenic-calcium interactions, combustion studies were also conducted with selected size-segregated pulverized coals. Three types of coals were obtained from the University of Utah for this study: Kentucky Elkhorn bituminous coal, North Dakota lignite coal, and Wyodak sub-bituminous coal. These specific coals were chosen because they have been studied extensively in the literature and because they are of different coal types commonly used in coal-fired electricity generating utilities. Analysis of these coals was completed previously. Pertinent coal analyses are provided in Table IV. Coal samples were size segregated in the

Table IV

Analysis of coals used in combustion experiments on an as received basis. Re- produced from Senior et al. [13] and Bool et al. [18]

\begin{tabular}{llll} 
Element & Kentucky [18] & Wyodak [13] & North Dakota [13] \\
\hline Proximate $(w t \%)$ & \multicolumn{3}{l}{} \\
\hline Fixed Carbon & 56.46 & 33.31 & 26.59 \\
Volatile Matter & 33.80 & 34.85 & 28.15 \\
Moisture & 2.33 & 25.81 & 35.88 \\
Ash & 7.41 & 6.03 & 9.38 \\
\hline Ash Composition $(w t \%)$ on a sulfur-free basis & \\
\hline $\mathrm{SiO}_{2}$ & 56.63 & 43.28 & 22.00 \\
$\mathrm{Al}_{2} \mathrm{O}_{3}$ & 34.76 & 17.17 & 20.38 \\
$\mathrm{Fe}_{2} \mathrm{O}_{3}$ & 5.25 & 6.32 & 11.75 \\
$\mathrm{TiO}_{2}$ & 1.73 & 1.38 & 0.50 \\
$\mathrm{CaO}$ & 1.87 & 22.74 & 30.25 \\
$\mathrm{MgO}$ & 0.61 & 4.03 & 8.00 \\
$\mathrm{Na}$ & 0.32 & 1.67 & 5.12 \\
$\mathrm{~K}_{2} \mathrm{O}$ & 1.55 & 0.45 & 1.38 \\
$\underline{\mathrm{P}_{2}} \underline{\mathrm{O}} \underline{5}$ & 0.23 & 1.78 & 0.13 \\
$\underline{\mathrm{Trace}}$ & & \\
$\underline{\mathrm{As}}$ & 4 & 1.4 & 8.1
\end{tabular}


laboratory to 106 - 125 micrometers $(\mu \mathrm{m})$ in diameter using No.120 and No.140 mesh sieves prior to being combusted in the drop tube furnace.

Two different methods of producing synthetic char were examined for the purpose of this study: polymerization using furfuryl alcohol and polymerization using a mixture of phenol and formaldehyde. Both produce synthetic char after periods of resin formation and carbonization. It has been reported that char from furfuryl alcohol resembles a low rank coal based on studies of weight loss during combustion [19], while the phenol and formaldehyde mixture produces a char more similar to a high volatile bituminous coal [20]. The phenol-formaldehyde mixture was therefore chosen for this study.

The procedure for producing synthetic char from phenol and formaldehyde is described in the literature [21]. Slight variations from the procedure were used in these experiments. The phenolformaldehyde (PF) resin reaction was catalyzed in this study using ammonium hydroxide $\left(\mathrm{NH}_{4} \mathrm{OH}\right)$ to provide nitrogen, an element naturally existing in coal. Instead of carbonizing the polymer under helium gas, nitrogen was used because it was readily available in the laboratory and any further incorporation of nitrogen was assumed to be beneficial. Additionally, materials such cacodylic acid, calcium oxide, and carbon black were added to the synthetic char. The fly ash material and carbon black were added prior to carbonization to be fully incorporated in the char matrix. The trace metal compound was added post-carbonization so that the least amount was lost due to vaporization during the vacuum heating portions of the synthetic char formation process and to reduce human exposure during the grinding and sieving steps. The trace metal and reactive fly ash compounds were added for the purpose of studying the gas-solid reaction between arsenic and calcium, while carbon black was added to increase the porosity of the material to more closely simulate the structure of coal.

Phenol-formaldehyde resins can be created under either acidic or basic conditions. When the reaction is carried out under acidic conditions with an excess of phenol, the product is a novolac. Novolacs are stable linear chains with relatively small molecular weights generally ranging from $500-1000 \mathrm{~g} / \mathrm{mol}$. Such a resin is water soluble and cured only with the addition of a hardener such as formaldehyde [22]. In the formation of a novolac, the addition of hydrochloric acid protonates formaldehyde at the oxygen in the molecule leaving the carbon atom with a slight positive charge. This carbon then forms complexes at either the para- or ortho- positions of the phenol molecule, which is slightly negative, and is the rate-limiting step. At this point a hydrogen ion is released and monomethylol phenol is formed. The carbon from the newly added formaldehyde molecule then reacts with the ortho- or para- position of another phenol molecule to form the polymerizing chain with a water molecule formed as a product [23].

Resols are resins prepared using a basic catalyst with an excess of formaldehyde. These resins are water insoluble with high molecular weight and high viscosity [24]. The resol shows an optimal polymerization when the $\mathrm{pH}$ is between 9-9.25. With a $\mathrm{pH}$ higher than 10 , the Cannizzaro reaction interferes with the polymerization by removing formaldehyde by transforming it into formic acid and methanol [25]. During the desired polymerization process the carbon in the formaldehyde attacks the ortho- or para- position of phenol with all three of the positions available to be filled. Upon addition of heat, the resin cross-links releasing water and 
formaldehyde and leaving a strengthened three dimensional resin [22]. The resol pre-polymers consist of phenol rings, methylene bridges, methylolgroups, and dimethylene ether bridges, a more complicated three dimensional structure [26] than the product of the acid-catalyzed polymerization.

The base-catalyzed polymerization was used for the preparation of synthetic char in this study because the product is cross-linked in three dimensions similar to the structures found in coal. Added benefits include water insolubility and high viscosity, making the incorporation of additives more likely. As mentioned previously, ammonium hydroxide was used to catalyze the PF resin reaction. Ammonia catalyzed resols are characterized with a yellow tint attributed to the azomethine group and higher average molecular weight [22]. Additionally, ammonium hydroxide adds small amounts of nitrogen to the mixture, increasing its similarity to coal while other catalysts described in the literature such as barium hydroxide or sodium hydroxide would add elements not desired for this study.

Solid phenol (99\%) was obtained from Fisher Scientific for the synthesis. Because the phenol was extremely hygroscopic, the phenol absorbed water from the air and became a solid crystal in the shipping jar. To make the phenol usable in the production of the phenol formaldehyde resin, de-ionized water was added once to the container and allowed to equilibrate over a day at room temperature. At equilibrium, the phenol-water mixture formed two liquid layers: phenol in water with a small phenol concentration and water in phenol with a large phenol concentration. At 293 $\mathrm{K}$ the layers were assumed to be $8.12 \%$ and $71.8 \%$ phenol by weight, respectively [27]. When the liquid was measured, the volumes of the two liquid layers were noted and the amount of phenol used calculated from the densities. If, after having used a portion of the phenol-water mixture in producing the polymer and only one liquid layer was present in the container, the liquid was assumed to be the water in phenol phase because it was visually observed to have a similar viscosity as the more dense phase.

Formaldehyde (37\%) was procured from Fisher Scientific and used as-received. The water present in these two reactants was subtracted from the amount needed for the polymerization to determine the additional amount of water to be added. Once the phenol and formaldehyde were added to the round bottom flask, make-up de-ionized water was added. The reactant mixture was composed of two liquid phases with the more dense phase being larger in volume than that of the original reactants separately.

Four synthetic char particle samples were produced for the study of trace metal compound and reactive fly ash interactions. The first, designated Syn-1, contained the phenol formaldehyde resin and carbon black and was combusted under the same conditions as the other samples to determine if the synthesizing processes, combustion environment, or base materials affected the results. The second, Syn-2, consisted of phenol formaldehyde resin, carbon black, and cacodylic acid. The third, Syn-3, consisted of phenol formaldehyde resin, carbon black, and calcium oxide. Syn-2 and Syn-3 were combusted together as Syn-2/3, the char mixture represented in Figure 3.32 and 3. The final sample, Syn-4, contained phenol formaldehyde resin, carbon black, calcium oxide, and cacodylic acid. The mass amounts used in producing each char is shown in Table V. 
Table V

Materials used in the formation of synthetic char samples

\begin{tabular}{lllll} 
Sample & PF resin $(\mathrm{g})$ & Carbon black $(\mathrm{g})$ & Calcium oxide $(\mathrm{g})$ & Cacodylic acid $(\mathrm{g})$ \\
\hline Syn-1 & 0.5282 & 2.1092 & - & - \\
Syn-2 & 0.4437 & 1.7717 & - & 0.0814 \\
Syn-3 & 0.5636 & 2.2601 & 0.2854 & - \\
Syn-4 & 0.5873 & 2.3552 & 0.2974 & 0.1953 \\
\hline
\end{tabular}

Once the resin pre-polymerization was completed, the excess liquid consisting of methanol, formaldehyde, and water was decanted and the polymer transferred to an Erlenmeyer flask. Acetone was used to dissolve the polymer and additives such as carbon black and calcium oxide were added. Carbon black powder (VXC-500) obtained from Cabot Corporation, with a reported surface area of $59 \mathrm{~m} 2 / \mathrm{g}$ and ash concentration of $0.01 \%$ by weight was then added to increase the porosity and surface area of the synthetic char $[24,28]$. Calcium oxide size segregated to $0.2-$ $2.1 \mu \mathrm{m}$ in diameter and with an $\mathrm{N}_{2}$-BET measured surface area of $23.5 \pm 1 \mathrm{~m} 2 / \mathrm{g}$ was included in the synthetic char as a reactive fly ash compound in Syn-3 and Syn-4 samples prior to carbonization to incorporate the reactive fly ash material throughout the synthetic char sample. Calcium oxide was added so that the final sample contained nearly $3 \%$ by weight calcium.

After adding the desired materials, the mixture was inserted into ceramic combustion boats and heated for 3 hours at $60^{\circ} \mathrm{C}$ under vacuum in a VWR 1420 heater to remove the acetone. The mixture was then heated at $120^{\circ} \mathrm{C}$ for 12 hours under vacuum to cure the resin. After the curing process was completed, the mixture was heated at $300^{\circ} \mathrm{C}$ for 6 hours under $\mathrm{N}_{2}$ flow to carbonize the resin and produce the final synthetic char [21]. The resulting samples were ground using a ceramic mortar and pestle and size segregated by sieving the samples using US No. 120 and No.140 sieves in a mechanical shaker resulting in particles between $106-125 \mu \mathrm{m}$ in diameter.

The intention of incorporating the calcium oxide prior to carbonization was to incorporate the reactive fly ash material throughout the synthetic char sample. To show that the calcium was embedded within the carbon matrix, secondary and backscattered emission imaging was conducted using a scanning electron microscope (SEM) at a magnification of $3517 x$. Figure 12 shows the secondary emission image presenting the surface of the particles, while the white portions shown in the backscattered images show the incorporated calcium near the surface of sample. 


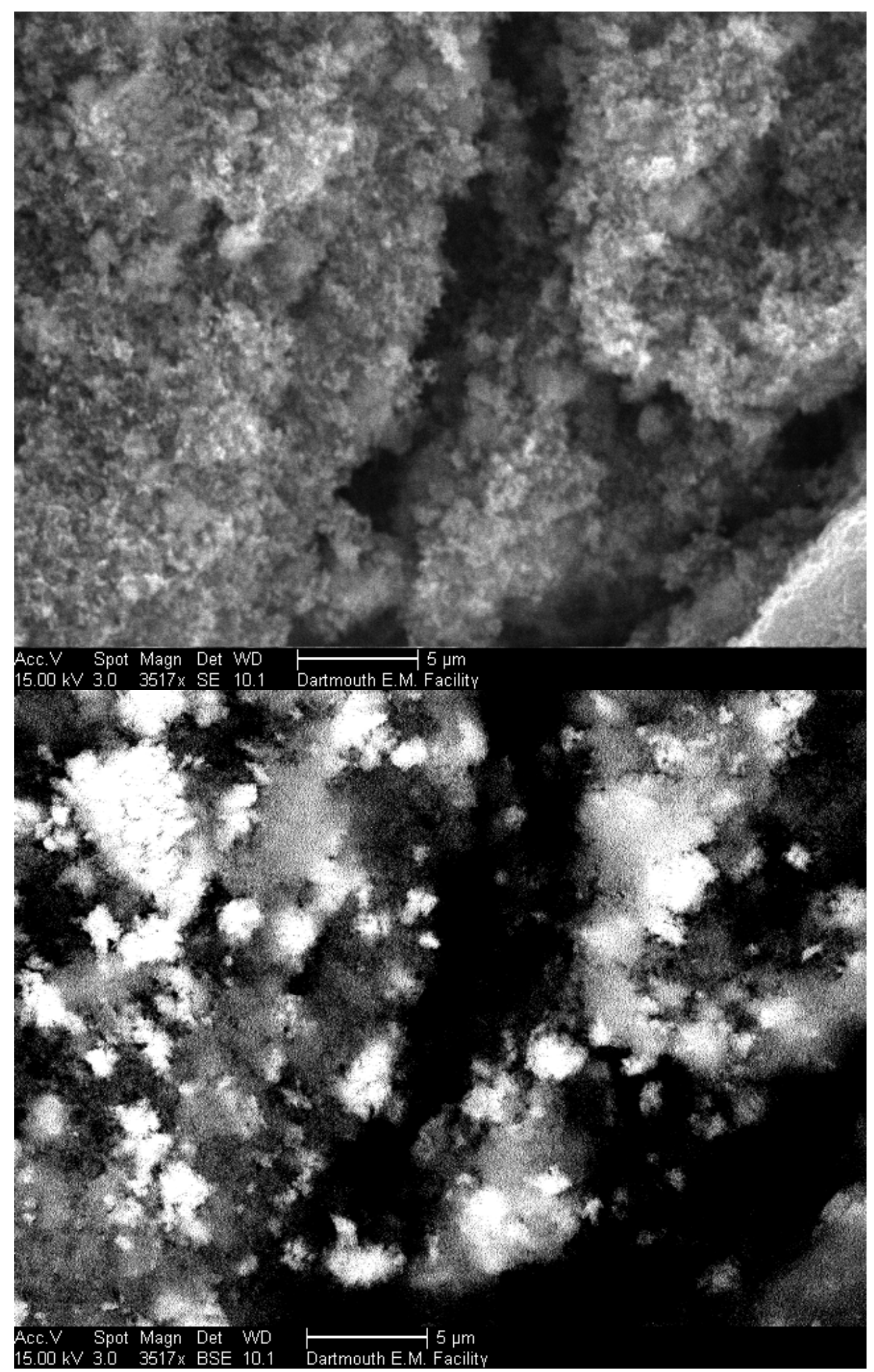

Figure 12: Secondary (left) and backscattered (right) emission image of Syn-3 particles. The white portions of the image show the calcium and the gray is carbon.

All of the samples were then wetted with de-ionized water, and those to contain arsenic had 
cacodylic acid added to the slurry so that the final char was near $1 \%$ As by weight. The samples were immersed in the solution for a period of 1 day at room temperature. While cacodylic acid is very soluble in water at $6 \mathrm{~g} / \mathrm{L}$ [29], calcium oxide transforms to calcium hydroxide in the presence of water, and is slightly soluble in water at $1.16 \mathrm{~g} / \mathrm{L}$ at $25^{\circ} \mathrm{C}[30]$. While some calcium was therefore expected to dissolve into the solution, the majority was expected to remain incorporated into the synthetic char particles. The solution was then vacuum heated for 20 hours under vacuum at $80^{\circ} \mathrm{C}$ and -8 inches of mercury (in. $\mathrm{Hg}$ ), followed by 7 hours at $90^{\circ} \mathrm{C}$ and -10 inches $\mathrm{Hg}$.

Synthetic char samples were analyzed for composition by digesting in acid, then using inductively coupled plasma mass spectrometry (ICP-MS), in solid form using energy dispersive $\mathrm{X}$-ray (EDX) analysis in the SEM, and the surface area of char samples determined qualitatively using SEM imaging and quantitatively using Brunauer-Emmett-Teller (BET) analysis.

\section{Size and constituent quantification}

Samples were digested using acid, then analyzed using ICP-MS for an ultimate analysis of the elemental concentrations within the particles. A portion of each char sample (between 3 and 5 $\mathrm{mg}$ ) was digested in 1 milliliter $(\mathrm{mL})$ of cold nitric acid overnight. Hydrogen peroxide $\left(\mathrm{H}_{2} \mathrm{O}_{2}\right)$ at a volume of $0.5 \mathrm{~mL}$ was then added to the sample and allowed to react for another night. This mixture was then heated to $110^{\circ} \mathrm{C}$ for 15 minutes in a microwave digestion unit (CEM, Matthews, NC). Once cooled, deionized water was added to the acid extract to produce a sample with total volume of $15 \mathrm{~mL}$. The extract was further diluted an additional 1000x prior to analysis by ICP-MS. After these preparations, the detection limit for elements in the solid sample were $0.0005 \%$ by weight. The results of the analysis are shown in Table VI.

Table VI

Elemental analysis of synthetic char samples

\begin{tabular}{lll} 
Sample & Calcium (\%wt) & Arsenic (\% wt) \\
\hline Syn-1 & ND & ND \\
Syn-2 & ND & 1.05 \\
Syn-3 & 3.10 & 0.003 \\
Syn-4 & 2.81 & 1.79 \\
\hline
\end{tabular}

$\mathrm{ND}=$ not detected

This analysis shows that Syn-1 char sample contained no detectable calcium or arsenic. The Syn2 char sample shows the expected arsenic content with no calcium detected. The Syn-3 char sample shows the expected calcium concentration and a detectable trace of arsenic which was not expected. It is assumed that the arsenic remained in the analyzing apparatus from the Syn-2 sample analyzed previously. Because the levels are much lower than the calcium levels in Syn-3, the detected presence of arsenic was not expected to affect the combustion experiment. The levels of $\mathrm{Ca}$ and As are as expected in Syn-4. 
The incorporation of calcium and arsenic were verified using SEM backscattered emission imaging and EDX analysis for each of these synthetic chars. The lighter regions shown in the backscattered electron micrographs in Figures 13 through 16 represent the added metallic compounds while the darker gray matrix is carbon with smaller amounts of oxygen.

An approximate indication of the synthetic char particle size distribution can be obtained from Figure 13 where the Syn-1 char particles are displayed in secondary and backscattered emission images. The particles are non-uniform in shape, and are generally between 100 and $125 \mu \mathrm{m}$ in diameter. From the lack of contrast in the backscattered images, it is clear that there are no metals on or near the surface of Syn-1 char particles.

SEM images of Syn-2 char particles are shown in Figure 14. Cacodylic acid was added as an arsenic-containing compound after the char was produced, as described previously. Because arsenic is likely to be concentrated on the char surface, all synthetic char particles were handled while wearing gloves and within a fume hood once the arsenic had been added.

Figure 15 shows the secondary and backscattered SEM images of Syn- 3 char particles, the particles containing phenol-formaldehyde resin, carbon black, and calcium oxide at $228 \mathrm{x}$ magnification. In these images as with then Syn-1 and Syn-2 char particles, the particles are generally between 100 and $125 \mu \mathrm{m}$ in diameter.

The backscattered and secondary emission images of the Syn- 4 char particles are shown in Figure 16. These particles contain the phenol-formaldehyde resin, carbon black, calcium oxide, and cacodylic acid and are imaged at 228x magnification. 

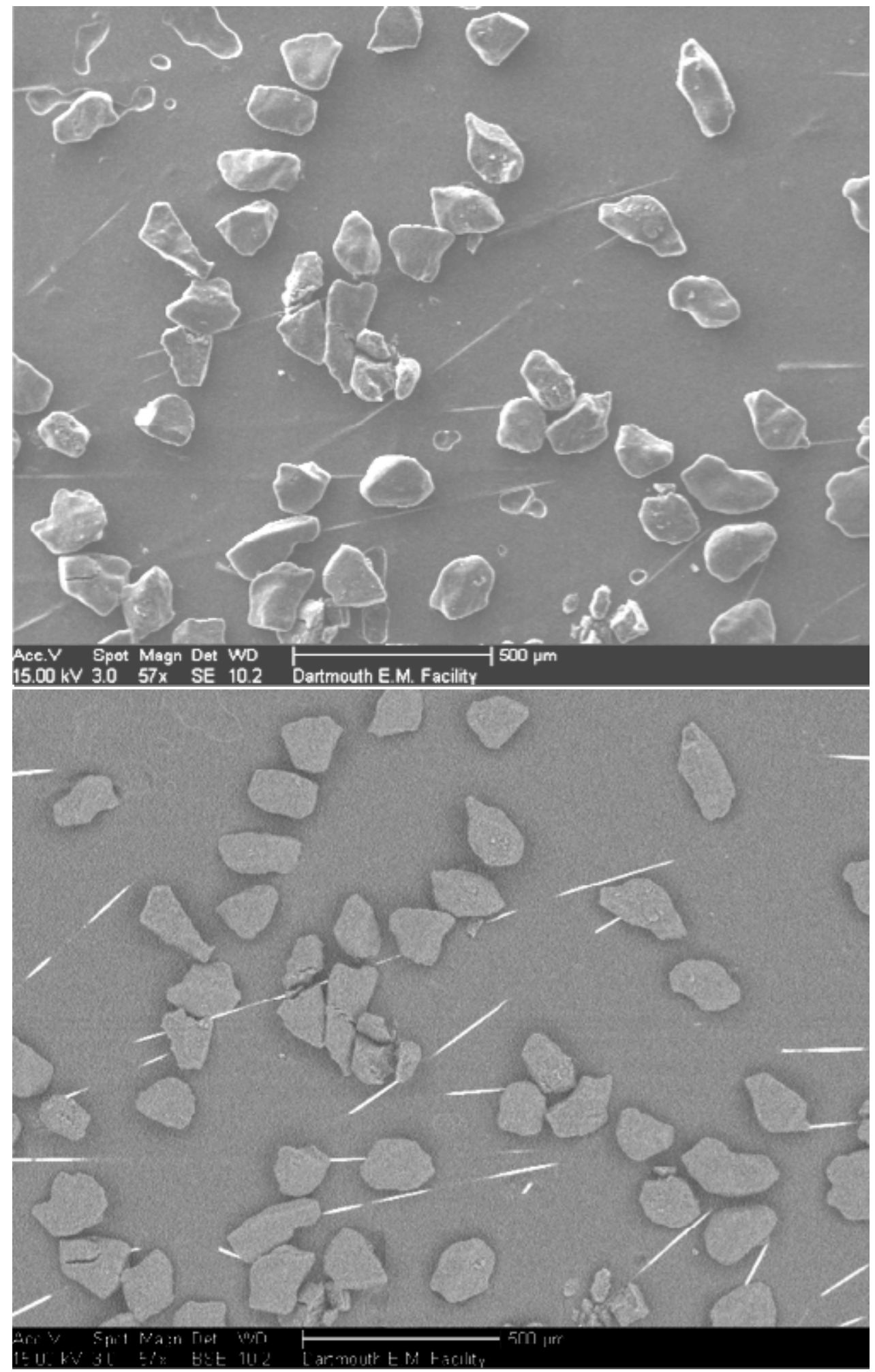

Figure 13: Secondary (top) and backscattered (bottom) SEM images of Syn-1 char particles at $57 \mathrm{x}$ magnification. The lack of contrast in the backscattered image shows no presence of metallic compounds. 


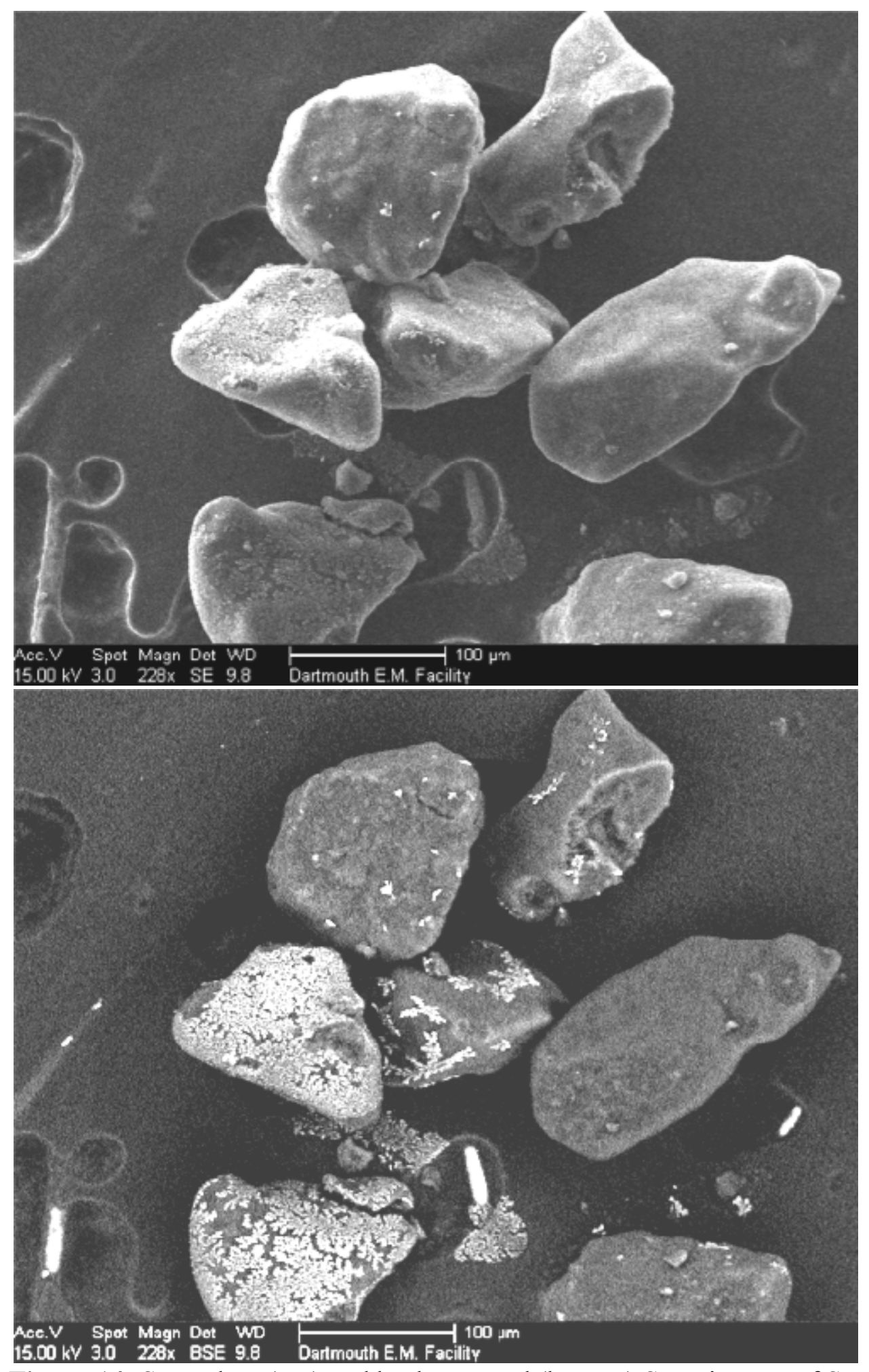

Figure 14: Secondary (top) and backscattered (bottom) SEM images of Syn-2 char particles at 228x magnification. Cacodylic acid crystals are visible as the white portion of the backscattered image with a darker background of carbon. 


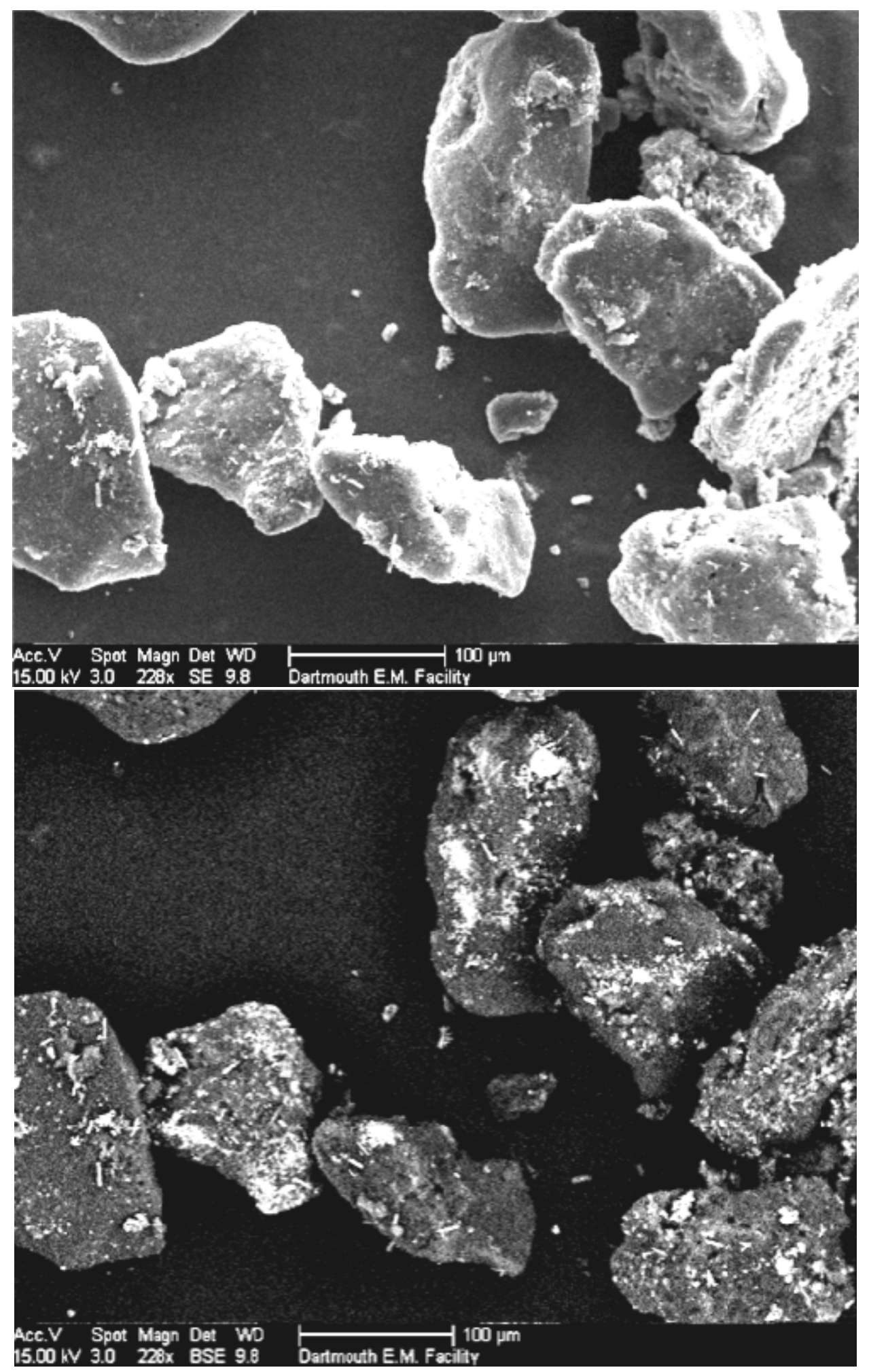

Figure 15: Secondary (top) and backscattered (bottom) SEM images of Syn-3 char particles at $228 \mathrm{x}$ magnification. Calcium is visible as the whitest part of the backscattered image with a darker gray carbon background. 


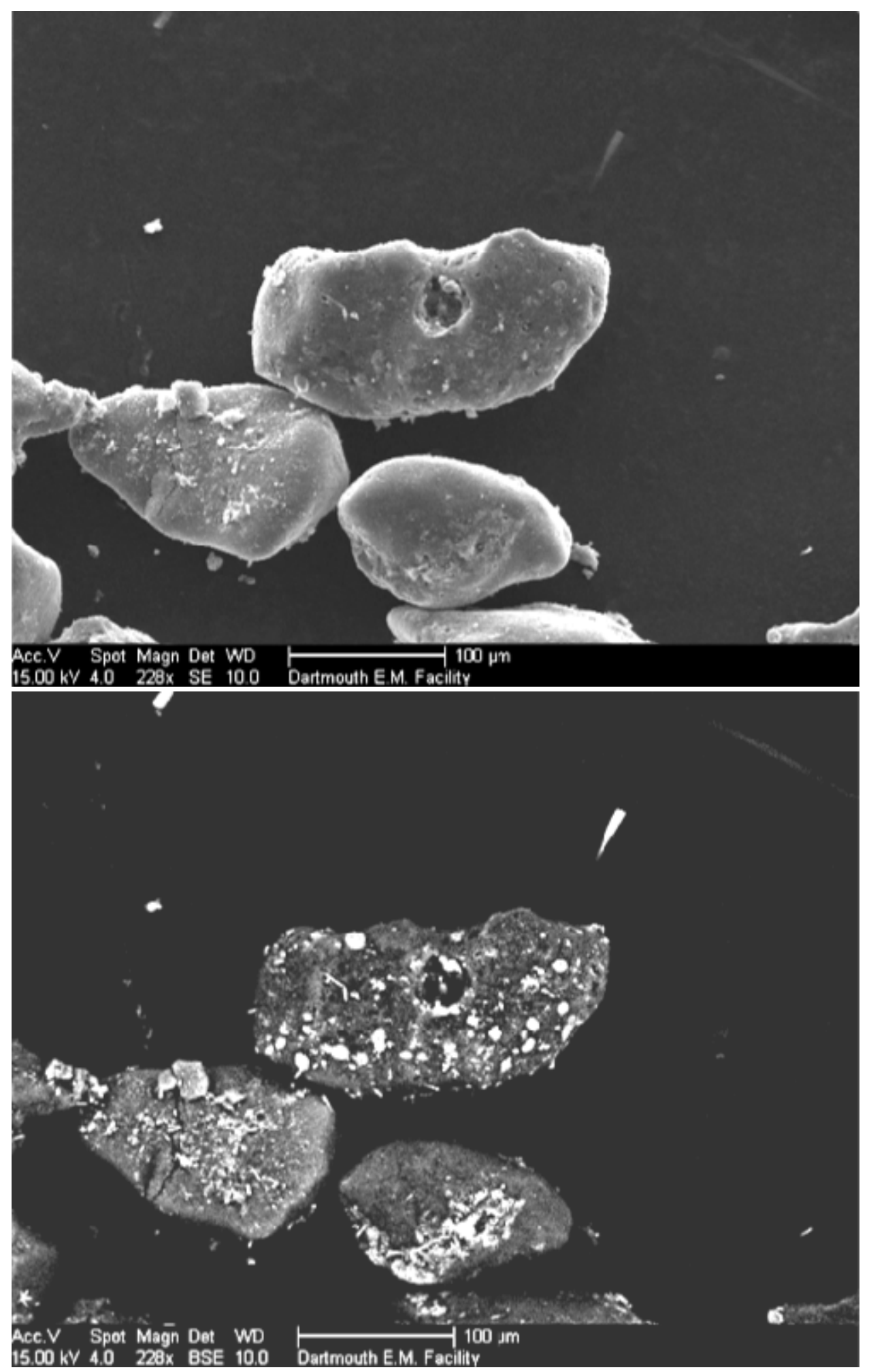

Figure 16: Secondary (top) and backscattered (bottom) SEM images of Syn-4 char particles at 228x magnification. Calcium is visible as the whitest part of the backscattered image with a darker gray carbon background. Arsenic is found associated with both the calcium and carbon rich areas. 

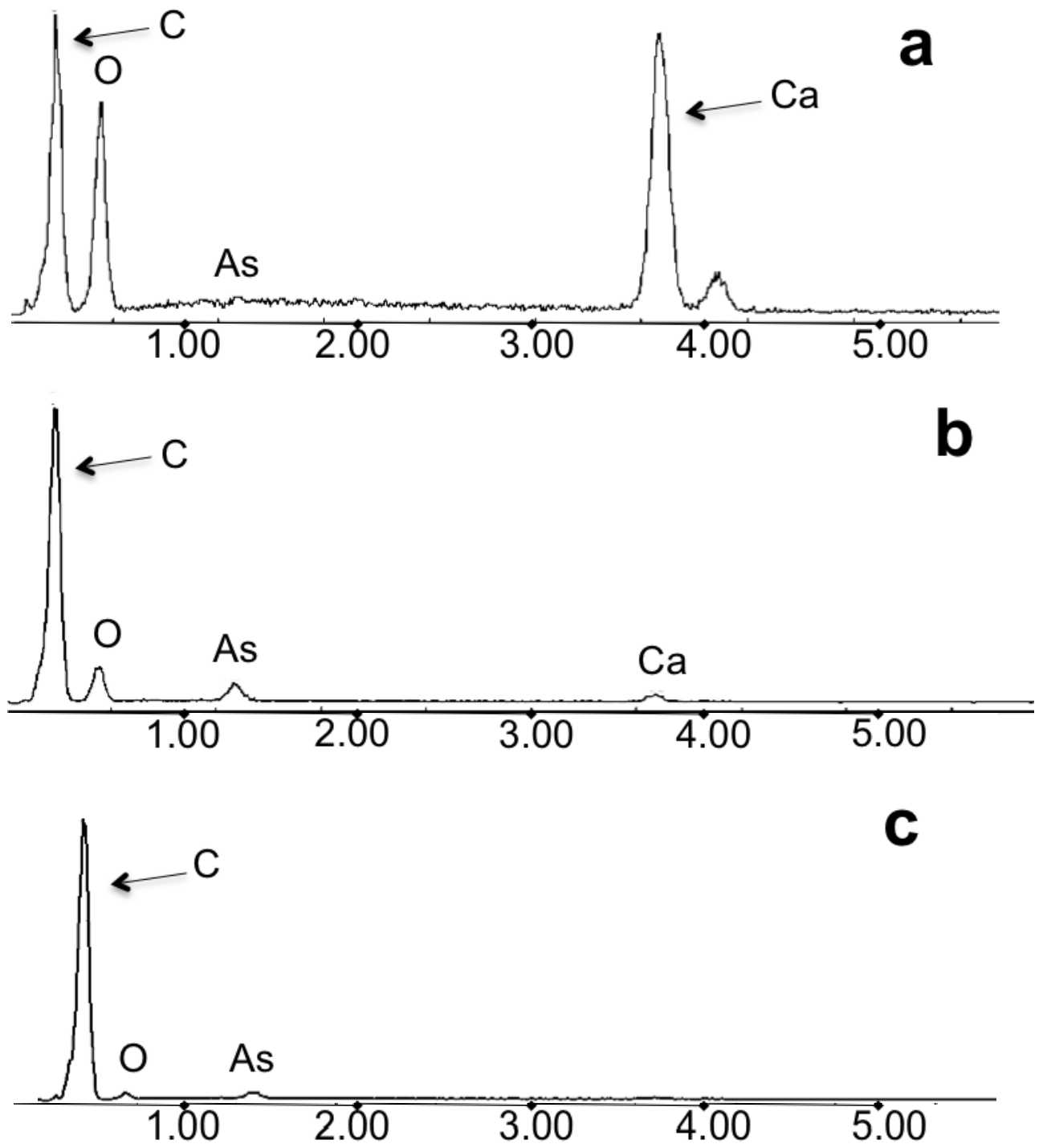

Figure 17: EDX image of a) white spot in a Syn-4 synthetic char particle containing calcium, b) a white spot in a Syn-4 synthetic char particle containing arsenic and calcium, and c) a gray mass in a Syn-4 synthetic char particle containing arsenic and no calcium.

The EDX spectra of a calcium rich surface, surface containing both arsenic and calcium, and an arsenic rich surface of Syn-4 synthetic char particles are shown in Figure 17. In the Syn-4 synthetic char particles, regions of carbon were distinguishable as the darker gray regions on the micrograph. Brighter regions were found to contain calcium with oxygen and carbon, and calcium and arsenic with oxygen and carbon.

While regions with higher arsenic than calcium concentration are found in the Syn-4 synthetic char sample as seen in Figure 17b, very rarely was arsenic found without calcium. Calcium-only surfaces were expected since calcium was added as discrete inclusions and at higher 
concentrations than was arsenic. The EDX spectrum for an arsenic-only surface is seen for a Syn-4 char particle in Figure 17c. This suggests that calcium and the cacodylate ion associated during the de-ionized water immersion and may have formed calcium cacodylate $\left(\mathrm{Ca}\left(\mathrm{AsO}_{2}\left(\mathrm{CH}_{3}\right)_{2}\right)_{2}\right)$ during the vacuum heating step. This calcium cacodylate molecule is soluble in water [31].

\section{Quantifying surface area}

The increased surface area of the synthetic char particles due to the addition of black carbon is visible in Figure 18, which shows the glass-like surface of the carbon particles from a PF resin produced without the addition of black carbon and the surface of a Syn-1 particle.
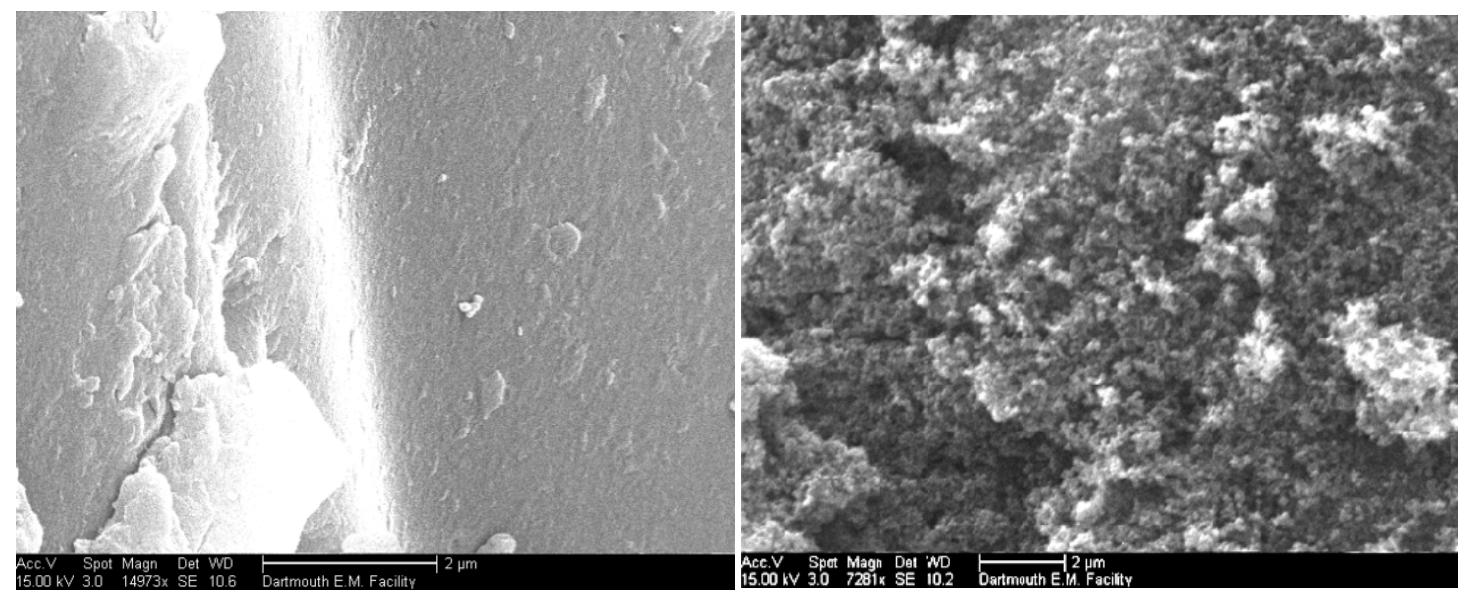

Figure 18: Secondary emission image of a phenol-formaldehyde resin particle at $14,973 \mathrm{x}$ magnification (left) and a synthetic char particle of carbon black and phenol-formaldehyde resin at 7,281x magnification (right).

The interior structure and composition of the synthetic char samples was also of interest to determine whether the porous structure was present throughout the particles, and to determine whether both the calcium and arsenic compounds were interspersed. Small amounts of each synthetic char sample were therefore embedded in epoxy (1 part Epon 828 resin: 2 parts curing agent, both procured from Miller-Stephenson). These samples were vacuum centrifuged at $45^{\circ} \mathrm{C}$ and -5 in $\mathrm{Hg}$ using a centrifuge for 10 minutes, then vacuum heated for more than 24 hours at $100 \circ \mathrm{C}$ and -10 in $\mathrm{Hg}$. Each sample was then sectioned using a microtome, coated in gold using a sputtering technique, and examined qualitatively using the SEM and quantitatively using SEMEDX analysis. The results are seen in Figures 19 and 20. 

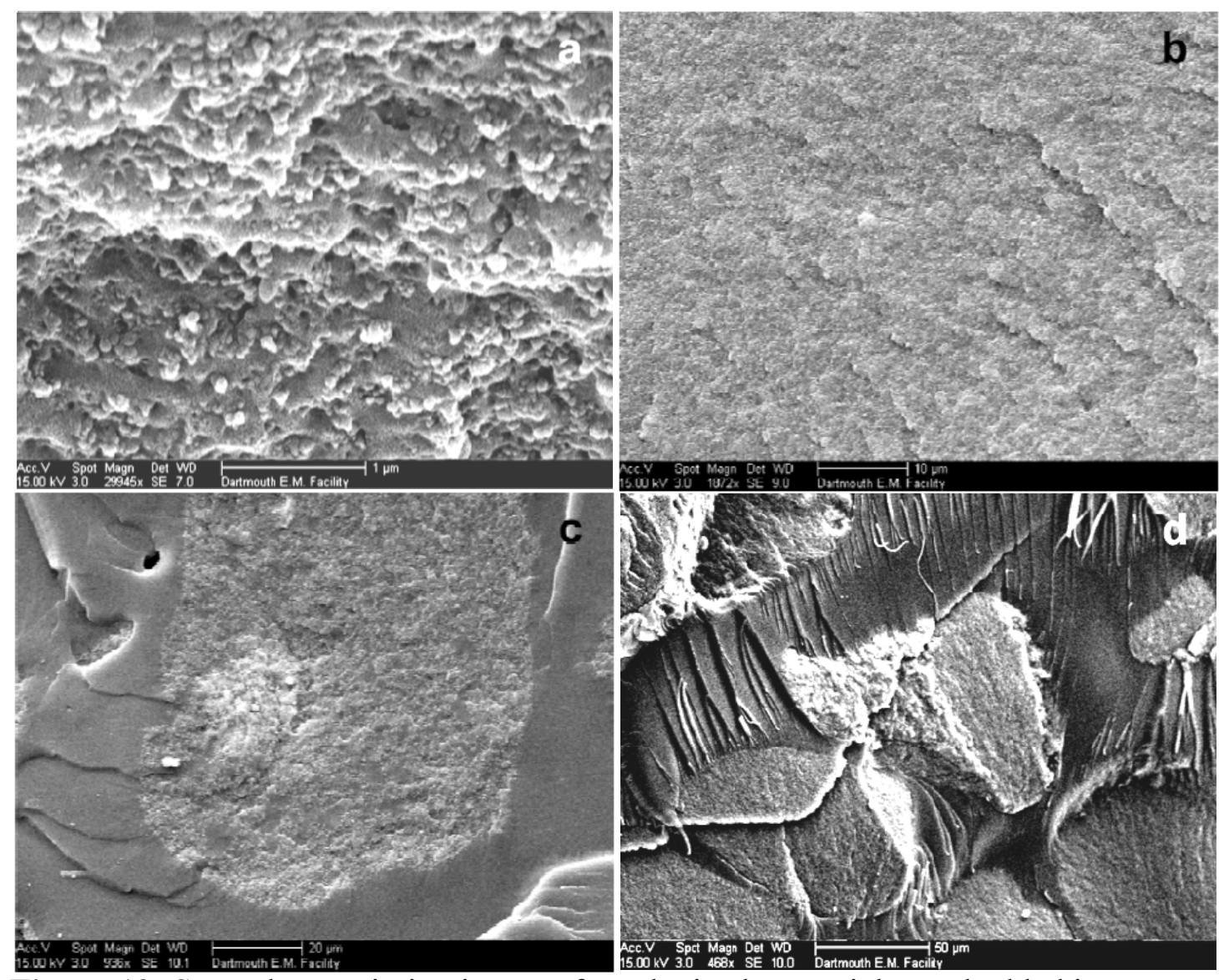

Figure 19: Secondary emission image of synthetic char particles embedded in epoxy, sectioned, and gold sputtered. Synthetic char particles shown are a) Syn-1 char at 29,945x magnification, b) Syn-2 char at 1,872x magnification, c) Syn-3 char at 936x magnification, and d) Syn-4 char at $468 \mathrm{x}$ magnification.

Figure 19 shows cross-sectioned images of the four synthetic char samples at varying magnification. The high surface area within the interior of the particles is seen in Figure 19a, where a cross-sectioned Syn-1 char particle is shown at 29,945x magnification. A crosssectioned Syn-2 char particle is shown in Figure 19b at 1,872x magnification. Any arsenic present is not clearly seen when solely using secondary emission imaging. The majority of a cross-sectioned Syn-3 char particle is seen in Figure 19c, where both the epoxy and char particle are visible along with a calcium oxide inclusion. Several cross-sectioned Syn-4 char particles are shown in Figure 19d.

EDX spectra from cross-sections of the four synthetic char samples are shown in Figure 20. The figure confirms a lack of detectable arsenic or calcium in Syn-1 char particles, presence of a small amount of arsenic in the interior of Syn-2 char particles, with arsenic primarily located on the outer surface of the Syn-2 char particles. A strong presence of calcium in the cross-section of a Syn-3 char particle is verified in the EDX spectrum shown in part $\mathrm{c}$ with no arsenic present. The presence of small quantities of arsenic and calcium are seen in the EDX spectrum of the cross-section of a Syn-4 char particle in Figure 20d. This suggests the association of calcium and 
arsenic during the immersion in water helped retain arsenic in the center of the char particles.

Further quantification of the surface area of the particles is provided by BET analysis with the results shown in Table VII. The samples were analyzed for specific surface area using a Micromeritics Gemini II 2370 Surface Area Analyzer to examine the effects of inclusions, deionized water treatment and arsenic addition on the structure of the synthetic particles. The specific surface area of the samples is presented along with the corresponding C-values and correlation constants. The calculated surface area

Table VII

Specific surface area measurements of synthetic char samples

\begin{tabular}{llcc} 
Sample & Specific surface area $(\mathbf{m} 2 / \mathbf{g})$ & C-value & Correlation constant \\
\hline Syn-1 & 41.8 & 111 & 0.99999 \\
Syn-2 & 32.5 & 96 & 0.99995 \\
Syn-3 & 41.7 & 119 & 0.99999 \\
Syn-4 & 36.7 & 79 & 0.99997 \\
\hline
\end{tabular}

for spherical non-porous PF resin char particles $106 \mu \mathrm{m}$ in diameter is $0.05 \mathrm{~m} 2 / \mathrm{g}$, while the measured surface area for the synthetic char particles range from 32 to $42 \mathrm{~m} 2 / \mathrm{g}$ showing a vast increase in surface area with the addition of carbon black. In comparison, specific surface areas have been reported between 2 and $5 \mathrm{~m} 2 / \mathrm{g}$ for coal particles $<297 \mu \mathrm{m}$ [32] and 2 and $7 \mathrm{~m} 2 / \mathrm{g}$ for particles $<100 \mu \mathrm{m}[33]$ using $\mathrm{N}_{2}$ BET analysis.

The surface area of the synthetic char particles is an order of magnitude higher than the reported coal particle values. This higher internal surface area should allow for higher carbon burn out due to increased accessibility to the oxidizing environment and increased likelihood of arsenic encountering calcium within a char particle prior to vaporization. 

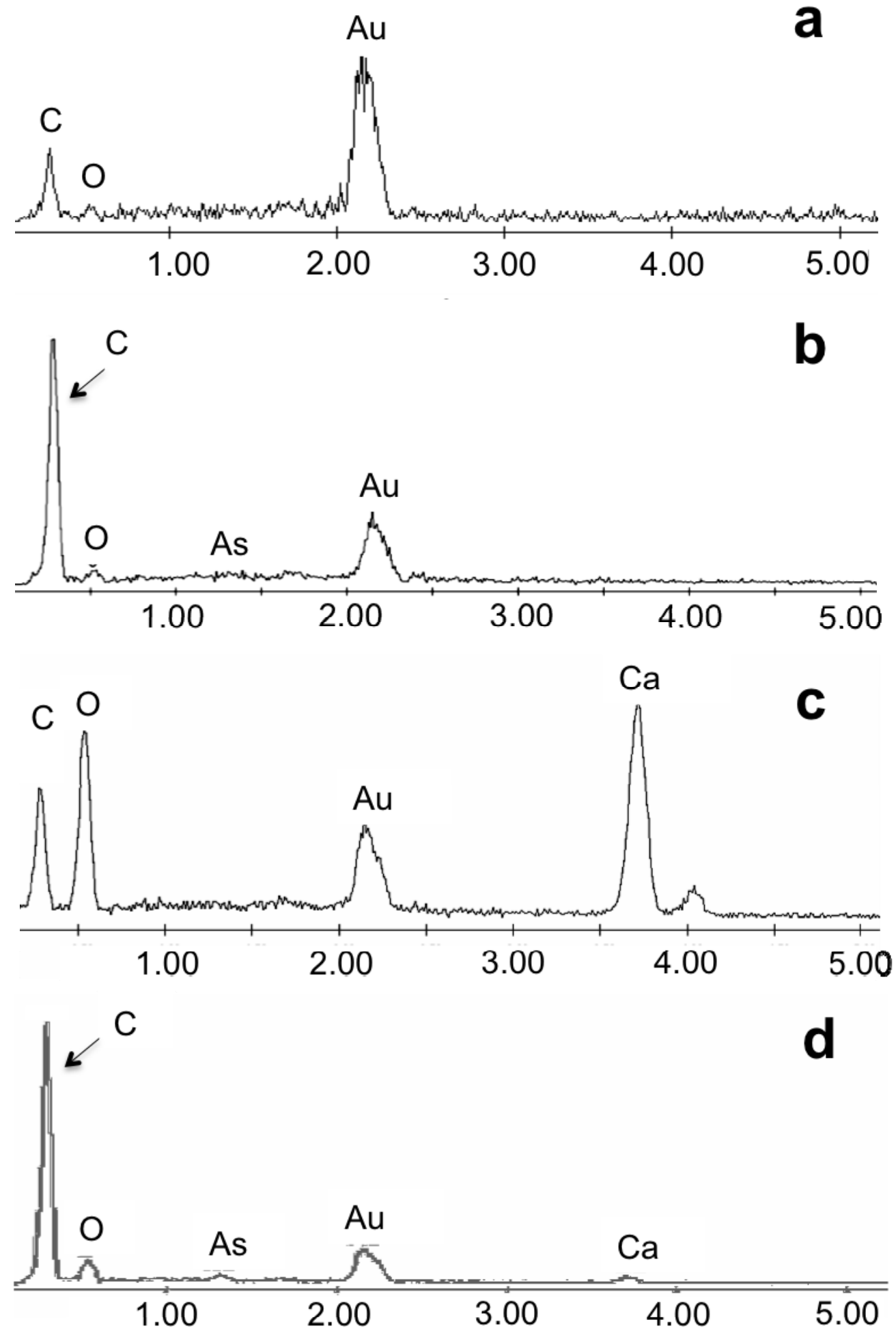

Figure 20: EDX spectra, particle embedded in epoxy, sectioned, and gold sputtered for a) Syn-1 synthetic char, b) Syn-2 synthetic char, c) Syn-3 synthetic char, and d) Syn-4 synthetic char. 


\section{Arsenic Experiments}

The combustion studies using the synthetic char samples were undertaken using $1-2 \mathrm{~g}$ per experiment in a laminar flow drop tube furnace at the University of Utah. The apparatus has been described in detail in the literature $[34,35]$ and is pictured in Figure 21. A vial of sample was placed in the port of the syringe pump, where a suction line $0.8 \mathrm{~mm}$ in inner diameter pulled sample at a flowrate of 0.02 standard liters per minute $(\mathrm{slpm})$ nitrogen carrier gas. Adjusting the speed at which the sample became available to the syringe pump allowed controlled variation of feedrate. An engraver at the first setting was attached to the feed line to ensure no aggregation of particles occurred.

The entrained sample then flowed from the feed line through a water-cooled injection probe where $0.07 \mathrm{slpm} \mathrm{N}_{2}$ auxiliary carrier gas was added to ensure laminar flow toward the reaction zone. The total carrier gas continued through a ceramic honeycomb flow straightener where it mixed with 2.3 slpm of the main combustion gases: a mixture of $\mathrm{N}_{2}$ and $\mathrm{O}_{2}$ such that the gas composition in the combustion zone was $20 \%$ or $40 \% \mathrm{O}_{2}$. At this point the flow entered the reaction zone which was externally heated to $1400 \circ \mathrm{C}$ for all experiments. Post-combustion, the gases and particulates entered a water-cooled sample probe where $13.0 \mathrm{slpm}$ of $\mathrm{He}$ or $\mathrm{N}_{2}$ quench gas decreased the temperature to a range of 87 to $127 \circ \mathrm{C}$.
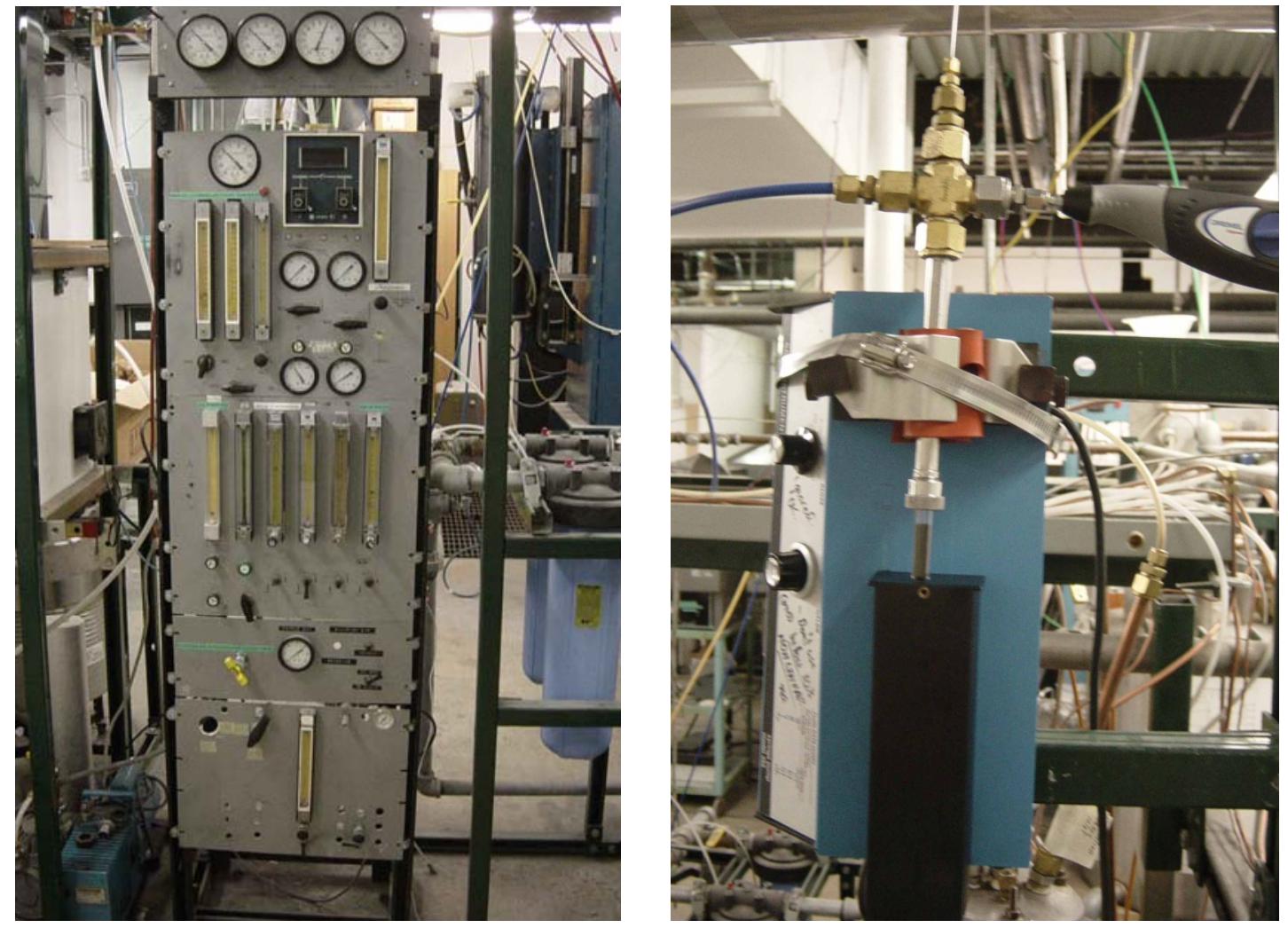

Figure 21: The gas flow panel (left) and sample vial (right) portions of the laminar flow drop tube furnace utilized for combustion experiments at the University of Utah. 
Particles were collected for X-ray absorption fine-structure (XAFS) spectroscopy and particleinduced X-ray emission (PIXE) spectrometry analysis using a Micro-Orifice Uniform Deposit Impactor (MOUDI)-type impactor and Isopore size $0.4 \mu \mathrm{m}$ polycarbonate filter. Total fly ash from the samples was collected using solely the Isopore filter using the filter holding stage of the MOUDI impactor, while sub-micron fly ash was collected by preceding the filter stage with the first four stages of the MOUDI impactor where the calculated 50\% aerodynamic cutoff diameter (d50) for the fourth stage was $1.8 \mu \mathrm{m}$. These four stages removing the larger particles from the collected fly ash were greased to prevent particle bounce and ensure particle size separation by taking an aluminum foil substrate, coating with Pyroil silicone spray, and baking above $60 \circ \mathrm{C}$ for more than 90 minutes to remove volatile compounds.

Additional experimental detail, including the gas flowrates and sample weights used are as noted in the appendix to Smith.

The order of coal and synthetic char experiments completed is shown in Table VII. This sequence was chosen to minimize the effects of contamination fly ash between experiments while retaining an amount of randomization. Samples were weighed prior to commencing combustion and after the experiments were completed to conduct mass balances of selected experiments.

Table VII

Experimental order for synthetic char and coal combustion experiments in the drop tube furnace

\begin{tabular}{lll} 
Sample & $\mathbf{2 0 \%} \mathbf{O}_{2}$ & $\mathbf{4 0 \%} \mathbf{O}_{2}$ \\
\hline Kentucky & 6 & 10 \\
Wyodak & 1 & 7 \\
North Dakota & 2 & - \\
Syn-1 & 4 & - \\
Syn-2/3 & 5 & 8 \\
Syn-4 & 3 & 9
\end{tabular}

\section{Results and discussion}

\section{Particle surface area}

Fly ash particles collected on TEM grids from stages 1, 5, 7, and 9 of a low-pressure (Bernertype) cascade impactor were imaged in a SEM or TEM using an Advanced Microscopy Techniques charge-coupled device (CCD) digital camera system. The two dimensional grayscale projected images were then used to create a binary image for each particle to be processed and analyzed using ImageJ. Over 100 fly ash particles were analyzed for each stage of particles collected. An image of a fly ash particle from combustion of Kentucky coal at $20 \%$ oxygen collected from stage 5 on the Berner-type impactor and its binary image are shown in Figure 22. 
Using the measurements capabilities in ImageJ, the perimeter and area of each particle is calculated. From these values, a fractal dimension (Df) signifying shape complexity is calculated for each particle using the perimeter-area method shown below. Using this method, a circle has a theoretical fractal dimension value of 1.00 . For the particle shown in Figure 22, the number of pixels calculated for the perimeter is 459 and the number of pixels for the area is 5,254 . The fractal dimension for this particle is calculated as 1.16.
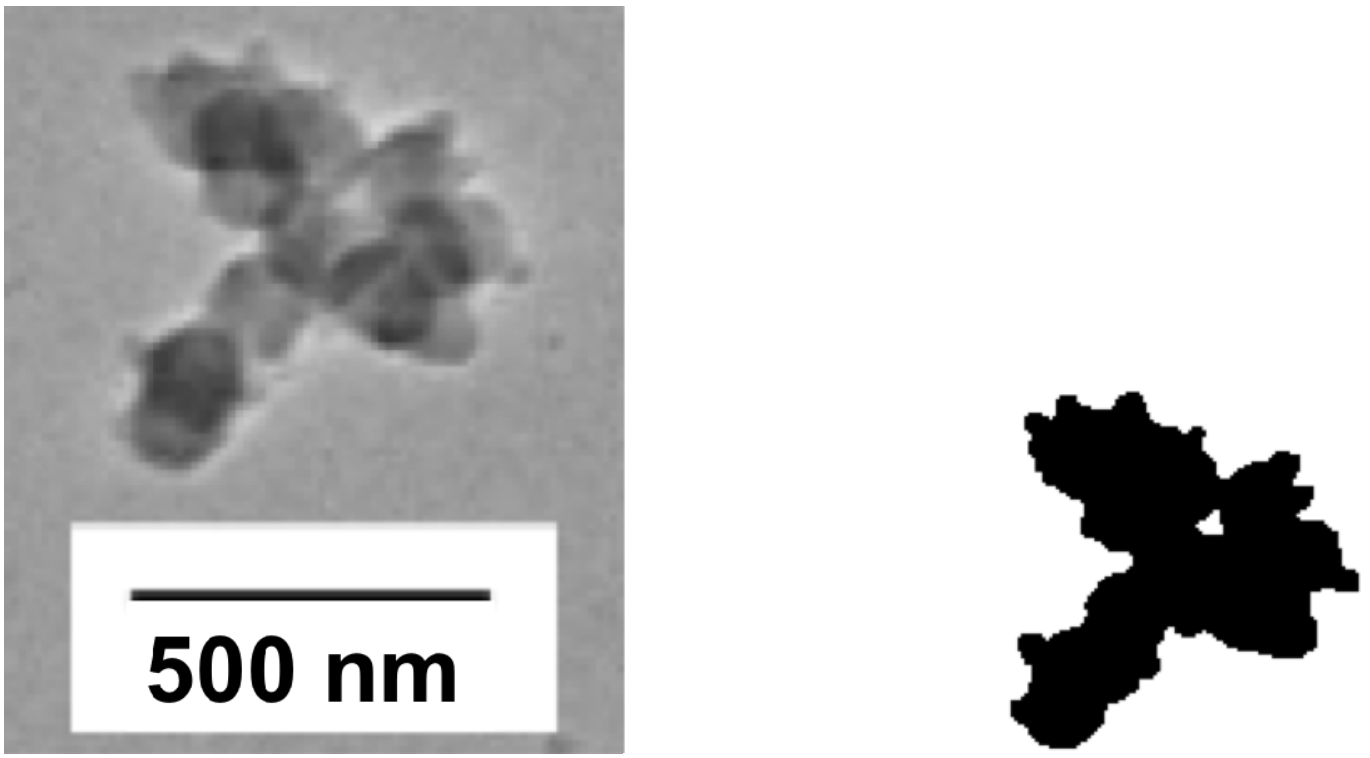

Figure 22: TEM image (left) of a fly ash particle collected from the combustion of Kentucky coal at $20 \%$ oxygen on Stage 5 of a Berner-type impactor and the resulting binary image (right) created in ImageJ.

$D_{f}=A \frac{2 \log \frac{P}{2 \pi}}{\log \frac{A}{\pi}}$

where $\quad \mathrm{P} / 2 \pi=$ the perimeter of the fly ash particle scaled to its radius, and $\mathrm{A} / \pi=$ the area of the fly ash particle scaled to its radius ${ }^{2}$.

Graphs of the number of fly ash particles of a fractal dimension produced from Kentucky coal, North Dakota coal, and Wyodak coal are shown in Figure 23 through 25. As seen in Figure 23, the frequency of fractal dimension varies for the Kentucky fly ash particles collected on stage 1 $\left(\mathrm{d}_{50}\right.$ of $\left.0.025 \mu \mathrm{m}\right)$ or stage $9\left(\mathrm{~d}_{50}\right.$ of $\left.2.5 \mu \mathrm{m}\right)$. The Df number distribution for fly ash collected on stage 1 from the combustion of bituminous Kentucky coal has a peak at a fractal dimension of 1.04 , near that of a perfect circle. Particles collected on stage 9 are more fractal (i.e. more nonspherical) in nature with the peak at a fractal dimension of 1.20. Stages 5 and 7 are more similar to stage 1 in that the peaks are at a fractal dimension of 1.02 and 1.03 , respectively. 
The peak in the fractal dimension number distribution for fly ash particles from the combustion of North Dakota lignite coal collected on stage 1 is at a fractal dimension of 1.02, near that of a perfect circle. Fly ash particles collected on stage 7 are slightly more fractal in nature with a maximum number of particles collected with a peak in the fractal dimension number distribution of 1.03. Stages 5 and 9 are more similar to stage 1 in that the peaks in the fractal dimension number distribution are at fractal dimensions of 1.02 and 1.01, respectively.

The peak in the fractal dimension number distribution for fly ash particles from the combustion of Wyodak sub-bituminous coal collected on stage 1 is at a fractal dimension of 1.0, that of a perfect circle. Particles collected on stages 5 and 7 are more fractal in nature with peaks in the fractal dimension number distribution of 1.06 and 1.07, respectively. Particles collected on stage 9 are more similar to stage 1 in that the peak in the fractal dimension number distribution is at a fractal dimension of 1.01 .

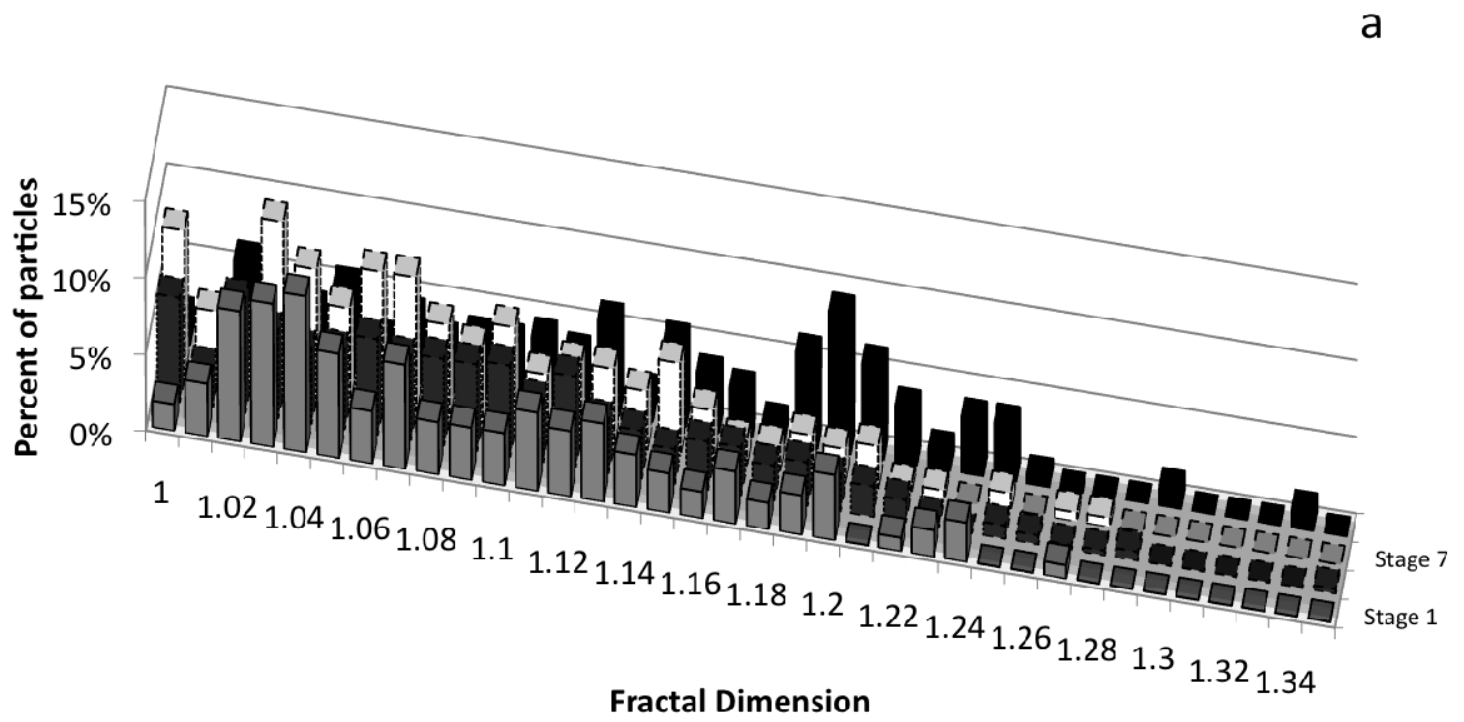

Figure 23: Fractal dimension distribution for fly ash particles combusted at $20 \backslash \%$ oxygen and collected on Stages 1, 5, 7 and 9 of a Berner-type cascade impactor for Kentucky coal. 
b

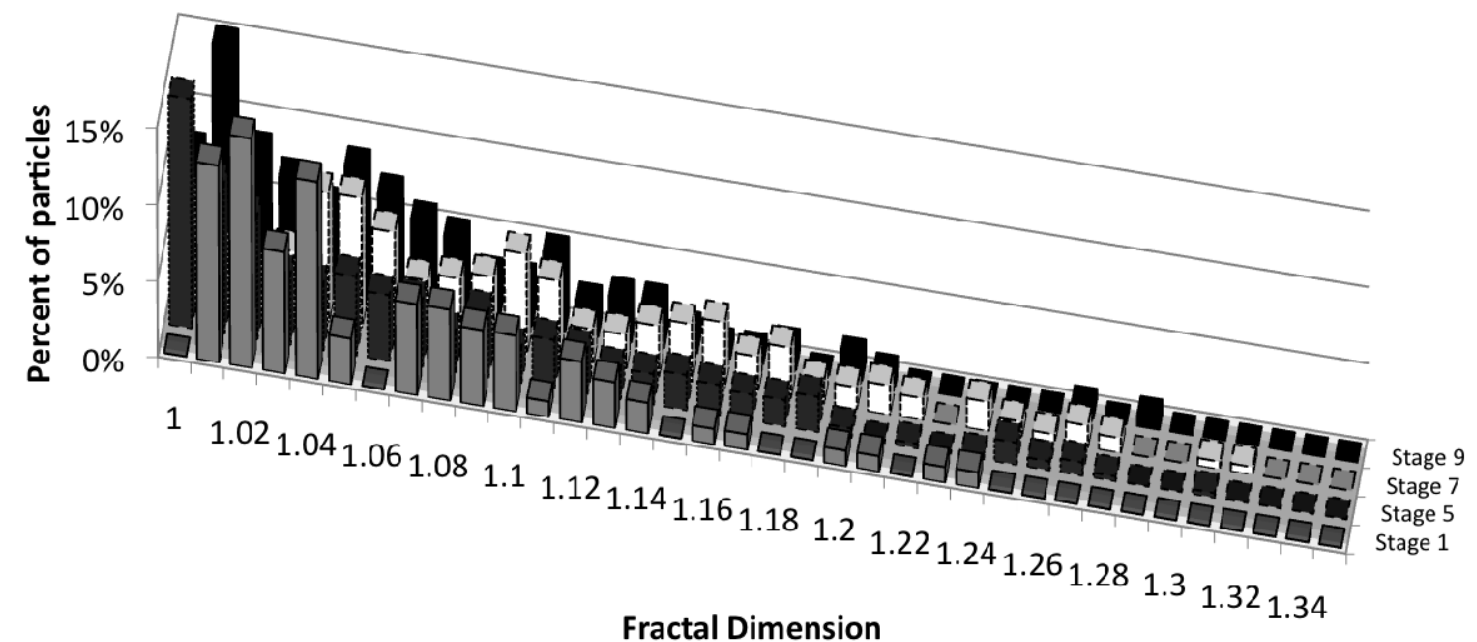

Figure 24: Fractal dimension distribution for fly ash particles combusted at $20 \nmid \%$ oxygen and collected on Stages 1, 5, 7 and 9 of a Berner-type cascade impactor for North Dakota coal.

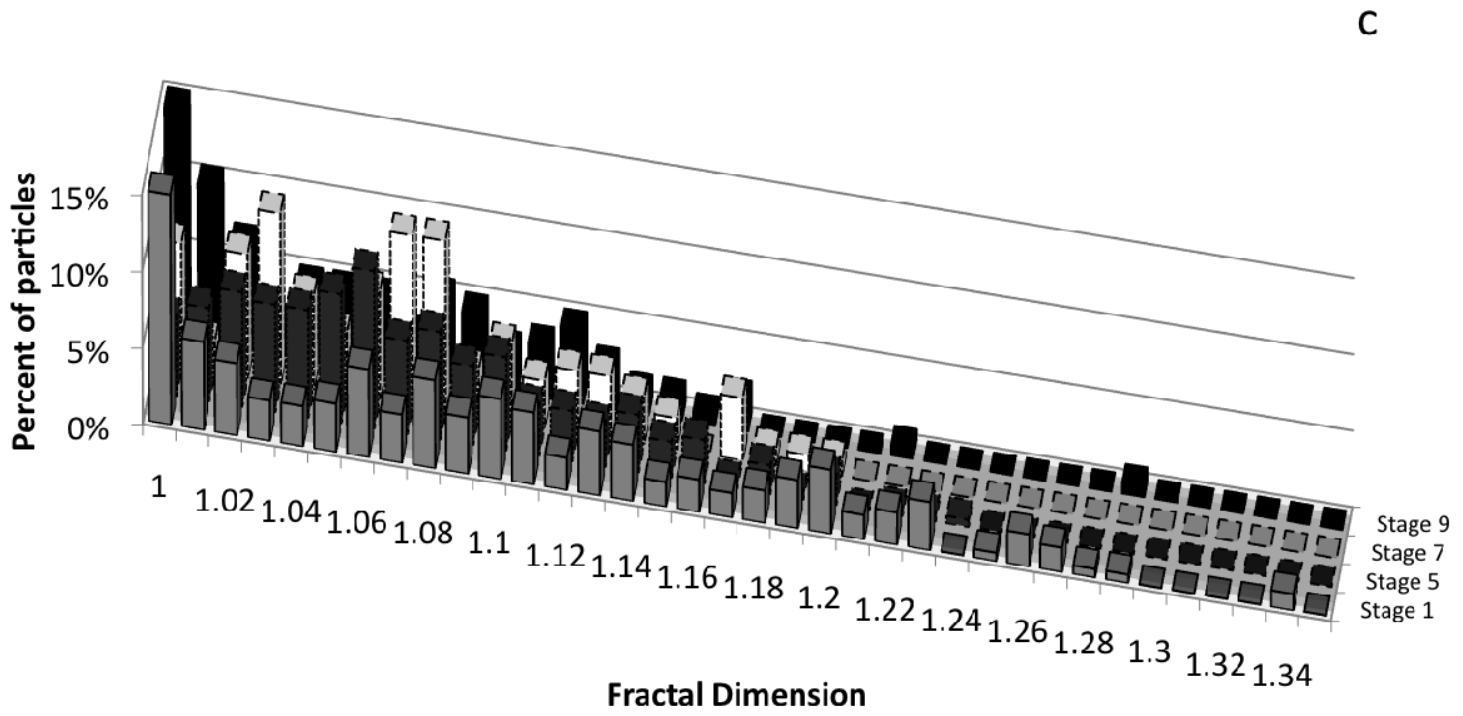

Figure 25: Fractal dimension distribution for fly ash particles combusted at $20 \nmid \%$ oxygen and collected on Stages 1, 5, 7 and 9 of a Berner-type cascade impactor for Wyodak coal.

Post-combustion interactions of arsenic and calcium

The association of calcium and arsenic in fly ash samples is determined by analyzing fly ash 
collected from synthetic char experiments. To determine the likelihood of arsenic reacting with calcium in a char particle prior to vaporization, the sub-micron and total fly ash collected using the MOUDI-type impactor from the synthetic char combustion experiments is analyzed using both XAFS spectroscopy via a subcontract to the University of Kentucky on this project, and PIXE spectrometry analysis. Samples of fly ash collected from the synthetic char experiments using the Berner-type impactor were analyzed using EDX analysis in a scanning electron microscope or a transmission electron microscope.

\section{PIXE analysis}

The results of arsenic and calcium concentrations measurements using PIXE analysis are reported in Table VIII. Arsenic was consistently collected at higher rates than calcium. This was expected in the synthetic chars because arsenic likely vaporizes and collects in the smaller fractions in the cascade impactor. Calcium, however, was incorporated into the synthetic chars as calcium oxide particles ranging from $0.2-2 \mu \mathrm{m}$ in diameter.

Table VIII

Arsenic mass balance for experiments, weights measured in $\mathrm{mg}$

\begin{tabular}{llllllll} 
Sample & Fly ash & \multicolumn{3}{c}{ Arsenic } & \multicolumn{3}{c}{ Calcium } \\
& Fraction & Input & Collected (\%) & Input & Collected & $(\%)$ \\
\hline As and Ca & $<1 \mu \mathrm{m}$ & 1.88 & 0.69 & 36 & 5.53 & 0.053 & 0.95 \\
Separate (Syn-2/3) $)$ & Total & 1.31 & 1.07 & 81 & 3.87 & 0.86 & 22 \\
\hline As and Ca & $<1 \mu \mathrm{m}$ & 9.52 & 1.23 & 13 & 14.94 & 0.082 & 0.55 \\
Together (Syn-4) & Total & 4.36 & 1.62 & 37 & 6.85 & 0.98 & 14 \\
\hline Kentucky & $<1 \mu \mathrm{m}$ & 0.0033 & 0.0011 & 34 & 15.05 & 0.0045 & 0.03 \\
coal & Total & 0.0011 & 0.0004 & 36 & 5.11 & 0.0004 & 0.008 \\
\hline North Dakota & $<1 \mu \mathrm{m}$ & 0.0067 & 0.0039 & 58 & 249.83 & 0.79 & 0.31 \\
coal & Total & 0.0018 & 0.0031 & 165 & 69.23 & 2.01 & 2.9 \\
\hline
\end{tabular}

Because the collection ratio of arsenic to calcium for the North Dakota samples was 185 for the sub-micron fly ash and 57 for the total fly ash, much less than those found for the Kentucky samples, it was concluded that the large amounts of arsenic collected with the Kentucky fly ash samples could be attributed to the arsenic left in the system by the synthetic char experiments. This was possible as the fly ash collection probe did not collect all the ash from the combusted samples. If contamination occurred, the earlier experiments would affect later experiments.

\section{XAFS analysis}

XAFS analysis provides oxidation state information for a given element. The weight percent of arsenic measured in the sample with an oxidation state of +5 , assumed to have formed calcium arsenate, is seen in Table IX. When comparing between the Syn-2/3 fly ash sample to the Syn-4 
fly ash sample combusted at $20 \% \mathrm{O}_{2}$, the amount of calcium arsenate in the Syn-4 fly ash is less than that found in the Syn-2/3 fly ash for both the collected sub-micron fly ash and the total fly ash. This result is unexpected because one would surmise that arsenic would more likely react within the char particle in the total fly ash sample, if not also the sub-micron sample. It is speculated that this value is affected by the experimental system. As the Syn-4 synthetic char experiment occurred previous to the Syn-2/3 synthetic char experiments, it is possible that calcium arsenate from the Syn- 4 char combustion experiments remained in the system and was collected with the fly ash from the Syn-2/3 combustion experiments.

\section{Table IX}

Percent arsenic as calcium arsenate in synthetic char and Kentucky coal-derived fly ash measured using XAFS spectroscopy with the remaining fraction as arsenic trioxide

\begin{tabular}{llll} 
Sample & Fly ash fraction & $\mathbf{2 0 \%} \mathbf{O}_{2}$ & $\mathbf{4 0 \%} \mathbf{O}_{2}$ \\
\hline As and Ca & $<1 \mu \mathrm{m}$ & $29 \%$ & $47 \%$ \\
Separate (Syn-2/3) & Total & $55 \%$ & $57 \%$ \\
As and Ca & $<1 \mu \mathrm{m}$ & $14 \%$ & $33 \%$ \\
Together (Syn-4) & Total & $36 \%$ & $67 \%$ \\
Kentucky & $<1 \mu \mathrm{m}$ & $103 \%$ & - \\
Coal & Total & $44 \%$ & - \\
\hline
\end{tabular}

When comparing the samples combusted in a $40 \% \mathrm{O}_{2}$ environment and therefore a higher particle combustion temperature, the total fly ash sample from Syn- 4 synthetic char combustion experiments has a larger percentage of arsenic as calcium arsenate than that collected from Syn$2 / 3$ synthetic char combustion experiments. If the $57 \%$ of arsenic as calcium arsenate found in the total fly ash from the Syn-2/3 synthetic char combustion experiments is produced from vaporized arsenic reacting with solid calcium, then any additional arsenic as calcium arsenate in the total fly ash from Syn-4 synthetic char combustion experiments (10\%) can be attributed to calcium and arsenic interactions occurring within the char particle.

When comparing fly ash collected from the Syn- $2 / 3$ synthetic char combustion experiments combusted in a $20 \% \mathrm{O}_{2}$ environment to the synthetic char combustion experiments combusted in a $40 \% \mathrm{O}_{2}$ environment, the percent of arsenic as calcium arsenate was observed to increase for both the sub-micron fraction and the total fly ash.

To compare arsenic and calcium interaction in the synthetic chars with chars used in industrial coal combustion, the sub-micron and total fly ash fractions from combustion of 106-125 $\mu \mathrm{m}$ diameter Elkhorn Kentucky coal combusted at $20 \% \mathrm{O}_{2}$ were examined using XAFS for percent arsenic as calcium arsenate. All of the arsenic collected in the sub-micron fly ash sample was found as calcium arsenate. 


\section{SEM/TEM EDX analysis}

To better understand the interactions on an individual particle basis, the fly ash samples collected on TEM grids were examined using EDX analysis in an SEM or TEM, which can then be compared to the bulk analysis produced using XAFS and PIXE. EDX emission spectra were collected from particles which show the presence of arsenic and/or calcium. Particles with an emission spectrum showing arsenic peaks without calcium peaks or large arsenic peaks with small calcium peaks are counted as arsenic only (As) particles. Particles with calcium peaks but no measurable arsenic content are considered calcium only particles $(\mathrm{Ca})$, while particles with significant amounts of arsenic and calcium are counted as arsenic and calcium particles.

An example of a sub-micron fly ash particle with only calcium present is seen in Figure 26 collected from a Syn-4 synthetic char combustion experiment on stage 5 of the Berner-type low pressure cascade impactor. The presence of black represents locations where arsenic or calcium are detected by the EDX detector. While some arsenic is detected by the instrument, the spatial variation suggests this detection is background noise.

Figure 27 shows a sub-micron fly ash particle with only arsenic present collected from a Syn-4 synthetic char combustion experiment on stage 9 of the Berner-type cascade impactor. The presence of black represents locations where arsenic or calcium are detected by the EDX detector in parts b and c. While some calcium is detected by the instrument, the spatial variation suggests this detection is background noise.

An example of a sub-micron fly ash particle with only arsenic present is seen in Figure 28 collected from a Syn-4 synthetic char combustion experiment on stage 5 of the Berner-type cascade impactor. The presence of black represents locations where arsenic or calcium are detected by the EDX detector. Both arsenic and calcium are detected by the instrument.

Figure 29 shows an example of a super-micron fly ash particle with only arsenic present collected from a Syn-4 synthetic char combustion experiment on stage 9 of the Berner-type cascade impactor. The presence of black represents locations where arsenic or calcium are detected by the EDX detector in Figures $27 \mathrm{~b}$ and $\mathrm{c}$. While some arsenic is detected by the instrument, the spatial variation suggests this detection is background noise.

An example of a super-micron fly ash particle with only calcium present is seen in Figure 30 collected from a Syn-2/3 synthetic char combustion experiment on stage 7 of the Berner-type cascade impactor. Both arsenic and calcium are detected by the instrument in this fly ash particle. 
Acc. $V$ Spot Magn Det WD $2 \mu \mathrm{m}$

$15.00 \mathrm{kV} 5.0 \quad 13421 \times$ SE 10.0 Dartmouth E. M. Facility

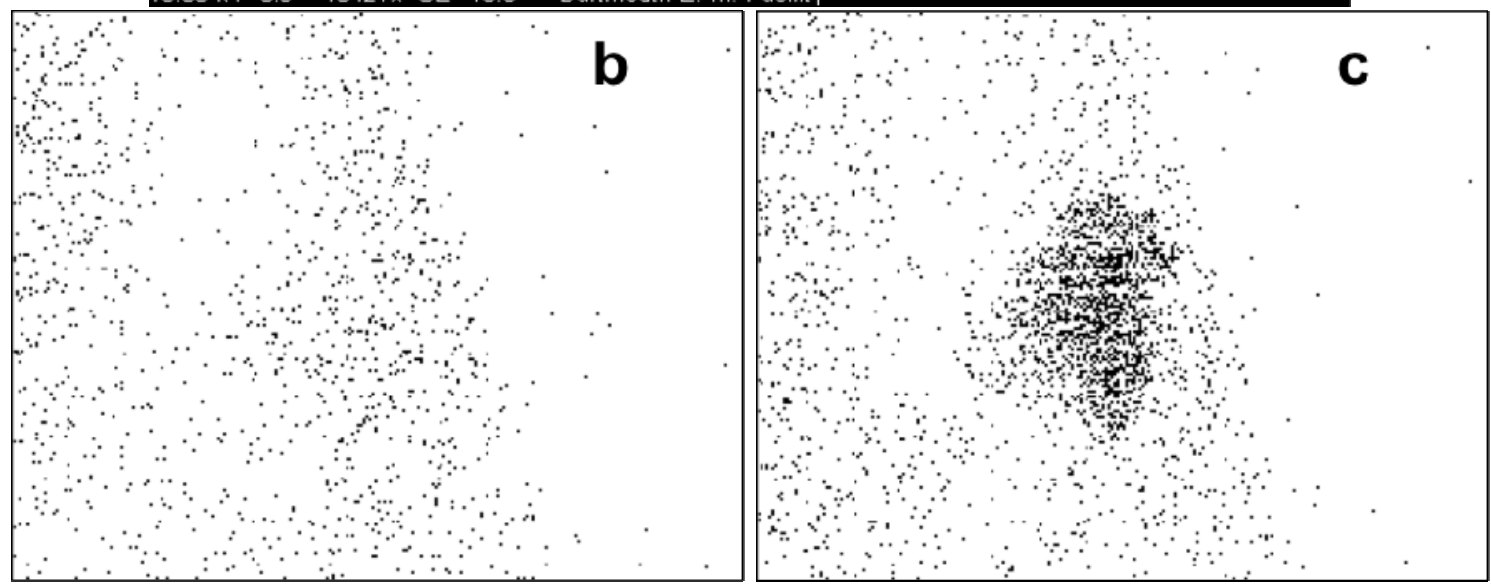

Figure 26: Image of a sub-micron fly ash particle with only calcium collected from the combustion of Syn- 4 synthetic chars at $20 \%$ oxygen on Stage 5 of the Berner-type impactor a) using the SEM at 13,421x magnification and the EDX elemental maps for b) arsenic and c) calcium. 


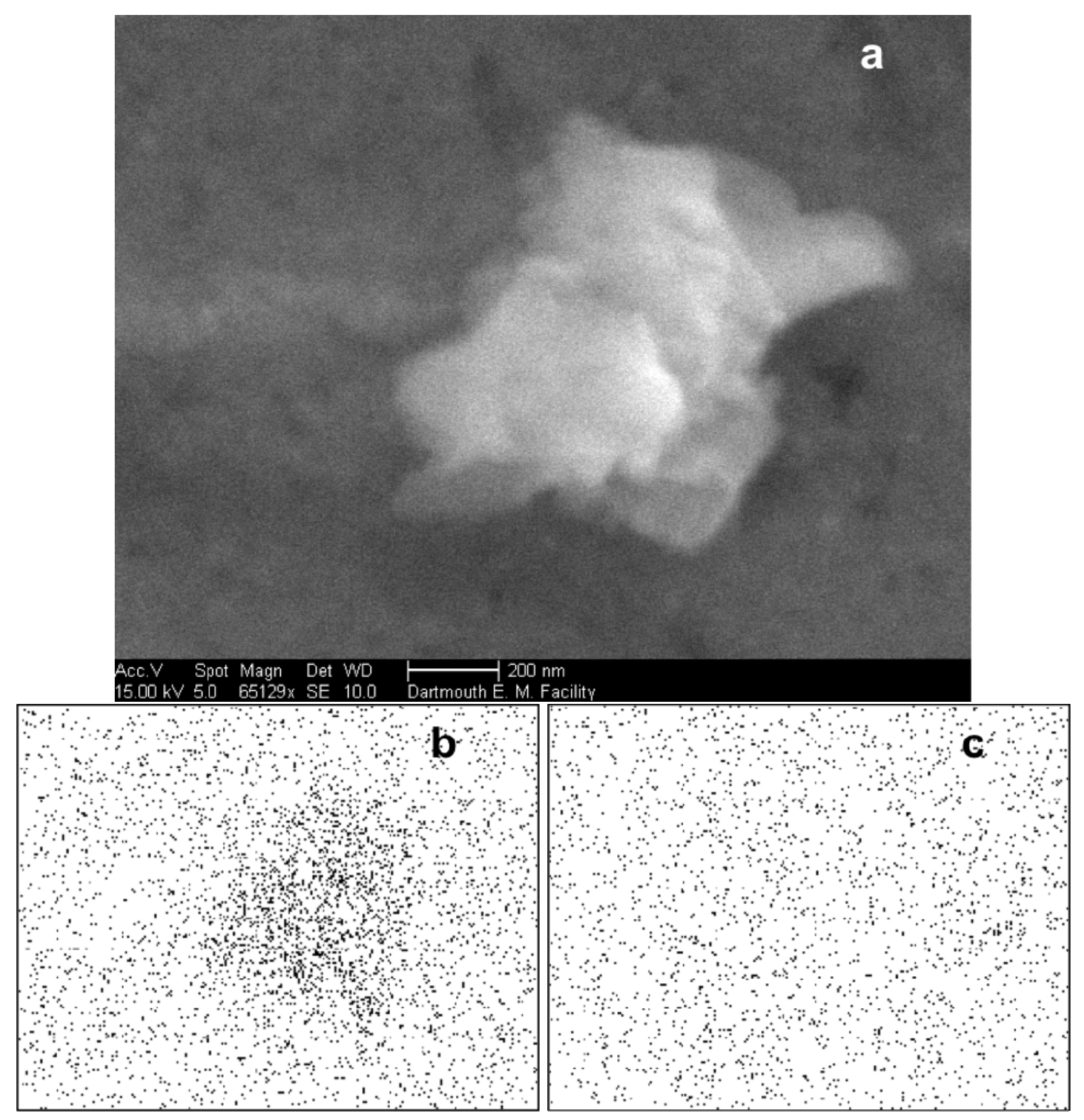

Figure 27: Image of a sub-micron fly ash particle with only arsenic collected from the combustion of Syn-4 synthetic chars at $20 \%$ oxygen on stage 9 of the Berner-type impactor a) using the SEM at 65,129x magnification and the EDX elemental maps for b) arsenic and c) calcium.

As seen in Table $\mathrm{X}$, several significant trends are visible in the particles collected from the synthetic char combustion experiments. No arsenic-only particles are found in the super-micron fly ash fraction. The synthetic char samples are composed of the elements nitrogen, oxygen, carbon, calcium, and arsenic. The only solids expected post-combustion are compounds containing arsenic and calcium. While complete burnout is the goal, a number of soot particles are found during inspection. Super-micron arsenic-only particles can be found if arsenic condensed onto soot particles not containing calcium. Instead, the super-micron fly ash fraction 
is relatively evenly divided between particles with calcium alone and particles with both arsenic and calcium.

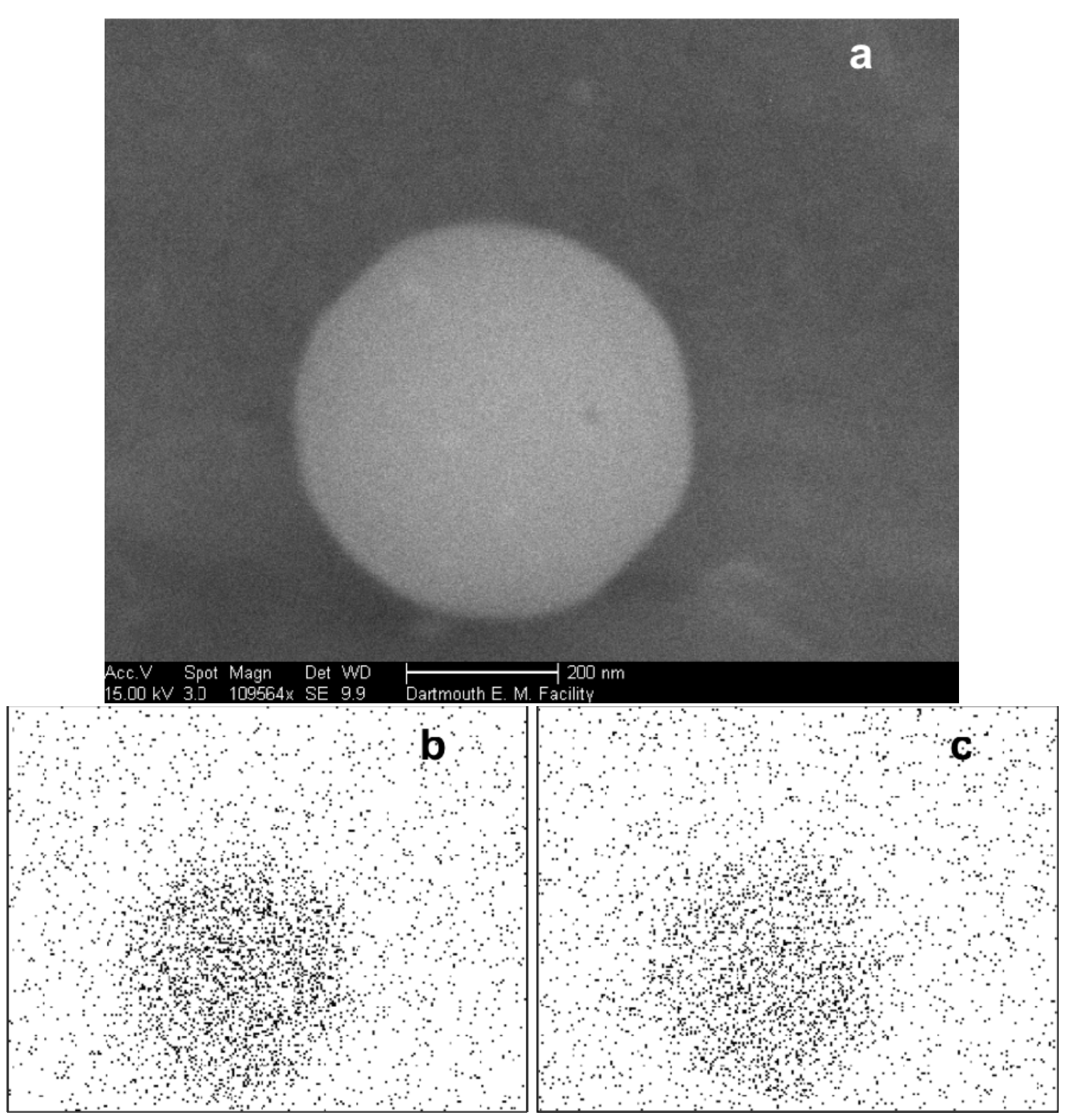

Figure 28: Image of a sub-micron fly ash particle with arsenic and calcium collected from the combustion of Syn- 4 synthetic chars at $20 \%$ oxygen on stage 5 of the Berner-type impactor a) using the SEM at 109,564x magnification and the EDX elemental maps for b) arsenic and c) calcium. 


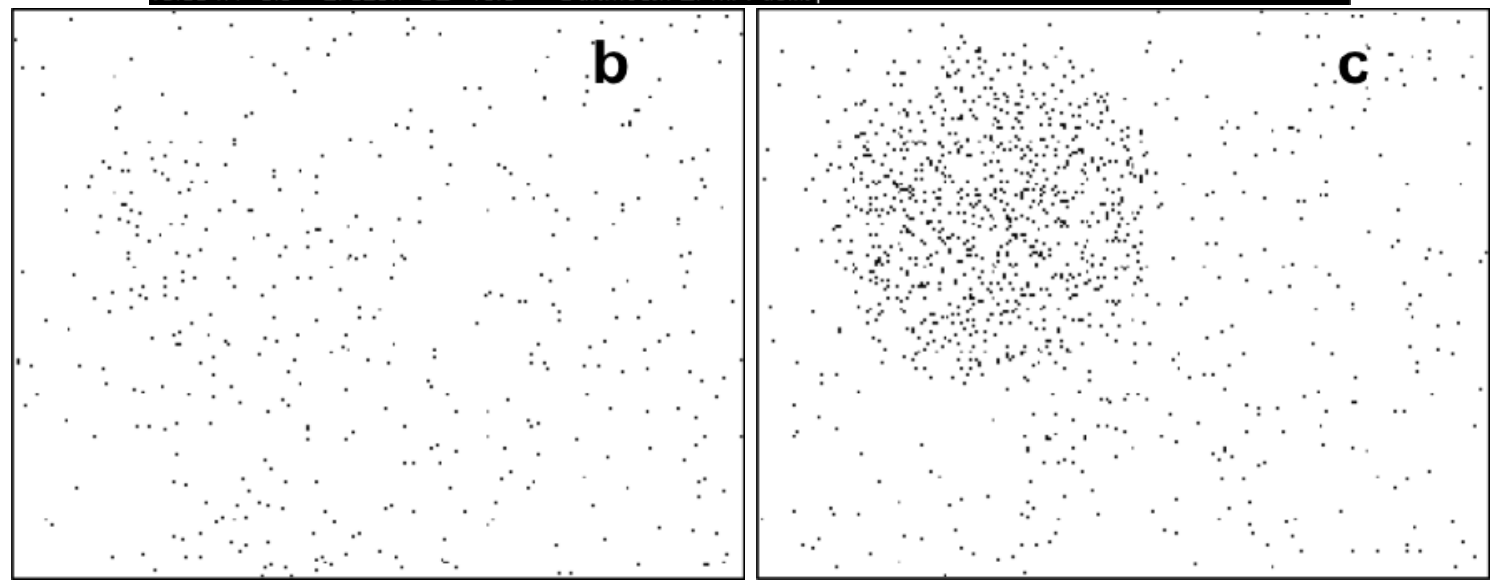

Figure 29: Image of a super-micron fly ash particle with only calcium collected from the combustion of Syn- 4 synthetic chars at $20 \%$ oxygen on stage 9 of the Berner-type impactor a) using the SEM at 27,325x magnification and the EDX elemental maps for b) arsenic and c) calcium. 


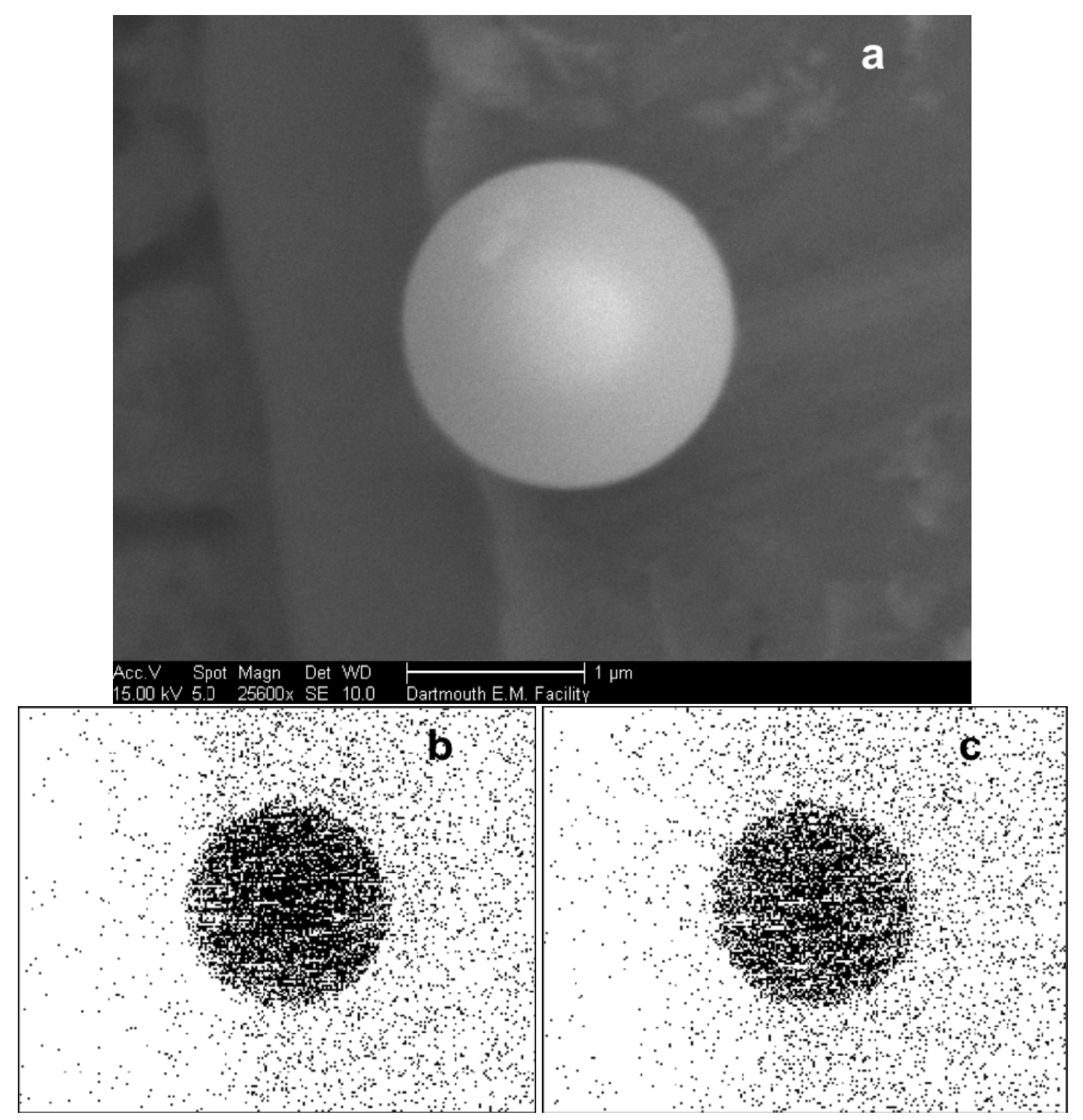

Figure 30: Image of a super-micron fly ash particle with arsenic and calcium collected from the combustion of Syn-2/3 synthetic chars at $20 \%$ oxygen on stage 7 of the Berner- type impactor a) using the SEM at 25,600x magnification and the EDX elemental maps for b) arsenic and c) calcium. 


\section{Table X}

Number of fly ash particles with As, Ca, or As+Ca found_using EDX analysis

\begin{tabular}{llllllll} 
Sample & Oxygen & \multicolumn{3}{c}{ Particles $<\mathbf{1} \boldsymbol{\mu m :}$} & \multicolumn{3}{c}{ Particles $>\mathbf{1} \boldsymbol{\mu m :}$} \\
& Content & As & Ca & As \& Ca & As & Ca & As \& Ca \\
\hline As and Ca & $20 \% \mathrm{O}_{2}$ & 9 & 3 & 0 & 0 & 11 & 13 \\
Separate $(\mathrm{Syn}-2 / 3)$ & $40 \% \mathrm{O}_{2}$ & 15 & 3 & 31 & 0 & 13 & 10 \\
As and $\mathrm{Ca}$ & $20 \% \mathrm{O}_{2}$ & 40 & 11 & 8 & 0 & 12 & 11 \\
Together (Syn-4) & $40 \% \mathrm{O}_{2}$ & 18 & 0 & 27 & 0 & 37 & 36 \\
\hline
\end{tabular}

The sub-micron particles exhibit different trends from the super-micron particles as arsenic and calcium are incorporated separately in the Syn-2/3 synthetic char and as the oxygen concentration increases. As the oxygen concentration increases from $20 \% \mathrm{O}_{2}$ to $40 \% \mathrm{O}_{2}$, fly ash particles containing arsenic from the combustion of Syn- $2 / 3$ synthetic char shift from $0 \%$ as arsenic and calcium particles or entirely as $\mathrm{As}_{2} \mathrm{O}_{3}$ to nearly $67 \%$ associated with calcium. When arsenic and calcium are incorporated in the same Syn- 4 synthetic char particles, the sub-micron fly ash has nearly $10 \%$ of arsenic as arsenic and calcium particles in a $20 \% \mathrm{O}_{2}$ environment increasing to $60 \%$ as arsenic and calcium particles in a $40 \% \mathrm{O}_{2}$ environment. It is speculated that this trend occurs due to vaporized calcium with increased particle combustion temperatures becoming available for reaction in the sub-micron fly ash fraction in addition to higher temperatures helping to facilitate the calcium/arsenic reaction. 


\section{Section 3: Arsenic partitioning model}

This final section of the report details the mathematical model used to determine arsenic compounds formed post-combustion and the processes by which arsenic is incorporated into fly ash. The intention of developing this model is to elucidate methods to produce less toxic forms of arsenic compounds during combustion processes and specifically to coal combustion processes. In the production of the model, the results from the two sets of experiments discussed in the previous section of the report were used to better understand fly ash surface area, arsenic vaporization, and the forms of arsenic likely to be present during combustion.

In this model, the effects of other trace metals in the system were ignored. The presence of arsenic in fly ash particles is attributed to remaining within fly ash during the combustion process or an un-vaporized portion of arsenic, condensation of arsenic trioxide, and surface reaction between arsenic trioxide and calcium oxide. The un-vaporized fly ash fraction of arsenic is a fraction of the total arsenic present in the parent coal. The un-vaporized arsenic is apportioned to fly ash particles by the measured fly ash particle calcium content. The arsenic added by condensation is calculated only for the dominant gaseous species of arsenic: arsenic trioxide. It is calculated using either the kinetic theory of gases for particles in the transition stage or free molecular regime and the Fuchs-Sutugin approximation for particles in the continuum regime. The transition between free molecular and continuum dynamics needed to calculate condensation is determined using the Knudsen number, which is dependent on the surrounding gas temperature. The gas-solid reaction between arsenic trioxide and calcium oxide is used as the dominant surface reaction to study addition of arsenic by this process.

In the model, trace element concentration, peak combustion temperature, and boiler temperature profile are all dependent in part on the coal under consideration. Modeling efforts in this study focused on arsenic partitioning during the combustion of specific coals from the United States, Kentucky Elkhorn bituminous coal, North Dakota lignite coal, and Wyodak sub-bituminous coal. These coals were burned in a laboratory scale experimental system at the University of Arizona as described previously Fly ash from combustion experiments was previously collected and analyzed for elemental composition. Table XI shows the coal and system parameters from these experiments used to construct the model, which are detailed in the literature [12-14, 18].

\section{Table XI}

Coal and system attributes

\begin{tabular}{lllll} 
Attributes & Units & \multicolumn{3}{c}{$\begin{array}{l}\text { Coal type } \\
\text { North Dakota }\end{array}$} \\
\hline & & Kentucky & \\
\hline Coal & & & & \\
\hline Arsenic concentration, [As] & g As/g coal & $4 \times 10^{-6}$ & $1 \times 10^{-6}$ & $1.4 \times 10^{-6}$ \\
Ash concentration, [ash] & g ash/g coal & $7.41 \times 10^{-2}$ & $9.38 \times 10^{-2}$ & $7.36 \times 10^{-2}$ \\
Fly ash fraction, FAF & g total fly ash/g ash & 0.34 & 0.75 & 0.75 \\
\hline System & & & & \\
\hline Coal feedrate, (fcoal) & g coal/hr & 2200 & 2200 & 2200 \\
Gas feedrate, (fgas) & slpm & 410 & 218 & 275 \\
\hline
\end{tabular}


The temperature profiles used in the model were those reported in the literature by Seames from port 14 in this system. This sampling port is located downstream of the combustion zone and before the baghouse in the system. The gas temperature at this location of the furnace is $1190 \mathrm{~K}$ for the combustion of Kentucky coal, $860 \mathrm{~K}$ for the combustion of North Dakota coal, and $875 \mathrm{~K}$ for the combustion of Wyodak coal [12]. The temperature profile through the sampling probe for the different experiments is modeled from specifications reported elsewhere [36] using FEMLAB. The results of the sampling probe temperature modeling predicts a decrease in temperature to $300 \mathrm{~K}$ within 0.03 seconds of entering the sampling probe and remaining at $300 \mathrm{~K}$ for at least 1.15 seconds before the stream is directed to the cascade impactor for particle collection.

Because reaction rate constants have been reported for a gas-solid reaction between calcium oxide and arsenic trioxide, calcium oxide is the only constituent modeled to react with arsenic trioxide.

In the model, several time-independent calculations are conducted once, at the beginning of the simulation while other time-dependent calculations are completed as time increases and temperature correspondingly decreases according to the measured temperature profiles.

To begin the calculations, the total amount of arsenic in the coal $\left(\mathrm{As}_{\mathrm{FA}}\right)$ is calculated as a ratio of total grams of arsenic in the system to the total grams of fly ash in the system ( $\mathrm{g} \mathrm{As} / \mathrm{g}$ total fly ash) from the amount available in the parent coal as shown in Equation 1.

$$
A s_{F A}=\frac{[A s]}{[a s h] \times F A F} \quad \text { Equation } 1
$$

where $\quad \mathrm{As}_{\mathrm{FA}} \quad=$ amount of arsenic in fly ash (g As /g total fly ash),

[As] = arsenic in coal $(\mathrm{g}$ As/g coal $)$,

[ash] $\quad=$ ash in coal $(\mathrm{g}$ ash $/ \mathrm{g}$ coal $)$, and

FAF $\quad=$ fly ash fraction (g total fly ash $/ g$ ash).

The calculations for any arsenic remaining within the particles are time-independent, completed once the fraction of arsenic vaporized $(\theta)$ in the simulation has been determined. Using the vaporized fraction, the total amount of un-vaporized arsenic is calculated using Equation 2.

$$
U_{\text {As,tot }}=(1-\theta) \times A s_{F A} \quad \text { Equation } 2
$$

where $\quad \mathrm{U}_{\mathrm{As}, \mathrm{tot}}=$ total un-vaporized arsenic in fly ash (g As/g total fly ash), and $\theta \quad=$ vaporized fraction of arsenic.

Once the calculations for un-vaporized arsenic partitioning are completed, the arsenic available in the gas phase at the start of the simulation is calculated as the arsenic partial pressure $\left(\mathrm{P}_{\text {As406 }}\right)$ using Equation 3. 


$$
P_{A_{4} O_{6}}(t=0)=\frac{\theta \cdot f_{\text {coal }}[A s]}{\eta \cdot f_{g a s} M W_{A s}} \times P_{P a}
$$

$$
\text { where } \quad \begin{array}{ll}
\mathrm{P}_{\mathrm{As} 4 \mathrm{OO} 6}(\mathrm{t}) & =\text { partial pressure of arsenic trioxide in combustion gas }(\mathrm{Pa}), \\
\mathrm{f}_{\text {coal }} & =\text { feedrate of coal }(\mathrm{g} \text { coal } / \mathrm{hr}), \\
\eta & =\text { molar conversion }\left(4 \mathrm{~mol} \mathrm{As} / 1 \mathrm{~mol} \mathrm{As} \mathrm{O}_{6}\right), \\
\mathrm{f}_{\mathrm{gas}} & =\text { feedrate of combustion gas }(\mathrm{mol} \mathrm{air} / \mathrm{hr}), \\
\mathrm{MW}_{\mathrm{As}} & =\text { molecular weight of arsenic }(74.922 \mathrm{~g} \mathrm{As} / \mathrm{mol} \mathrm{As}), \text { and } \\
\mathrm{P}_{\mathrm{Pa}} & =\text { atmospheric pressure }(101325 \mathrm{~Pa}) .
\end{array}
$$

The un-vaporized fraction of arsenic is assumed to partition within the super-micron particles proportional to the calcium concentration in the particles. This proportion is calculated using Equation 4, a ratio of calcium oxide in each super-micron size fraction to the calcium oxide in the total super-micron fly ash. This equation is calculated for each fly ash size fraction represented by the index (i). Because only the super-micron sizes are of concern for unvaporized arsenic, the calculations are zero for fly ash collected from stages 1 through 6 and dependent on calcium oxide content for fly ash collected from stages 7 through 11 .

$$
C a_{s t}(i)=\frac{[C a O](i) \times A M F(i)}{\sum_{i=7}^{11}[C a O](i) \times A M F(i)} \quad \text { Equation } 4
$$

where $\quad$ Cast $(\mathrm{i}) \quad=$ percentage of calcium oxide in a particle size fraction for $\mathrm{i}=7 \rightarrow 11$,

(i) = index of fly ash size fraction (1 through 11),

$[\mathrm{CaO}](\mathrm{i})=$ calcium oxide in fly ash size $(\mathrm{g} \mathrm{CaO} / \mathrm{g}$ sized fly ash), and

$\operatorname{AMF}(\mathrm{i}) \quad=$ percentage of ash of a particular size in total fly ash (g sized fly ash /g fly ash)

Multiplying Equation 2 with the Equation 4 produces the amount of un-vaporized arsenic in each super-micron particle size fraction. This calculation has units of grams of arsenic per grams of sized fly ash (g As/g sized fly ash).

$$
U_{A s, s t}(i)=U_{A s, t o t} \times C a_{s t}(i) \quad \text { Equation } 5
$$

where $\quad \mathrm{U}_{\mathrm{As}, \mathrm{st}}(\mathrm{i}) \quad=$ un-vaporized arsenic in super-micron fly ash (g As/g sized fly ash), for $\mathrm{i}=7 \rightarrow 11$.

Calcium associated with un-vaporized arsenic is calculated using Equation 6:

$$
C a_{u}(i)=U_{A s}(i) \times \frac{M W_{C a O}}{M W_{A s}} \times \frac{3 \mathrm{~mol} \mathrm{Ca}}{2 m o l ~ A s} \quad \text { Equation } 6
$$


where

$$
\begin{array}{ll}
\mathrm{Ca}_{\mathrm{u}}(\mathrm{i}) & =\text { calcium oxide reacted with un-vaporized arsenic in fly } \\
& \text { ash }(\mathrm{g} \mathrm{CaO} / \mathrm{g} \text { sized fly ash }), \\
& =\text { atomic weight of arsenic }(74.922 \mathrm{~g} \mathrm{As} / \mathrm{mol} \mathrm{As}), \text { and } \\
\mathrm{MW}_{\mathrm{As}} & =\text { molecular weight of calcium oxide } \\
\mathrm{MW}_{\mathrm{CaO}} & (56.08 \mathrm{~g} \mathrm{CaO} / \mathrm{mol} \mathrm{CaO}) .
\end{array}
$$

Because the amount of arsenic in coal combustion is much smaller than the amount of calcium, the reduction of available calcium calculated using Eq. 6 is not expected to limit potential surface reaction between arsenic and calcium. Calcium arsenate $\left(\mathrm{Ca}_{3}\left(\mathrm{AsO}_{4}\right)_{2}\right)$ is the expected product of this reaction, therefore $3 / 2$ calcium atoms are assumed to attach to one arsenic atom.

A mass balance is then constructed to determine the calcium available for surface reaction shown in Eq. 7.

$$
C a_{\text {free }}(i, t)=C a_{\text {tot }}(i)-C a_{u}(i)-C a_{r x n}(i, t) \quad \text { Equation } 7
$$

where $\quad \mathrm{Ca}_{\text {free }}(\mathrm{i}, \mathrm{t})=$ unreacted calcium oxide in fly ash $(\mathrm{g} \mathrm{CaO} / \mathrm{g}$ fly ash $)$ and

$\mathrm{Ca}_{\mathrm{rxn}}(\mathrm{i}, \mathrm{t})=$ calcium oxide calculated to participate in surface reaction with arsenic (g CaO/g fly ash).

The calcium initially available for surface reaction $\left(\mathrm{Ca}_{\text {free }}(\mathrm{i}, \mathrm{t}=0)\right)$ is then calculated using the mass balance shown in Eq. 7. At $t=0$ seconds, the calcium calculated as reacted at the surface with arsenic $\left(\mathrm{Ca}_{\mathrm{rxn}}(\mathrm{i}, \mathrm{t}=0)\right)$ is zero, simplifying the initial equation to Eq. 8 .

$$
C a_{\text {free }}(i, t=0)=C a_{\text {tot }}(i)-C a_{u}(i) \quad \text { Equation } 8
$$

The time-dependent calculations are completed for one fly ash particle in a fly ash size fraction at a specific point in time. To account for the arsenic addition for a fly ash size fraction, the total number of fly ash particles in the fly ash size fraction $\left(\mathrm{N}_{\mathrm{p}}(\mathrm{i})\right)$ is necessary. This calculation is conducted using Equation 9.

$$
N_{p}(i)=\frac{1}{V(i) \times \rho_{a s h}} \quad \text { Equation } 9
$$

where $\quad \mathrm{N}_{\mathrm{p}}(\mathrm{i})=$ number of particles in each stage (\# particles /g sized fly ash),

$\mathrm{V}(\mathrm{i}) \quad=$ volume of particles, assumed to be spherical $\left(\mathrm{m}^{3}\right)$, and

$\rho_{\text {ash }} \quad=$ density of fly ash $\left(2,200,000 \mathrm{~g}\right.$ fly ash $\left./ \mathrm{m}^{3}\right)$.

The compound expected to condense onto fly ash particle surfaces post-combustion is arsenic trioxide $\left(\mathrm{As}_{4} \mathrm{O}_{6}\right)$. Vapor pressure is calculated from: 


$$
P_{\mathrm{As}_{4} \mathrm{O}_{6}}^{\text {sat }}(t)=10^{\left(9.905-\frac{6067}{T(t)}\right)} \times C_{P a}
$$

where $\quad \mathrm{P}_{\text {As406 }}^{\mathrm{sat}}(\mathrm{t})=$ dewpoint pressure of arsenic trioxide at the temperature and pressure of the system $(\mathrm{Pa})$,

$\mathrm{T}(\mathrm{t}) \quad=$ temperature of the system $(\mathrm{K})$, and

$\mathrm{C}_{\mathrm{Pa}}=$ unit conversion from $\mathrm{mm} \mathrm{Hg}$ to Pascals (101325 Pa/760 mm Hg).

The calculations in Eq.3 and 10 are used in calculating the quantity of arsenic added to a fly ash particle by condensation. Two methods of calculating arsenic addition by condensation are employed in the simulation for two regimes: the free molecular regime and the continuum regime. The free molecular regime is defined as the scenario where the Knudsen number (Kn) is greater than or equal to one, where the Knudsen number is a unitless ratio of the mean free path of the gas $(\lambda)$ to the diameter of the particle $\left(d_{p}\right)$. In this situation, the particle diameter is smaller than the distance to the next particle in the surrounding gas. The mean free path is calculated using Equation 11.

$$
\lambda(i, t)=\frac{R T(t)}{\sqrt{2} \pi d_{p}(i)^{2} N_{A} P(t)}
$$

where $\mathrm{R}=$ universal gas constant $(8.314 \mathrm{~J} / \mathrm{mol} \cdot \mathrm{K})$,

$\mathrm{d}_{\mathrm{p}}(\mathrm{i})=$ diameter of the fly ash particle $(\mathrm{m})$,

$\mathrm{N}_{\mathrm{A}}=$ Avogadro's number $\left(6.022 \times 10^{23}\right.$ molecules $\left./ \mathrm{mole}\right)$, and

$\mathrm{P} \quad=$ pressure of the system $(\mathrm{Pa})$.

The rate of addition of arsenic trioxide to a single fly ash particle by condensation for particles in the free molecular regime $\left(\mathrm{K}_{\mathrm{c}, \mathrm{FM}}\right)$ is calculated using Equation 12.

$$
K_{c, F M}(i, t)=\frac{\phi \pi d_{p}(i)^{2}\left[P_{A s_{4} O_{6}}(t)-P_{A_{4} O_{6}}^{s a t}(t)\right] M W_{A s} \eta}{\sqrt{2 \pi R T(t) M W_{A s_{4} O_{6}}}} \quad \text { Equation } 12
$$

where $\quad \mathrm{K}_{\mathrm{c}, \mathrm{FM}} \quad=$ mass addition rate for a single fly ash particle in the free molecular regime (g As/particle·s),

$\varphi \quad=$ accommodation coefficient (1), and

$\mathrm{MW}_{\mathrm{As} 4 \mathrm{O} 6}=$ molecular weight of arsenic trioxide $(\mathrm{g} / \mathrm{mol})$.

For particles sufficiently large to be governed by the transition from free molecular to continuum and continuum regime dynamics, the addition rate is described by the Fuchs - Sutugin approximation shown in Equation 13:

$$
K_{c, C}(i, t)=\frac{2 \pi d_{p}(i) D_{i}(t)\left[P_{A_{4} O_{6}}(t)-P_{A s_{4} O_{6}}^{s a t}(t)\right] M W_{A s} \eta(1+K n(i, t))}{R T(t)\left(1+1.71 K n(i, t)+1.33 K n(i, t)^{2}\right)} \quad \text { Equation } 13
$$


where $\quad \mathrm{K}_{\mathrm{c}, \mathrm{C}}=$ mass addition rate for a single fly ash particle in the continuum regime (g As/s ),

$\mathrm{D}_{\mathrm{i}} \quad=$ diffusion coefficient $\left(\mathrm{m}^{2} / \mathrm{s}\right), 4.432 \times 10^{-11} \mathrm{~T}^{3 / 2}$,

To calculate the rate of arsenic addition rate to fly ash particles due to surface reaction, the preexponential factor and activation energy of the Arrhenius equation for the dominant reaction are needed. As discussed in earlier reports, the gas-solid reaction of calcium oxide and arsenic trioxide has been previously studied and the reaction rate constants reported [37]. Addition of arsenic by surface reaction is calculated using the following equation:

$$
K_{r}(i, t)=\frac{\pi d_{p}(i)^{2}[C a O] A \exp \left(\frac{-E_{a}}{R T(t)}\right) P_{A s_{4} O_{6}}(t) M W_{A s} \eta}{R T(t)} \quad \text { Equation } 14
$$

where $\quad \mathrm{K}_{\mathrm{r}}(\mathrm{i}, \mathrm{t})=$ mass of arsenic added to one fly ash particle in one second due to surface reaction ( $\mathrm{g}$ As /particle·s),

$\mathrm{A}=$ pre-exponential factor $\left(1.4 \times 10^{-3} \mathrm{~m} \cdot \mathrm{g}\right.$ fly ash $\left./ \mathrm{s} \cdot \mathrm{g} \mathrm{CaO}\right)$, and

$\mathrm{E}_{\mathrm{a}}=$ activation energy $(23 \mathrm{~kJ} / \mathrm{mol})$.

Using this equation for arsenic addition by condensation or surface reaction, an iterative process is constructed to simulate arsenic addition to fly ash occurring in a specific combustion process.

Following the calculation of time-independent variables including calcium available for surface reaction and partial pressure of arsenic in the combustion gas at the start of the system, the timedependent calculations are conducted for a small time step which are iterated as time progresses. This time progression corresponds to fly ash particles traveling through the combustion furnace, the sampling probe, until being collected on a cascade impactor. The method employed in these calculations uses a time step of 0.0001 second:

The computer code used in producing the results for the arsenic partitioning model is included in the Appendix to Smith (2010).

\section{Modeling results}

Results from the modeling calculations are shown in Figures 31- 33 using the reaction rate constants from the literature, where the arsenic in the fly ash particles from each process is represented individually. In the calculations conducted for fly ash particles from the combustion of Kentucky coal sampled at port 14 of the combustion system, the results of the simulation are presented along with the experimental results for two replicate experiments in Figure 33. An arsenic vaporized fraction of 0.6 is used to adequately model the arsenic concentration found in the super-micron fly ash particle size range. With this vaporized fraction of arsenic, the concentration of arsenic calculated for the sub-micron fly ash particle size range is overestimated by nearly two orders of magnitude. However, the concentration of arsenic in particles ranging from $0.337 \mu \mathrm{m}$ to $0.973 \mu \mathrm{m}$ in $50 \%$ cutoff aerodynamic diameter are underestimated in these simulations. The addition of arsenic to fly ash particles by surface reaction is seen to be 
negligible under these conditions.
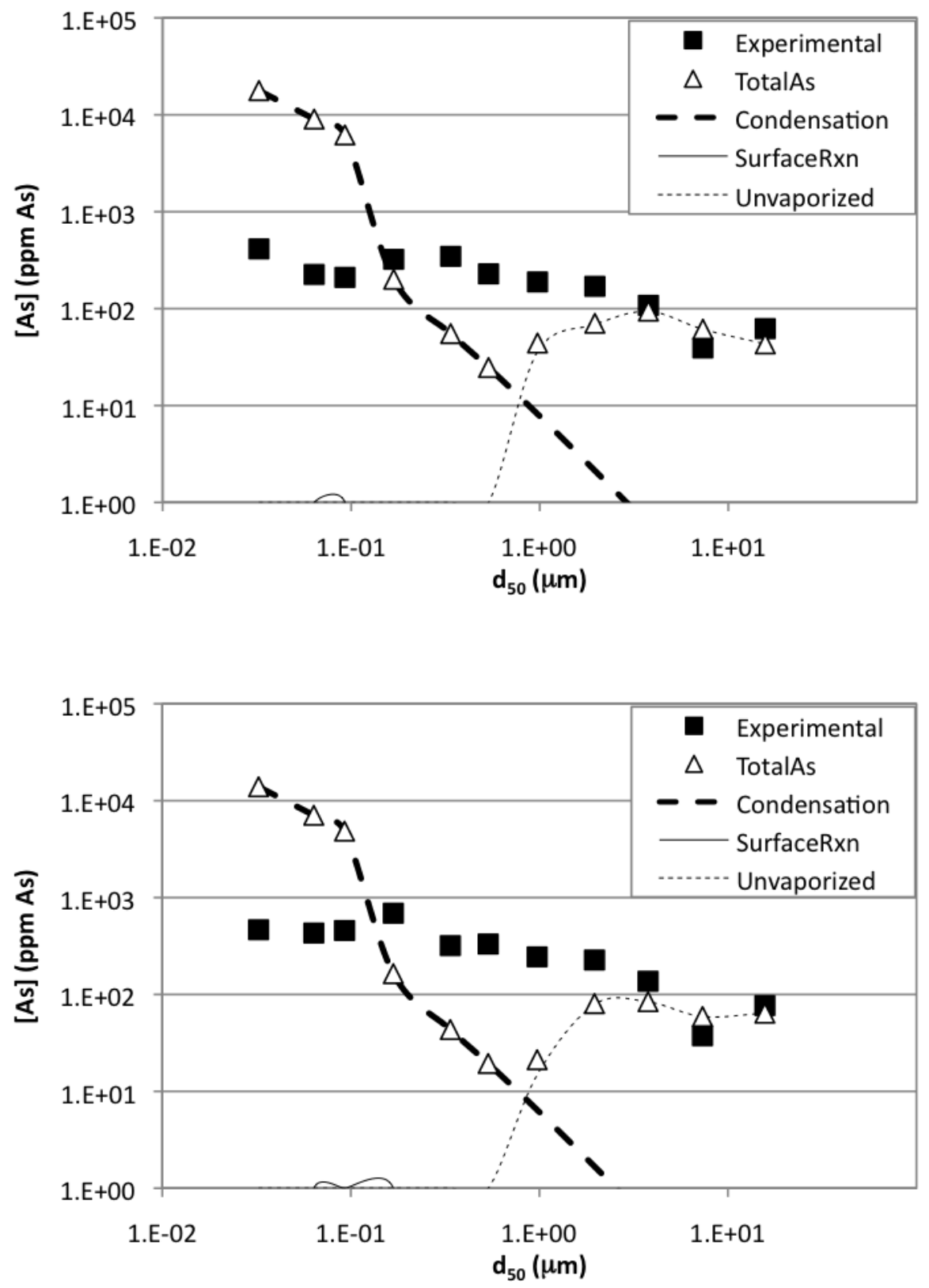

Figure 31: Predicted and measured arsenic distribution for fly ash particles with a $50 \%$ cutoff aerodynamic diameter of $0.03-15 \mu \mathrm{m}$ collected from Kentucky coal combustion over two replicate experiments with $\theta=0.6$ and assuming spherical fly ash particles. 

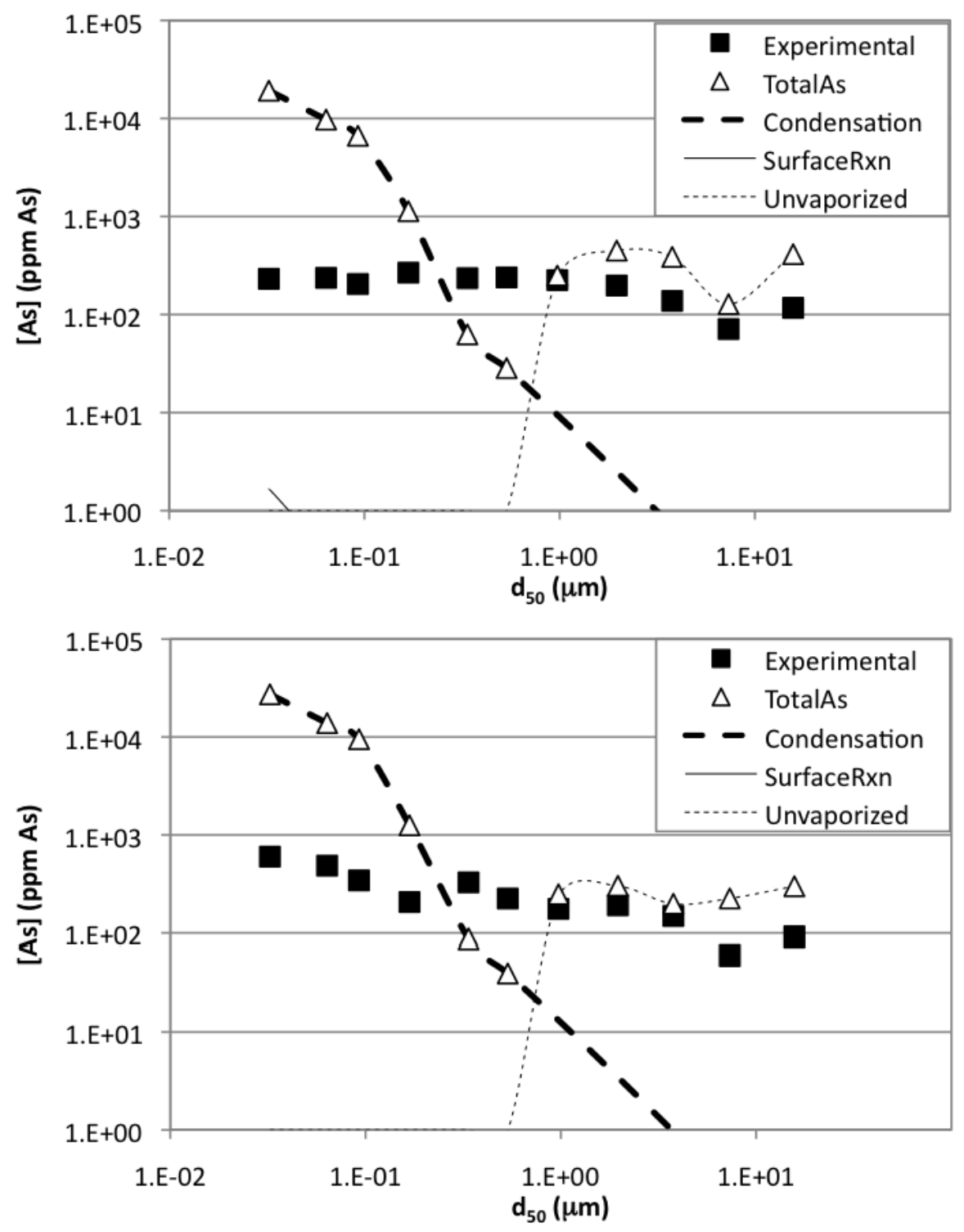

Figure 32: Predicted and measured arsenic distribution for fly ash particles with a $50 \%$ cutoff aerodynamic diameter of $0.03-15 \mu \mathrm{m}$ collected from North Dakota coal combustion over two replicate experiments with $\theta=0.6$ and assuming spherical fly ash particles. 

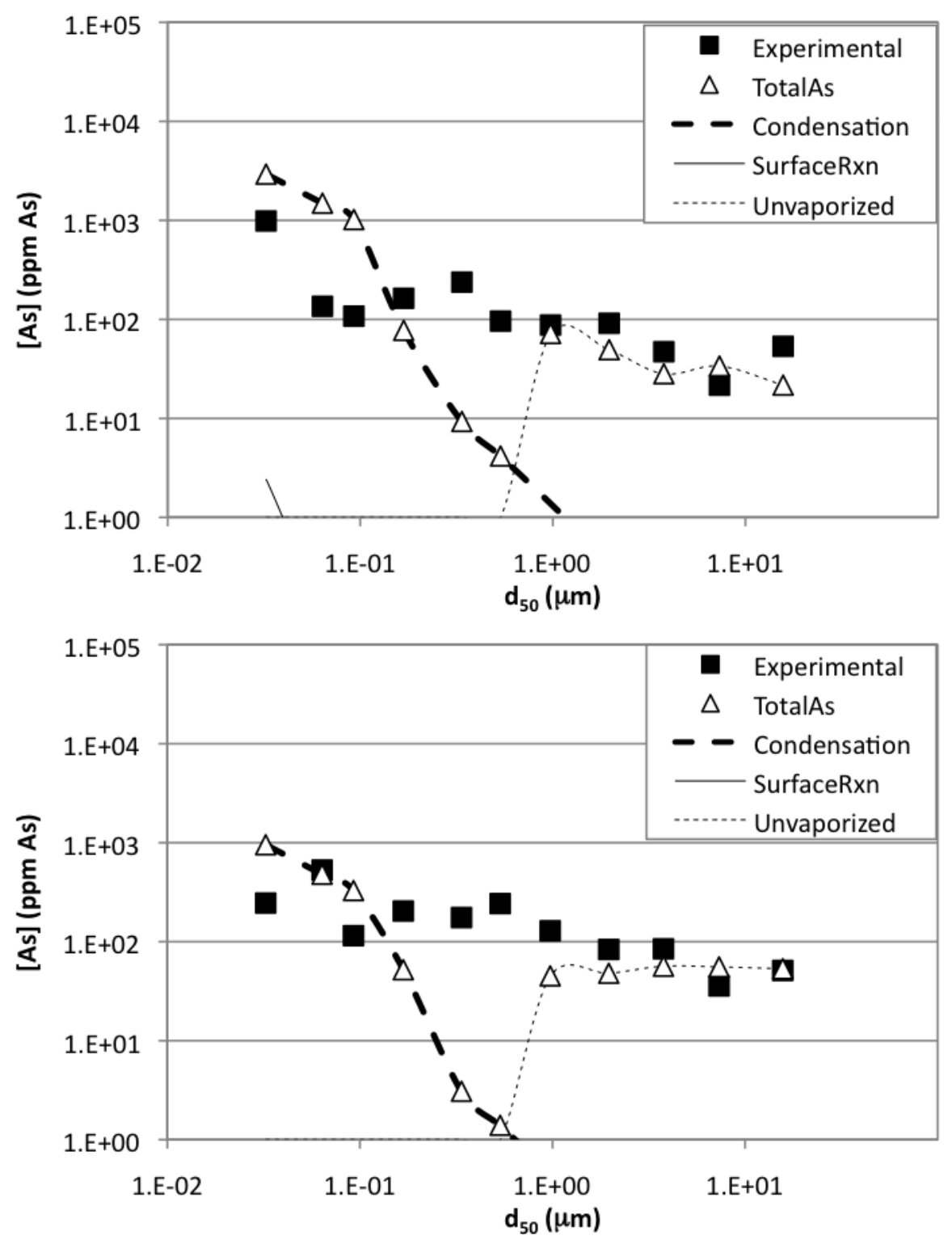

Figure 33: Predicted and measured arsenic distribution for fly ash particles with a 50\% cutoff aerodynamic diameter of $0.03-15 \mu \mathrm{m}$ collected from Wyodak coal combustion over two replicate experiments with $\theta=0.6$ and assuming spherical fly ash particles.

These results suggest that the arsenic found in sub-micron fly ash particles should entirely be in the form of arsenic trioxide and the arsenic found in the super-micron fly ash particles should be entirely in an arsenate form or calcium-associated compound. The results from the XAFS analysis of fly ash collected from combustion experiments discussed in the prior section of this report and in the literature [38-42] show that calcium and arsenic form calcium arsenate in measurable quantities during combustion. Having found arsenic as calcium arsenate in the char 
combustion fly ash, it is likely that the reaction rate constants for the reaction between arsenic

To examine the effect of a higher pre-exponential factor for the gas-solid reaction between arsenic trioxide and calcium oxide on arsenic partitioning in fly ash particles, the simulation is conducted using a pre-exponential factor 5 orders of magnitude larger than the reported value, $140 \mathrm{~m} \cdot \mathrm{g}$ fly ash $/ \mathrm{s} \mathrm{g} \mathrm{CaO}$. The results of these simulations for fly ash from the combustion of Kentucky coal is shown in Figure 34. In the calculations, the fly ash particles are again assumed
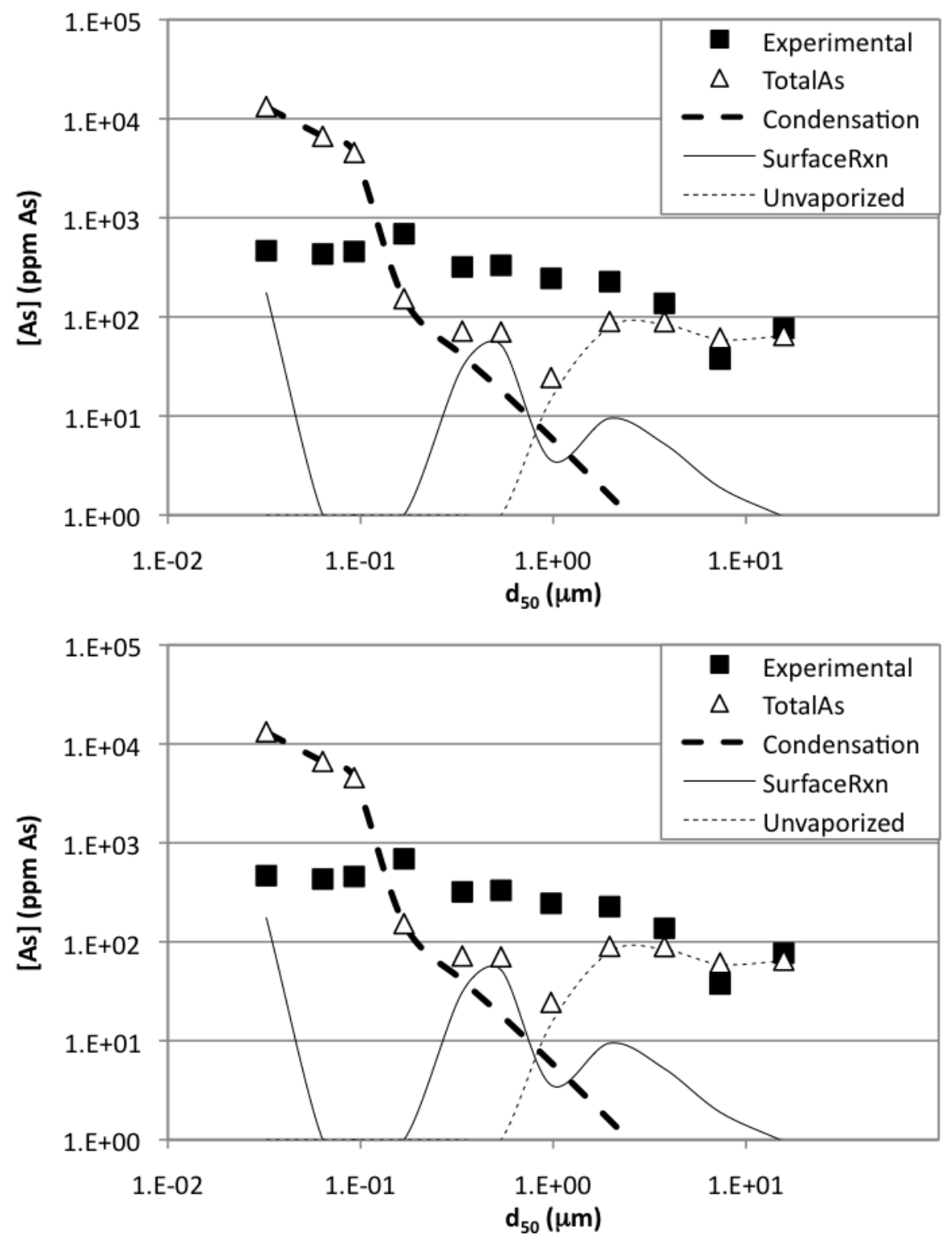

Figure 34: Predicted and measured arsenic distribution for fly ash particles with a 50\% cutoff aerodynamic diameter of 0.03 - $15 \mu \mathrm{m}$ collected from Kentucky coal combustion for two replicate experiments with $\theta=0.6, \mathrm{Ea}=15 \mathrm{~kJ} \mathrm{~mol}^{-1}$, pre-exponential factor of $14 \mathrm{~m} \cdot \mathrm{g}$ fly ash $/ \mathrm{s} \cdot \mathrm{g}$ $\mathrm{CaO}$, and assuming spherical fly ash particles. 
to have a spherical shape. Calculated arsenic concentrations are within an order of magnitude of the experimentally determined arsenic concentrations for size fractions with a $50 \%$ cutoff aerodynamic diameter between $0.337 \mu \mathrm{m}$ and $15.7 \mu \mathrm{m}$. The sub-micron fly ash particles with a $50 \%$ cutoff aerodynamic diameter between $0.0324 \mu \mathrm{m}$ and $0.0926 \mu \mathrm{m}$ are overestimated by an order of magnitude in these simulations. With the increased pre-exponential factor used in these simulations, the amount of arsenic that is added to the fly ash particles by surface reaction increases as expected. As seen in the figures, the amount of arsenic in the super-micron region remains controlled by the arsenic that does not vaporize during combustion. The presence of arsenic in the fly ash particles with a 50\% cutoff aerodynamic diameter between $0.168 \mu \mathrm{m}$ and $0.535 \mu \mathrm{m}$ is attributed to reaction between arsenic and calcium, and arsenic in the smallest particles with a 50\% cutoff aerodynamic diameter between $0.0324 \mu \mathrm{m}$ and $0.0926 \mu \mathrm{m}$ is attributed to the condensation of arsenic trioxide.

These simulations provide a different possibility for processes controlling arsenic partitioning in the sub-micron and super-micron regions of fly ash particles. While he form of arsenic calculated to exist in fly ash is almost entirely as arsenates, results suggest that (a) some reaction may occur within burning char particles, and (b) gas-solid reaction rates reported in the literature for the CaAs system are too slow to account for the observed formation of arsenates, which clearly can occur through gas-solid reaction pathways as demonstrated from the results of synthetic char experiments described in this report. 


\section{REFERENCES}

[1] C.L. Senior, et al. Gas-phase transformations of mercury in coal-fired power plants. Fuel Processing Technology, 63:197-213, 2000.

[2] E.M. Prestbo and N.S. Bloom. Mercury Speciation Adsorption (MESA) method for combustion flue gas: methodology, artifacts, intercomparison, and atmospheric implications. Water, Air, and Soil Pollution, 80:145-158, 1995.

[3] J. Zhou, et al. Factors impacting gaseous mercury speciation in postcombustion. Energy \& Fuels, 21:491-495, 2007.

[4] B. Hall, et al. Chemical reactions of mercury in combustion flue gas. Water, Air, and Soil Pollution, 56: 3-14, 1991.

[5] L.E. Bool III, et al. Toxic substances from coal combustion: A comprehensive assessment. Quarterly Report 1 DE-AC22-95PC95101, United States Department of Energy, October 1996.

[6] W.L. Johnson. A laboratory combustion system for emission studies. MS thesis, University of Arizona, 1995.

[7] M.D. Allen and O.G. Raabe. Slip correction measurements of spherical solid aerosol particles in an improved Millikan aparatus. Aerosol Science and Technology, 4:269-286, 1985.

[8]C.A. Smith, The chemistry of arsenic and mercury under post-combustion conditions, Ph.D. Thesis, Thayer School of Engineering, Dartmouth College, 2010.

[9] S.B. Ghorishi, et al. Effects of fly ash transition metal content and flue gas $\mathrm{HCl} / \mathrm{SO} 2$ ratio on mercury speciation in waste combustion. Environmental Engineering Science, 22(2):221-231, 2005.

[10] R.O. Sterling, et al. Effects of SO2 and NOx on mercury homogeneous gas-phase chemistry. In 18th Annual ACERC Technical Conference, volume 18th, Provo, Utah, February 2004. Advanced Combustion Engineering Research Center.

[11] J.S. Lighty, et al. Fundamentals of mercury oxidation in flue gas. Final Report DE-FG2603NT41797, U.S. DOE, 2008.

[12] W. Seames. The partitioning of trace elements during pulverized coal combustion. $\mathrm{PhD}$ thesis, University of Arizona, 2000. 
[13] C.L. Senior, et al. Toxic substances from coal combustion: A comprehensive assessment. Final Report DE-AC22-95PC95101, United States Department of Energy, July 2001.

[14] H. Kobayashi. Devolatization of pulverized coal at high temperatures. $\mathrm{PhD}$ thesis, Massachusetts Institute of Technology, 1976.

[15] C.L. Senior, et al. Laboratory study of trace element vaporization from combustion of pulverized coal. Fuel Processing Technology, 63(2-3):109-124, April 2000.

[16] G.P. Huffman, et al. Speciation of arsenic and chromium in coal and combustion ash by XAFS spectroscopy. Fuel Processing Technology, 39(1-3):47-62, August 1994.

[17] A.G. Kim and G. Kazonich. The silicate/non-silicate distribution of metals in fly ash and its effect on solubility. Fuel, 83(17-18):2285-2292, December 2004.

[18] L.E. Bool III, et al. Toxic substances from coal combustion: A comprehensive assessment. Quarterly Report DE-AC22-95PC95101, U.S. DOE, January 1997.

[19] D.K. Ludlow and W.M. Vosen. Characterization of synthetic-coal char particles using fractal dimension analysis. Particle and Particle Systems Characterization, 10(6):313-320, 1993.

[20] A. Arenillas, et al. Comparison between the reactivity of coal and synthetic coal models. Fuel, 82:2001-2006, 2003.

[21] C. Tyberg. Void-free flame retardant phenolic networks: properties and processability. $\mathrm{PhD}$ thesis, Virginia Polytechnic Institute and State University, 2000.

[22] R. Rego, et al. Fully quantitative carbon-13 NMR characterization of resol phenolformaldehyde prepolymer resins. Polymer, 45:33-38, 2004.

[23] S. Das and D. Prevorsek. Thermosettable modified phenolic imide resins. US Patent 4650839, March 1987.

[24] D. Davidson and M.T. Bogert. The preparation of aromatic alcohols by the crossed Cannizzaro reaction with formaldehyde. Journal of the American Chemical Society, 57(5):905, 1935.

[25] M. Wojtowicz. Thermogravimetric study of active sites in the process of low temperature oxidation of char. PhD thesis, Brown University, Providence, Rhode Island, 1988. 
[26] H.C. Malhotra and M. Avinash. Kinetics of the acid-catalyzed phenol-formaldehyde reaction. Journal of applied polymer science, 20:2461-2471, 1976.

[27] O.R Howell. A study of the system water-phenol. Part I.-Densities. Proceedings of the Royal Society of London Series A-Containing papers of a mathematical and physical character. 137(832):418-433, 1932.

[28] C.L. Senior and R.C. Flagan. Synthetic chars for the study of ash vaporization. In Twentieth Symposium (International) on Combustion, volume 24, pages 921-929. The Combustion Institute, 1984.

[29] WSSA Herbicide Handbook Committee. Herbicide Handbook of the Weed Science Society of America. WSSA, Champaign, IL, 5th edition, 1983.

[30] L.B. Miller and J.C. Witt. Solubility of calcium hydroxide. Journal of Physical Chemistry, 33(1):285-289, 1929.

[31] JEOL Technology. Energy table for EDS analysis. Electronic, 2006.

[32] N.H. Andersen, et al. Broad-temperature range spectroscopy of the two-centre modular redox metalloprotein desulfovibrio desulfuricans desulfoferrodoxin. Dalton Transcripts, pages 3328-3338, 2003.

[33] P. Ghetti, et al. Coal combustion: correlation between surface area and thermogravimetric analysis data. Fuel, 64(7):950-955, July 1985.

[34] H.G. Linge. The surface area of coal particles. Fuel, 68(1):111-113, January 1989.

[35] J.J. Helble. Mechanisms of ash particle formation and growth during pulverized coal combustion. PhD thesis, Massachusetts Institute of Technology, June 1987.

[36] K. Matsuoka, et al. Mode of occurrence of calcium in various coals. Fuel, 81:1433-1438, 2002.

[37] R.O. Sterling and J.J. Helble. Reaction of arsenic vapor species with fly ash compounds: kinetics and speciation of the reaction with calcium silicates. Chemosphere, 51:1111-1119, 2003.

[38] F. Goodarzi, et al. Assessment of elements, speciation of As, Cr, Ni and emitted $\mathrm{Hg}$ for a 
Canadian power plant burning bituminous coal. International Journal of Coal Geology, 74:1-12, 2008.

[39] B.P. Jackson and W.P. Miller. Arsenic and selenium speciation in coal fly ash extracts by ion chromatography-inductively coupled plasma mass spectrometry. Journal of Analytical Atmoic Spectroscopy, 13:1107-1112, 1998.

[40] F.E. Huggins, et al. Quantifying hazardous species in particulate matter derived from fossilfuel combustion. Environmental Science \& Technology, 38:1836-1842, 2004.

[41] F.E. Huggins, et al. Selenium and arsenic speciation in fly ash from full-scale coal-burning utility plants. Environmental Science \& Technology, 41:3284-3289, 2007.

[42] M.E. Hirsch, et al. Speciation of combustion-derived particulate phase arsenic. Environmental Engineering Science, 17(6):315-327, 2000.

[43] R.O. Sterling. The heterogeneous and homogeneous chemistry of arsenic and mercury under post combustion conditions. $\mathrm{PhD}$ thesis, University of Connecticut, 2004.

[44] R.O. Sterling, et al. Effects of SO2 and NOx on mercury homogeneous gas-phase chemistry. In 18th Annual ACERC Technical Conference, volume 18th, Provo, Utah, February 2004. Advanced Combustion Engineering Research Center. 


\section{LIST OF ACRONYMS AND ABBREVIATIONS}

BET

CCD

Df

EDX

EPA

ICP-MS

MOUDI

PIXE

RMSE

SEM

TEM

XAFS
Brunauer-Emmett-Teller gas adsorption surface area charge-coupled device

fractal dimension

energy-dispersive $\mathrm{x}$-ray analysis

U.S. Environmental Protection Agency

inductively coupled plasma-mass spectrometry

micro-orifice uniform deposit impactor

particle (or proton)-induced x-ray emission

root-mean squared error

scanning electron microscopy (or microscope)

transmission electron microscopy (or microscope)

x-ray absorption fine structure (spectroscopy) 